\title{
MODELING THE EFFECTS OF ATMOSPHERIC EMISSIONS \\ ON GROUNDWATER COMPOSITION
}

by

Theresa Jean Brown

A thesis submitted in partial fulfillment of the requirements for the degree of

Doctor of Philosophy

(Geology)

at the

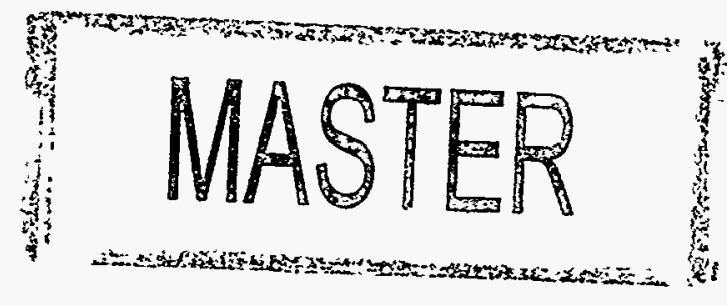

\section{UNIVERSITY OF WISCONSIN-MADISON}

1994

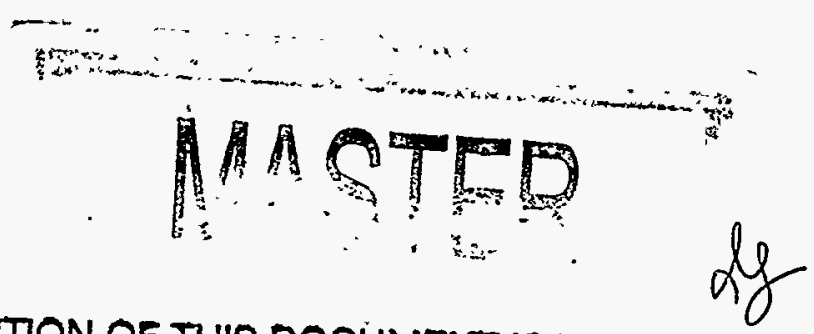

HSTRIBUTTON OF THIS DOCUMENT IS UNLIMTEED 


\section{DISCLAIMIER}

Portions of this document may be illegible in electronic image products. Images are produced from the best available original document. 


\begin{abstract}
A composite model of atmospheric, unsaturated and groundwater transport is developed to evaluate the processes determining the distribution of atmospherically derived contaminants in groundwater systems and to test the sensitivity of simulated contaminant concentrations to the input parameters and model linkages. The modeling technique is demonstrated using simulations of two hypothetical groundwater systems subjected to chronic and ephemeral atmospheric emissions.
\end{abstract}

One application of the composite model is as a tool to screen specific atmospheric emissions for their potential in determining groundwater age. Temporal changes in atmospheric emissions whether due to the introduction of a source, seasonally variable emission rates, elimination or a sudden change in the emission rates, could provide a recognizable pattern in the groundwater system. The model also provides a method for quantifying the significance of uncertainties in the tracer source term and transport parameters on the contaminant distribution in the groundwater system, an essential step in using the distribution of contaminants from local, point source atmospheric emissions to examine conceptual models of groundwater flow and transport.

The composite model is designed to utilize the level and type of data that is available or easily attainable for an ephemeral or chronic atmospheric emission and the subsurface hydraulic conditions. A lumped parameter model is used to describe 
contaminant depletion and storage at the ground surface. The parameters used to simulate the surface processes may vary temporally and spatially. The use of a linked numerical model of subsurface flow allows the modeler to de-couple flow systems that may require discretization at very different time or spatial scales, making it a very useful tool for evaluating the potential arrival time, maximum concentration and distribution of a contaminant from an atmospheric source in a groundwater system. 


\section{ACKNOWLEDGEMENTS}

I am greatful to many people for their guidance and support. To my advisor Mary Anderson who inspires all who meet her to strive for a higher plane and then model it. To the members of my committee Jean Bahr, Roland Stull, Dave Mickelson and Fred Madison, who have asked insightful questions and shown tremendous enthusiasm for this research. This research was performed under appointment to the Environmental Restoration and Waste Management Fellowship program administered by Oak Ridge Institute for Science and Education (ORISE) for the U.S. Department of Energy. I will always be greatful for their financial support and for the friends I have at ORISE. The most important person in seeing that I continued my education is my companion, Marianne Ouren, who selflessly gave up a business that she loved to move to Wisconsin. I can not thank her enough. 


\section{TABLE OF CONTENTS}

LIST OF TABLES

vii

LIST OF FIGURES

viii

1. INTRODUCTION $\ldots \ldots \ldots \ldots \ldots \ldots \ldots \ldots \ldots \ldots \ldots \ldots \ldots$

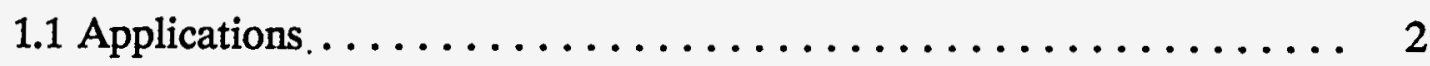

1.2 Methods $\ldots \ldots \ldots \ldots \ldots \ldots \ldots \ldots \ldots \ldots \ldots \ldots \ldots \ldots$

1.3 Previous Studies $\ldots \ldots \ldots \ldots \ldots \ldots \ldots \ldots \ldots \ldots \ldots$

2.0 COMPOSITE ATMOSPHERIC-SUBSURFACE TRANSPORT MODEL . 13

2.1 Conceptual Model $\ldots \ldots \ldots \ldots \ldots \ldots \ldots \ldots \ldots \ldots \ldots \ldots$

2.2 Flow and Transport Models $\ldots \ldots \ldots \ldots \ldots \ldots \ldots \ldots \ldots$

3.0 MODEL LINKAGES $\ldots \ldots \ldots \ldots \ldots \ldots \ldots \ldots \ldots \ldots \ldots \ldots \ldots \ldots$

3.1 Atmospheric and Unsaturated Zone Link ........... 31

3.2 Unsaturated Zone and Groundwater Link .......... 46

4.0 MODEL IMPLEMENTATION $\ldots \ldots \ldots \ldots \ldots \ldots \ldots \ldots \ldots \ldots \ldots . \ldots \ldots$

4.1 Chronic Emission $\ldots \ldots \ldots \ldots \ldots \ldots \ldots \ldots \ldots \ldots . \ldots . \ldots$ 
4.2 Ephemeral Emission $\ldots \ldots \ldots \ldots \ldots \ldots \ldots \ldots \ldots \ldots \ldots .98$

5.0 CONCLUSIONS $\ldots \ldots \ldots \ldots \ldots \ldots \ldots \ldots \ldots \ldots \ldots \ldots \ldots \ldots \ldots \ldots$

6.0 REFERENCES $\ldots \ldots \ldots \ldots \ldots \ldots \ldots \ldots \ldots \ldots \ldots \ldots \ldots \ldots \ldots \ldots \ldots \ldots \ldots \ldots$

7.0 APPENDIX $\ldots \ldots \ldots \ldots \ldots \ldots \ldots \ldots \ldots \ldots \ldots \ldots \ldots \ldots \ldots \ldots \ldots \ldots \ldots \ldots$

7.1 Conversion Factors $\ldots \ldots \ldots \ldots \ldots \ldots \ldots \ldots \ldots \ldots \ldots \ldots \ldots \ldots$

7.2 Symbols $\ldots \ldots \ldots \ldots \ldots \ldots \ldots \ldots \ldots \ldots \ldots \ldots \ldots \ldots \ldots \ldots \ldots$

7.3 Governing Equations for Mass Stored at the Ground Surface ... . 175

7.4 Data for the Sturgeon Falls Site Simulations ........... 178

7.5 CNPP Data $\ldots \ldots \ldots \ldots \ldots \ldots \ldots \ldots \ldots \ldots \ldots \ldots \ldots \ldots \ldots \ldots \ldots \ldots \ldots$

7.6 CATS Model Linkages and Example Input and Output Files. . . . . . disk 


\section{LIST OF TABLES}

Table 1 Sturgeon Falls Site Model Parameter Values for Base Case and

Ranges for Sensitivity Analysis $\ldots \ldots \ldots \ldots \ldots \ldots \ldots \ldots \ldots, 56$

Table 2 Flow Model Calibration: Residual Errors in Water Table Elevation . 60

Table 3 Sturgeon Falls Site Simulated Recharge Distributions $(0.00001 \mathrm{~m} / \mathrm{d})$. 61

Table 4 CNPP Site Base Case and Range of Parameter Values ........ 101 


\section{LIST OF FIGURES}

1. Conceptual Model of atmospheric emission, deposition and subsurface

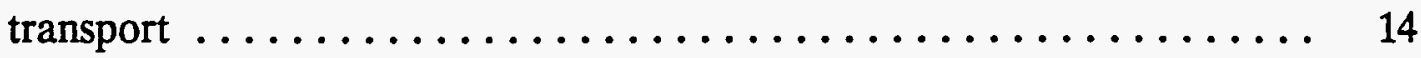

2. CATS model framework and mass transport pathways .......... 19

3. Amount of mass stored at the ground surface relative to the mass deposited from a constant chronic emission as a function of constant dissolution and decay over time $\ldots \ldots \ldots \ldots \ldots \ldots \ldots \ldots \ldots, 40$

4. Amount of mass stored at the ground surface relative to the mass deposited from an ephemeral emission as a function of dissolution of and suspension. $\ldots \ldots \ldots \ldots \ldots \ldots \ldots \ldots \ldots$

5. Dissolution functions used in the sensitivity analysis of the simulated amount of mass stored at the ground surface $\ldots \ldots \ldots \ldots \ldots \ldots \ldots$

6. Infiltration concentration relative to the maximum concentration simulated using an exponential function, discontinuous linear and constant dissolution functions after an ephemeral emission $\ldots \ldots \ldots \ldots \ldots$

7. Sensitivity of the CATS model to the dissolution $\left(\mathrm{g}_{2}\right)$ coefficient: mass stored at the surface and infiltration concentration over time

8. Sturgeon Falls site location map (after Energy, Mines and Resources Canada, 1983 a,b ............................... 50

9. Sturgeon Falls site water table elevations (m above MSL) August, 1986, with monitoring well locations; river and escarpment are located along 
the $212 \mathrm{~m}$ contours, contour interval 1 meter (grid and water table elevations based on mapped values of Robertson and Cherry, 1989) . . 52

10. Sturgeon Falls site model grid and cross section $\ldots \ldots \ldots \ldots \ldots \ldots . \ldots 4$

11. Sturgeon Falls site simulated water table elevations (m) above MSL: base case and revised flow

12. Sturgeon Falls site base case and revised flow model calibration errors in simulated head distribution, sum of the absolute residual error by

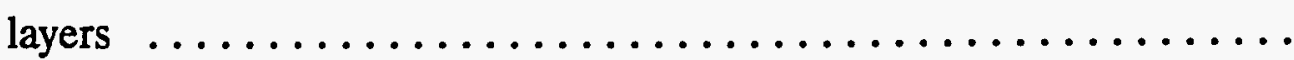

13. Sturgeon Falls site base case and revised flow model calibration errors in the vertical gradients along the transect (model column 12) $\ldots \ldots \ldots$

14. Sudbury Basin estimated average annual sulfur emission rates (moles/s): basin total and individual smelter contributions $\ldots \ldots \ldots \ldots \ldots \ldots 6$

15. Simulated combined, ten year average sulfur emission rates (moles/s) for the Sudbury Basin $\ldots \ldots \ldots \ldots \ldots \ldots \ldots \ldots \ldots \ldots \ldots \ldots$

16. Sturgeon Falls site atmospheric model sensitivity analysis: extreme atmospheric concentration functions using wind parameters $(\mathrm{u}, \mathrm{F})$ and effective source release height (h') $\ldots \ldots \ldots \ldots \ldots \ldots \ldots \ldots$

17. Sturgeon Falls site simulated average annual dry deposition of sulfate using base case parameter values (North Bay wind data, h' = stack

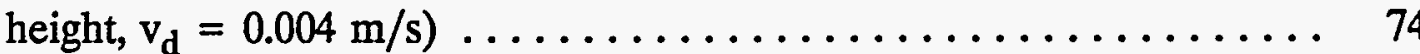

18. Sturgeon Falls site simulated infiltration concentration as a function of 
the amount of solvent (solvent equals all precipitation, precipitation less runoff and precipitation less evapotranspiration) $\ldots \ldots \ldots \ldots .76$

19. Simulated infiltration concentration sensitivity to the atmosphericunsaturated zone model link (dissolution coefficient, suspension coefficient and deposition velocity) $\ldots \ldots \ldots \ldots \ldots \ldots \ldots \ldots \ldots, 79$

20. Sturgeon Falls site simulated steady state water content distributions for different unsaturated thicknesses $(b)$ and infiltration rates $\left(q_{i}\right) \ldots \ldots . \quad 82$

21. Sturgeon Falls site simulated recharge concentration functions for $25 \mathrm{~cm}$ and $300 \mathrm{~cm}$ unsaturated thicknesses $(\mathrm{b}[\mathrm{cm}])$ and various infiltration $\operatorname{rates}\left(\mathrm{q}_{\mathrm{i}}[\mathrm{cm} / \mathrm{d}]\right) \ldots \ldots \ldots \ldots \ldots \ldots \ldots \ldots \ldots \ldots \ldots \ldots \ldots \ldots \ldots$

22. Sensitivity of the Sturgeon Falls simulated recharge concentration function to unsaturated zone thickness and soil hydraulic fitting parameter $\beta \ldots 86$

23. Map views of sulfate distribution in layers 1 and 4 for the base case and revised flow simulations for the Sturgeon Falls site $\ldots \ldots \ldots \ldots \ldots \ldots 89$

24. Sturgeon Falls site measured and simulated sulfate concentrations (ppm) along the transect (model column 12) ................ 90

25. Mass distribution for the base case and revised flow simulations of the Sturgeon Falls site $\ldots \ldots \ldots \ldots \ldots \ldots \ldots \ldots \ldots \ldots \ldots \ldots, 92$

26. Cumulative mass balance error in the Sturgeon Falls site simulation $\ldots . .96$

27. CNPP 30 kilometer zone location map, surface cesium concentration, inferred plume centerlines and model area 
28. CNPP atmospheric model calibration to mapped surface concentrations using wind speed with Pasquill's dispersion model for four stability categories and Hanna's dispersion model for longer distances . . . . . 103

29. CNPP atmospheric model calibration using effective release height with the best wind speed simulations for each dispersion simulation . . . . 104

30. CNPP site simulated cesium surface concentration $\left(\mathrm{Bq} / \mathrm{m}^{2}\right)$ using base case atmospheric parameters with single and double plumes (A stability single plume $u=2 \mathrm{~m} / \mathrm{s}, v_{d}=0.05 \mathrm{~m} / \mathrm{s} ;$ B stability double plume $\left.\mathrm{u}=5 \mathrm{~m} / \mathrm{s}, \mathrm{v}_{\mathrm{d}}=0.055 \mathrm{~m} / \mathrm{s}\right)$

31. Sensitivity of CNPP site simulated cesium and strontium infiltration concentrations to dissolution coefficient $\left(g_{2}\right)$ extreme values . . . . . 109

32. Simulated seasonal precipitation (P) and infiltration (I) functions for the CNPP site (minimum infiltration function used for the base case) $\ldots .112$

33. CNPP site simulated seasonal infiltration concentrations in the zone of maximum cesium deposition (base case) .

34. CNPP site model grid, sediment types, unsaturated thickness, and groundwater model boundary conditions .

35. Steady state flow simulation: maximum recharge concentration functions for the four soil type/thickness zones $\ldots \ldots \ldots \ldots \ldots \ldots \ldots \ldots \ldots$

36. Seasonal flow simulation: maximum recharge concentration functions for the four soil type/thickness zones .

$\mathrm{xi}$ 
37. Simulated cesium recharge concentration (maximum) for 2 soil types with

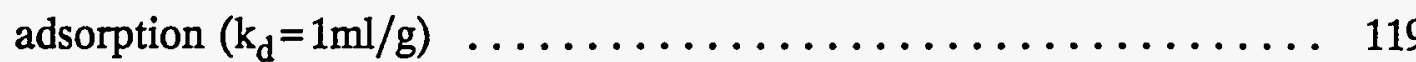

38. Simulated seasonal water table fluctuations as a function of model assumptions (constant or variable specific yield), soil texture and unsaturated thickness $\ldots \ldots \ldots \ldots \ldots \ldots \ldots \ldots \ldots \ldots \ldots \ldots \ldots$

39. Average differences in the simulated water table elevation (by model row) using constant verses time variant specific yield $(t=360$ days $)$ in the seasonal simulation of the CNPP site $\ldots \ldots \ldots \ldots \ldots \ldots \ldots \ldots . \ldots \ldots$

40. CNPP site simulated groundwater cesium concentrations $\left(\mathrm{Bq} / \mathrm{m}^{3}\right) 1$ year after deposition for steady-state and seasonal flow systems $\ldots \ldots \ldots$

41. CNPP site simulated groundwater cesium concentrations $\left(\mathrm{Bq} / \mathrm{m}^{3}\right) 5$ years after deposition for steady-state and seasonal flow systems $\ldots \ldots \ldots \ldots 128$

42. Difference in CNPP site simulated recharge concentration functions using April recharge concentration and recharge weighted concentration for $1 \mathrm{~m}$ sand and sandy loam columns

43. Cumulative mass distribution and mass balance errors in the CNPP site steady state simulation $\ldots \ldots \ldots \ldots \ldots \ldots \ldots \ldots \ldots \ldots \ldots \ldots$

44. Cumulative mass distribution and mass balance errors in the CNPP site seasonal simulation 


\section{INTRODUCTION}

The purpose of this research is to develop a useful composite model of atmospheric and subsurface transport. Composite modeling provides a tool for assessing the potential impact of atmospherically derived contaminants on groundwater systems and evaluating subsurface flow and contaminant transport processes. This research focuses on model construction and developing appropriate links between model systems.

The need for models to evaluate the impact and source terms for groundwater contaminants from atmospheric emissions has recently been recognized (Winter, 1984; IAEA, 1986; Heim and Giuliana, 1988; Mercado, 1989; Schleyer and Milde, 1990; Gass, 1991). A composite transport model is necessary to evaluate the potential effect of atmospheric pollutants on groundwater systems. A numerical model allows the user to quantify a complex system and evaluate the significance of individual physical processes and uncertainties in the parameters on the predicted contaminant distribution. Pollutant sources include natural and anthropogenic emissions. These emissions include aerosols and gases propelled into the atmosphere by fires and explosions, through stacks, automobile exhaust, volcanic activity, and wind deflation of sediments or liquids. Atmospheric emissions may be characterized as ephemeral (short-term) or chronic (long-term) releases.

The model developed in this research is a numerical modeling technique for 
combining atmospheric, unsaturated and groundwater transport models. The conceptual and numerical models used in this research are discussed in Chapter 2. Chapter 3 contains explanations of the model linkages and the sensitivity of the simulation to the linking options. The composite model is applied to two hypothetical field sites. The simulated emissions are based on actual atmospheric pollution sources. The atmospheric and unsaturated zone linkage and the cumulative mass balances are calculated using spread-sheet models. The spread sheet and example input and output files are contained on disks (in pocket)

\subsection{Applications}

Applications of the Composite ATmospheric Subsurface (CATS) model developed in this research include evaluating the potential for groundwater contamination from chronic emissions (e.g., hazardous waste incineration, metal smelting) or large, accidental emissions (e.g., fires, explosions), and determining the usefulness of specific emissions as non-point source groundwater tracers. Atmospheric pollutants are not generally considered a threat to groundwater (Pye and Quarles,1983; Anderson, 1987). However, as drinking water standards become more stringent and chronic emissions continue, the significance of atmospheric sources of contamination may increase. As the waste industry continues to move toward incineration as the disposal method of choice (Sorbo et al., 1986; Howes et al., 1987; Trenholm et al., 1987), coal combustion continues to be used for power 
generation, radionuclides used in fuel and weapons, and smelting for metal refinement continues, the potential long-term effects on the drinking water supplies for the areas receiving the fallout from these processes should be evaluated. For example, an estimated one half ton of cadmium $(\mathrm{Cd})$ and eleven tons of lead $(\mathrm{Pb})$ are emitted every year from a refuse incineration plant near London, England (Hutton and Wadge, 1987).

A second application of the CATS model is as a tool in evaluating the subsurface flow system using atmospheric pollutants as groundwater tracers. Significant temporal changes in atmospheric emissions whether due to the introduction of a source, seasonally variable emission rates, elimination of the source or a sudden change in the emission rates, may provide a pattern that is recognizable in the groundwater system. The 1963 peak in atmospheric tritium is one example of a temporal change in an atmospheric pollutant that makes it a useful groundwater tracer. The CATS model will allow the user to evaluate the significance of uncertainties in the tracer source term and transport parameters on the contaminant distribution in the groundwater system.

\subsection{Methods}

Studies by Pikul et al. (1974), Gilding (1983), Jones et al. (1987), Van der Zee et al. (1991), Kandil et al. (1992) and others have shown that linked unsaturated and groundwater models effectively simulate water flow and 
contaminant transport from the ground surface down through the groundwater system. In this research, atmospheric, unsaturated and groundwater transport models are linked at their boundaries. The boundary between the atmosphere and the unsaturated zone is the ground surface. The bottom of the unsaturated zone is at the water table. In this research, the unsaturated zone model is used to simulate the region of the subsurface where pore fluid pressures are less than atmospheric pressure including the tension saturated zone above the water table. The conceptual and numerical models developed by Brown (1989) and Brown and Sharp (1992) are refined. Existing, well documented transport and flow codes are used to model contaminant transport through the atmospheric, unsaturated and groundwater systems.

Using linked models couples systems that may have very different time or spatial scales. Linking allows the modeler to evaluate the systems independently, use smaller spatial scales for the unsaturated zone to solve the highly non-linear transport problem and select different codes to fit the physical systems. The primary disadvantage of linked models is the discontinuity at the boundaries of the numerical model. This discontinuity makes simulating rapid or small scale changes in the flow or transport system more difficult because very small time steps or numerous iterations may be required to resolve the dynamics of the interaction between the systems. The composite model approach would not be appropriate for evaluating the changes at system interfaces (e.g., soil surface, water table). In these instances 
an integrated modeling approach would be more appropriate.

Integrated models combine the saturated and unsaturated systems into a single system using a single governing equation for unsaturated and saturated flow (e.g., Lappala et al., 1987; Winter, 1983; Narasimhan and Witherspoon, 1977; Freeze, 1971). The integrated models are more realistic. However, for unsaturated flow the governing equation is highly non-linear which necessitates a small grid spacing in the unsaturated zone. As a result, integrated models applied to field scale problems are often limited to two-dimensional flow (e.g., Winter, 1983; Lappala et al., 1987, Yeh et al., 1993). Linked models are more appropriate for larger scale problems (Frind and Verge, 1978).

In the composite model of Brown (1989), the magnitude of the contaminant concentration predicted in groundwater is controlled by the atmospheric source term and the unsaturated zone parameters when a transfer function is used to simulate unsaturated transport (Brown, 1989). For this research, a one-dimensional, advection-dispersion based flow and transport model is used to simulate the movement and storage of the contaminant within the unsaturated zone. This allows evaluation of the time discretization and makes the composite model more generic. Additional revisions to the Brown (1989) model include using three-dimensional groundwater flow and transport models (instead of two-dimensional models) and major revisions of the model linkages. A three-dimensional groundwater model is necessary to determine the vertical distribution of the contaminant within the 
groundwater system and to exploit the advantages of a linked modeling approach.

The model is used to simulate two field sites to demonstrate how the model is applied to ephemeral and chronic emissions and to evaluate the sensitivity of the model to parameter uncertainty. The first simulation uses the chronic sulfur dioxide emissions from nickel and copper smelters in the Sudbury Basin, Ontario, Canada as the source term for a model of a hypothetical groundwater flow system. The second simulation uses the geometry of a surface water basin in the 30 kilometer zone of the Chernobyl Nuclear Power Plant (CNPP) to demonstrate the application of CATS to a large, ephemeral release of radionuclides.

The goal of this research is to develop a useful composite model. This implies the model must be versatile and have reasonable (e.g., obtainable) input requirements. One of the questions this research is designed to answer is which parameters in the composite model are the most significant and which are relatively insignificant in predicting the contaminant magnitude and distribution in the groundwater system. A parameter's significance will be controlled by the influence the parameter has in the numerical model and by the possible or reasonable range of values for that parameter.

\subsection{Previous Studies}

Field Investigations

The conceptual and composite-numerical models developed in this research 
are based on a diverse range of modeling and field studies. Studies that use a water budget approach to estimate recharge or runoff in essence link atmospheric deposition (rainfall) to the surface and subsurface flow systems. Contaminant. transport studies are generally focused on one of the three systems (atmospheric, unsaturated or groundwater).

Most investigations of atmospheric pollutants in groundwater neglect atmospheric and unsaturated transport and the effects of these systems on the source term for the groundwater system (e.g., Bradbury,1991; Robertson and Cherry, 1989; Van Ommen, 1986; Egboka et al., 1983). Similarly, studies on the fate and transport of atmospheric pollutants are primarily concerned with atmospheric and surface water impacts, neglecting the effects on the unsaturated and groundwater systems (e.g., Voldner and Schroeder, 1989; Turner and Lindberg, 1978). There are exceptions. The impact of acid deposition on surface water and soil systems is the focus of many scientific studies (e.g., Johnson and Lindberg, 1992; Dethier, 1979; Hendrey, 1983; Fuhs et al., 1983; Raynal et al., 1983; Troutman and Peters, 1982; Galloway and Likens, 1979; Nielson et al., 1983). These studies do not assess the potential impact on the groundwater system.

The concentration of tritium from atmospheric weapons testing is often used to determine the relative age of groundwater. The source term for tritium is generally based on averages from precipitation data (e.g., Bradbury, 1991; Robertson and Cherry,1989; Egboka et al., 1983). Atmospheric testing of nuclear weapons was 
a very different mechanism for the source term than many other emissions, because of the magnitude and high release altitude. The result is a global scale tracer. The CATS model could be used to evaluate the potential impact of tritium storage in the unsaturated zone on the groundwater distribution. Since the source term for tritium is well known, atmospheric transport modeling is not necessary.

Other, more local scale, radionuclide releases have been proposed as groundwater tracers. Beasley et al. (1992) suggest ${ }^{36} \mathrm{Cl}$ releases at the Savannah River nuclear fuel reprocessing site provide a suitable tracer in the vicinity of the Savannah River Plant and similar plants (e.g., Idaho National Laboratory). With local-scale, near ground surface emissions, dry deposition as well as wet deposition processes should be considered (Morenco and Fontan, 1976; Sehmel, 1980).

\section{Composite Models}

Many composite models have been developed to simulate the flow and transport between interactive systems. The links are generally accomplished using a mass balance approach with distribution coefficients to partition the water or solute mass into components.

Linked atmospheric-unsaturated zone models are generally used to estimate runoff (e.g., Cabral et al., 1992). Surface water and groundwater flow models are generally linked by groundwater discharge or surface water seepage. Arnold et al. (1993) use a quasi three-dimensional basin scale surface water model linked to an 
empirical model of groundwater storage to compute the daily water table height and the potential discharge to surface water systems based on changes in surface water levels.

Linked models of saturated and unsaturated flow generally use the output from the unsaturated flow model to determine the boundary conditions for the saturated flow system (e.g., Kandil et al., 1992; Nielsen and Widjaya, 1989; Watson, 1986; Gilding, 1983; Cichowicz, 1979; Crutcher and Sykes, 1977; Oakes, 1977; Pikul et al., 1974; Elzy et al., 1974). The unsaturated flow model simulates the flux to the saturated system and the distribution of water in the unsaturated zone. In several studies an unsaturated zone model is used to estimate recharge to a groundwater system (e.g., Stoertz et al., 1991; Watson, 1986; Krishnamurthi et al., 1977). Some models allow transient simulations, using an iterative solution to the boundary position and flux rate (Purkey and Wallender, 1993; Pikul et al., 1974). The water content of the soil is used to estimate the storage coefficient for the saturated zone. Keen and Pfannkuch (1992) developed a variable storage coefficient based on the soil hydraulic parameters and the soil column length. Other estimates of the storage coefficient are based on a minimum effective water content for the unsaturated zone (e.g., Dos Santos and Youngs, 1969; Lohman, 1972; Bear, 1972; Pikul et al., 1974). Composite transport models have been developed for several atmospheric pollutants and many different purposes. Some researchers estimate the concentration of atmospheric pollutants in runoff (Akan, 1987). Others estimate 
radionuclide concentration at the ground surface (Sjoreen et al., 1984).

Models differ in how the atmospheric concentration is simulated. Some researchers assume a constant concentration and model the deposition rate (Sjoreen et al., 1984; Chan et al., 1984). Others use an atmospheric transport and deposition model to simulate the contaminant concentration on the ground surface (Raridon and Andren, 1975).

Simulations of the concentration of contaminants in runoff from contaminants stored at the ground surface are often simulated using lumped parameter models (e.g., Steenhuis and Water, 1980; Haith, 1980). More sophisticated models utilizing rate limited (kinetic) adsorption and desorption processes coupled with runoff models are used to examine the time dependant release of contaminants from the surface zone into runoff (Wallach and Shabtai, 1993).

Linked models of unsaturated and groundwater transport are used to estimate the impact of contaminant sources located on the ground surface and in the unsaturated zone on groundwater quality in shallow unconfined aquifers (e.g., Kandil et al., 1992; Van der Zee and Boesten, 1991; Jones et al., 1987; Oakes, 1977). The unsaturated transport model is used to estimate the concentration of recharge and the arrival time of the contaminant at the water table. The groundwater flow and transport model is used to simulate the lateral movement of the contaminant and to estimate the dilution of the contaminant concentration with uncontaminated groundwater. Steady flow through the unsaturated zone is often assumed and the 
issues of variable storage and the transient position of the water table are ignored (e.g., Oakes, 1977; Jones et al., 1987; Kandil et al., 1992).

A few models evaluate the potential impact of atmospheric sources of contaminants on groundwater composition. Van Ommen (1986) uses a mass balance approach, the "perfectly stirred tank" model, to estimate the impact of a groundwater solute from an atmospheric source on surface water quality. The application mentioned for this model is estimating the effect of the Chernobyl fire on surface water quality. This method neglects the atmospheric source term as well as unsaturated transport. The results of the model are presented as breakthrough curves for a distributed, decaying contaminant pulse in spring water. Brown (1989) developed a simplified composite model of atmospheric, unsaturated and groundwater transport. The composite model consisted of a Gaussian atmospheric model with a continuous point source, a transfer function to estimate unsaturated transport and a two-dimensional groundwater transport model (Konikow and Bredehoeft, 1978). In linking the atmospheric model to the unsaturated model, Brown (1989) assumed that the mass in a unit volume of air at the ground surface is deposited and then dissolved evenly in the total infiltration for each time step.

The CATS model simulates the transport of an atmospheric pollutant into the subsurface. It accounts for transport and storage in the unsaturated zone, provides a tool to evaluate the effects of adsorption, decay and evaporative enrichment in the unsaturated zone on the contaminant concentration and arrival 
time at the groundwater system. CATS uses linked models to simulate systems with different temporal and spatial scales and has the ability to simulate basin scale or large field scale problems. The CATS model simulates contaminant transport in the atmospheric, unsaturated and groundwater systems. The surface water system acts as a sink for the model, transporting contaminant particles and solutes in runoff to surface water bodies and out of the model area. The model is greatly improved over the Brown (1989) model. It uses a refined and detailed conceptual model, more appropriate links, allows for storage of the contaminant at the ground surface and incorporates an advection dispersion based unsaturated model. The CATS model can simulate the distribution and concentration of the contaminant on the surface and in the subsurface as a result of dissolution and transport with infiltration and losses due to runoff. The model's primary function is to estimate the water and contaminant source functions for the groundwater system. It is an essential tool for evaluating the potential impact of atmospheric emissions on groundwater composition. 


\subsection{COMPOSITE ATMOSPHERIC-SUBSURFACE TRANSPORT MODEL}

\subsection{Conceptual Model}

Figure 1 is a simplified visual representation of the conceptual model. Atmospheric pollutants are emitted from a point source somewhere at or above the ground surface. The pollutants, consisting of gases and particles (liquid or solid), are transported from the source by convection (due to local thermal gradients), mechanical turbulence and advection. The distribution of the atmospheric pollutants will be a function of the temperature of the source relative to the ambient air temperature, particle size, gas phase, the emission height, duration of the release, advective velocity, and the turbulence and transience of the wind field. Factors influencing the wind velocity include the temporal and spatial distributions of pressure and temperature gradients, surface roughness and barriers to flow. Mass will be removed from the atmospheric system by deposition on the ground surface. Particles will be deposited by gravitational settling, impact with barriers at or near the ground surface (dry deposition), or impact then settling with precipitation (wet deposition). The aerosols may interact with each other, forming aggregates, or with precipitation to form larger particles that settle out of the atmosphere more quickly 


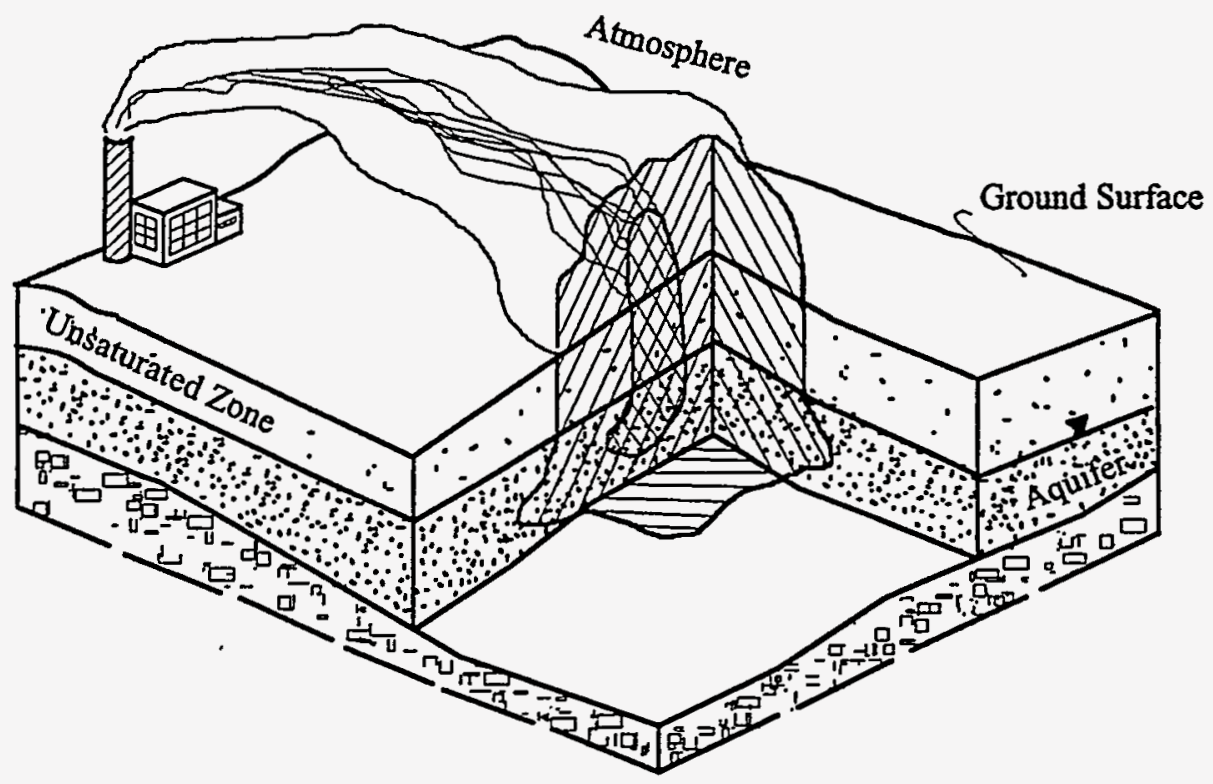

Figure 1 Conceptual Model of atmospheric emission, deposition and subsurface transport 
than individual particles. The aerosol may react quickly with precipitation, dissolving before reaching the ground surface.

Aerosols and solutes of aerosols are deposited on the ground cover. The ground cover includes some combination of bare soil, rock, plants, surface water bodies (oceans, lakes, rivers), buildings, parking lots, roads, animals, and vehicles. Aerosols that are deposited in solution will move with the runoff and water infiltrating the unsaturated zone, be resuspended in the atmosphere or stored at the ground surface. Dry deposition will cause accumulation of the aerosols on the ground cover until they are resuspended in the atmosphere, washed off and transported with runoff to surface water bodies (in suspension or as solutes), or transported with water infiltrating the unsaturated zone (as solutes or colloids). Aerosols deposited on animals and cars may be transported on the ground surface then, possibly, washed off into a surface water body. Storage of the contaminant (e.g., distribution and residence time) on the ground surface is a function of the type and distribution of ground cover, the distribution, intensity and timing of precipitation events, the surface water system (topography, runoff and impoundments), and the interaction between the surface water and unsaturated flow systems.

Transport of the contaminant in the unsaturated zone is a function of the infiltration rate, unsaturated hydraulic conductivity, effective porosity, hydraulic and chemical gradients, sorption, uptake by plants, chemical precipitation and 
biodegradation. The unsaturated hydraulic conductivity is controlled by the soil texture, structure and water content. The distribution of preferential pathways, zones of high hydraulic conductivity due to heterogeneities in the unsaturated medium, root holes, worm burrows, fractures or other macropores controls the transport rate and distribution of the contaminant in the upper portion of the unsaturated zone. Many of the macropores only persist to some maximum depth (e.g., root zone, worm burrow and fractures). Below that depth, heterogeneities in the porous medium control the flow field.

The contaminant is transported into the groundwater system as a solute or colloid moving with the water recharging the system. In unconfined systems, contaminant stored in the unsaturated zone may enter groundwater due to fluctuations in the water table. As the water table rises, the contaminant stored in the unsaturated zone would become part of the groundwater system. Molecular diffusion may also provide a pathway from the unsaturated zone to the groundwater system. Once in the saturated system, the contaminant will continue to be transported by advection and diffusion. Contaminants may be retarded or retained by sorption or entrapment of colloids in small pores (if they are colloidal or sorbed on colloids). Another contaminant pathway to the groundwater system is through interaction with surface water where contaminants may accumulate due to runoff processes.

The contaminant may be attenuated due to chemical reactions, radioactive 
decay and biodegradation processes that alter the chemical characteristics of the contaminant. The distribution of the contaminant in the groundwater is a function of the groundwater velocity, distribution of adsorbents, chemical composition of the groundwater and aquifer matrix, the distribution and amount of recharge and the concentration of the contaminant in the recharge.

Many simplifying assumptions are made in order to form a numerical model of the system. The simplifying assumptions used in CATS include the following: chemical and biological reactions can be modeled using first order decay or adsorption (linear or nonlinear), macropores can be modeled as a porous medium, surface water is a sink that removes the contaminant from the model area, contaminant transported by plants and animals is insignificant, the mass will be normally distributed in the atmosphere during periods with relatively constant wind velocities, flow in the unsaturated zone is vertical, density and solute concentrations do not influence the flow system, the system is isothermal, and the subsurface can be modeled as a rigid porous medium. The significance of these assumptions will depend on the system being modeled and they should be carefully considered.

\subsection{Flow and Transport Models}

The basic CATS model framework is depicted in figure 2. The CATS model consists of an atmospheric transport model to estimate the dry deposition of 
atmospheric contaminants on the ground surface, a one-dimensional unsaturated flow and transport model to simulate contaminant transport through the unsaturated zone and a three-dimensional groundwater flow and transport model. Dry and wet atmospheric deposition processes are treated separately. Wet deposition is accounted for by entering the solute concentration as measured or estimated in precipitation. This is based on the assumption that for chronic sources, the wet deposition does not significantly alter the long-term average ground-level atmospheric concentration and that for ephemeral sources either wet or dry deposition dominates. Symbols are defined when first introduced and a list of symbols and their definition can be found in the appendix.

Atmospheric Model

A Gaussian atmospheric transport model is used to estimate the pollutant concentration in the air above the site (equation 1). The Gaussian model is based on the assumption of a normal distribution of the mass from an atmospheric pollutant emitted into a uniform wind field with mean wind speed $(u)$, at a constant rate $\left(Q_{0}\right)$ and an effective height ( $h$ '). The model estimates the average concentration in air $\left(C_{2}\right)$ at a reference altitude $\left(z_{0}\right)$ and a down-wind $(x)$ and cross-wind $(y)$ distance from the source for a specified time period $(\Delta \mathrm{t})$. Vertical $\left(\sigma_{\mathrm{z}}\right)$ and cross-wind $\left(\sigma_{\mathrm{y}}\right)$ dispersion coefficients are used to simulate plume spread. These empirical coefficients are time and distance dependent. CATS assumes that no decay of the contaminant occurs in the atmosphere. 


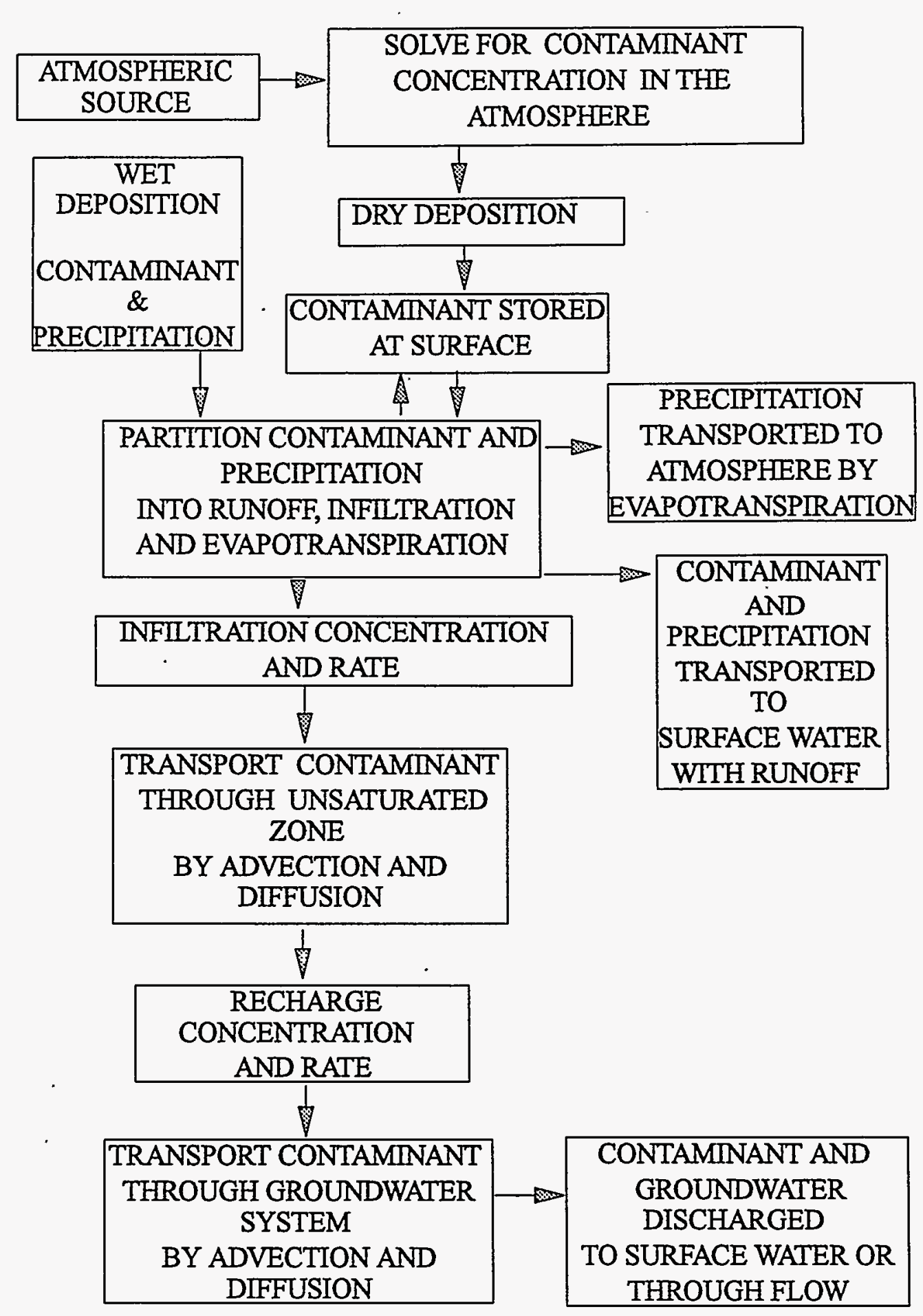

Figure 2 CATS model framework and mass transport pathways 


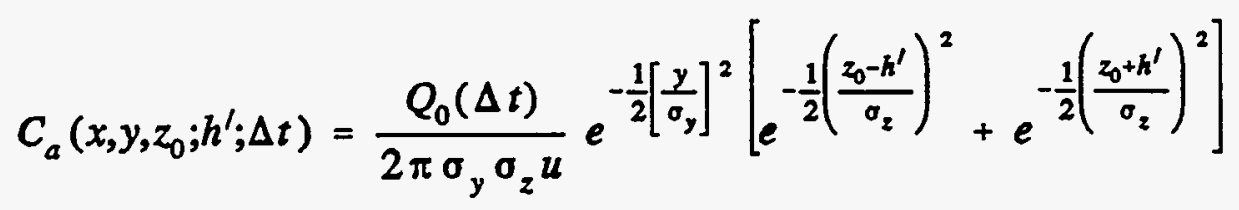

This model does not account for plume depletion due to deposition processes. It assumes that all of the mass is reflected at the ground surface. Other models have been developed to account for the loss of mass due to dry deposition. One method is the surface depletion technique of Overcamp (1976) that uses the deposition velocity and average wind speed to modify the amount of mass reflected by the ground surface. Another technique uses an effective source strength to account for depositional mass loss. The surface depletion technique decreases the atmospheric concentration at the ground surface and tends to underestimate deposition (Hanna et al., 1982). The source depletion technique assumes the mass is lost from the entire thickness of the plume and tends to overestimate deposition (Horst, 1980). The pure reflection model is used in CATS for ephemeral source example simulation, however in a true field application the plume depletion should be accounted for when simulating the atmospheric concentrations.

The Gaussian model is modified to estimate the long-term average atmospheric concentration from a chronic source. CATS uses Turner's (1969) modified Gaussian transport model to estimate reasonable ranges for the average ground-level-atmospheric concentration $\left(\mathrm{C}_{\mathrm{a}}(\mathrm{x}, \omega)\right)$ due to chronic atmospheric 
emissions (equation 2).

$$
C_{a}(x, \omega)=\sum_{S^{\prime}} \sum_{N^{\prime}} \frac{16 Q_{0} F\left(\omega, S^{\prime}, N^{\prime}\right)}{\sqrt{2 \pi} \sigma_{z}\left(S^{\prime}\right) u\left(N^{\prime}\right) \pi x} e^{-\frac{1}{2}\left(\frac{k^{\prime}(u)}{\sigma_{z}\left(S^{\prime}\right)}\right)^{2}}
$$

In this equation the concentration is a function of the atmospheric source term $\left(\mathrm{Q}_{0}\right)$; frequency function $(F)$ for the wind direction $(\omega)$, wind speed class $\left(N^{\prime}\right)$ and stability class $\left(S^{\prime}\right)$; the vertical dispersion coefficient $\left(\sigma_{z}\right)$ the average wind speed $(u)$ and the downwind distance (x). The effective source release height is calculated as a function of the stack gas velocity, stack radius, average wind speed and stack gas temperature relative to the ambient air temperature (Briggs, 1969).

Although trajectory based models of atmospheric transport are physically based and scientifically more appealing, the use of a Gaussian plume model is justified by the limitations of the data available. Ellis and others (1980), in a comparison of 58 atmospheric transport models, found that the accuracy of the model concentration predictions had little to do with the modeling technique, but was a function of the accuracy of the measured wind direction. Average daily or hourly wind velocities limit the predictions to order of magnitude approximations of pollutant concentration. Derwent et al. (1989) in a comparison of long-term predictions of acid deposition by atmospheric transport models found that an empirical Gaussian model performed as well as or better than physically based 
trajectory models. For this reason, it is assumed that a Gaussian model will yield a suitable estimate of ground-level pollutant concentration for chronic atmospheric emissions. The application of the Gaussian model to ephemeral releases is justified by data limitations.

The atmospheric source term $\left(Q_{0}\right)$ is one of the most important factors in determining the distribution and maximum concentration of the contaminant in the groundwater system (Brown,1989). As with other atmospheric transport models, the CATS model depends on accurate estimates of mean wind speed (u) at the release site in order to yield valid estimates of the atmospheric concentration $\left(C_{a}\left(x, y, z ; h^{\prime}\right)\right)$. When these data are unavailable, the model can only be used in an interpretive mode.

Unsaturated Flow and Transport

The original composite model (Brown, 1989) used a transfer function to simulate transport through the unsaturated zone. Although convenient, it does not allow the modeler to analyze the distribution of the contaminant or water in the unsaturated zone with respect to time. This causes problems in estimating the transport of contaminants from ephemeral atmospheric sources, time dependent storage and dissolution of the contaminant on the ground surface, and the effects of transient flow systems due to seasonal or daily changes in the direction and rate of infiltration due to changes in precipitation and evapotranspiration rates.

The CATS model uses the computer code HYDRUS (Kool and van 
Genuchten, 1991) to simulate one-dimensional, transient, variably saturated flow and transport. The code is in the public domain and uses fully implicit, Galerkin linear finite element (FE) solutions to the governing equations. The governing equation for unsaturated flow includes the effects of hysteresis, evaporation and root water uptake. HYDRUS uses the van Genuchten (1980) parametric functions and Mualem's (1976) hydraulic conductivity model $(\mathrm{m}=1-1 / \beta$, where $\mathrm{m}$ is the exponential fitting parameter) to describe the soil hydraulic properties: water content as a function of pressure head $\left(\theta\left(h_{\mathrm{p}}\right)\right)$ and hydraulic conductivity as a function of water content $(K(\theta)$ ) (equation 3 ). The relative saturation $(\theta)$ is a function of the volumetric water content $(\theta)$, residual water content $\left(\theta_{\mathrm{r}}\right)$ and the saturated water content $\left(\theta_{s}\right)$. The relative saturation is calculated for the given . pressure head $\left(h_{p}\right)$ using the characteristic curve of soil water content as described by the fitting parameters $\alpha$ and $\beta$.

$$
\begin{aligned}
K\left(h_{p}\right) & =K_{s} \theta^{1 / 2}\left[1-\left(1-\theta^{\frac{\beta}{\beta-1}}\right)^{1-\frac{1}{\beta}}\right]^{2} \\
\theta & =\frac{\theta-\theta_{r}}{\theta_{s}-\theta_{r}}=\frac{1}{\left[1+\left(\alpha h_{p}\right)^{\beta}\right]^{1-\frac{1}{\beta}}}
\end{aligned}
$$

The governing equation for the flow model is based on Richard's equation (hbased), allowing simulation and evaluation of temporal changes in the unsaturated flow system (equation 4). Richard's equation combines the Buckingham-Darcy flow 
equation with the continuity equation. For one dimensional flow, the continuity expression states that the change in water content over time in a representative elemental volume is equal to the vertical flux gradient $\left(\partial \mathrm{q}_{\mathrm{z}} / \partial \mathrm{z}\right)$. The change in the vertical fluid flux $\left(q_{z}\right)$ with depth $(z)$ is equal to the pressure head dependent water capacity function $\left(\mathrm{C}_{\mathrm{w}}\left(\mathrm{h}_{\mathrm{p}}\right)\right)$ times the vertical pressure-head gradient. The water capacity function describes the change in water content as a function of changes in the pressure head.

$$
\frac{\partial \theta}{\partial t}=-\frac{\partial q_{z}}{\partial z}=C_{w}\left(h_{p}\right) \frac{\partial h_{p}}{\partial t}=\frac{\partial\left[K\left(h_{p}\right)\left(\frac{\partial h_{p}}{\partial z}+1\right)\right]}{\partial z}
$$

The upper boundary at the ground surface is simulated using specified flow conditions (equation 5). HYDRUS estimates the initial pressure head distribution based on the infiltration flux $\left(\mathrm{q}_{\mathrm{I}}\right)$ and the initial water content or pressure head values, at a minimum of 2 depths, using the characteristic curves (equation 3 ).

$$
\begin{aligned}
\frac{\partial h_{p}}{\partial z}=\frac{q_{I}}{-K\left(h_{p}\right)}-1 \\
\quad q_{I}=\frac{I}{\Delta t}=\frac{P\left(1-g_{r}-g_{e}\right)}{\Delta t}
\end{aligned}
$$

In the CATS model, the infiltration flux is estimated using a mass balance approach. The amount of infiltration (I) is equal to the amount of precipitation $(\mathrm{P})$ less runoff 
(R) and evapotranispiration (E). The runoff and evapotranspiration components are estimated using partitioning coefficients $\left(g_{\mathrm{T}}\right.$ and $\left.\mathrm{g}_{\mathrm{e}}\right)$. A specified flux or pressure head condition is used at the lower boundary to simulate the position and hydraulic conditions at the water table (equation 6).

$$
\begin{gathered}
q_{R}=\left[1-\frac{\partial h_{p}}{\partial z}\right] K\left(h_{p}\right) \\
\text { or } \\
h_{p}\left(z_{w t}, t\right)=0
\end{gathered}
$$

A specified flux boundary condition is used only in steady-state flow simulations when the position of the water table is fixed and the recharge rate is determined by calibrating the groundwater flow model. Specified pressure boundary conditions are used to simulate the position of the water table and are used when the unsaturated flow model estimates the recharge rate.

The initial conditions for the unsaturated flow model are specified pressure heads for the entire depth of the column (equation 7).

$$
h_{p}(z, 0)=f_{1}(z) \quad: t=0
$$

The unsaturated flow model determines the vertical velocity of water for the transport simulation, the recharge rate for the groundwater system and the volumetric water content distribution for estimating the water storage term for 
transient groundwater flow simulations.

The unsaturated transport model is used to simulate contaminant transport through the unsaturated zone in order to estimate the concentration of the contaminant in the recharge to the groundwater system. The advection-dispersion based governing equation for unsaturated transport includes terms for equilibrium adsorption (Freundlich isotherms) and first order decay (equation 8).

$$
\frac{\partial(\theta C)}{\partial t}+\frac{\partial \rho_{b} k_{1} C^{\eta}}{\partial t}=\frac{\partial}{\partial z}\left(\theta D \frac{\partial C}{\partial z}\right)-\frac{\partial q_{z} C}{\partial z}-\lambda_{1} \theta C-\lambda_{2} \rho_{b} k_{1} C^{\eta}
$$

The contaminant concentration in the unsaturated zone $(\mathrm{C})$ is a function of the dispersion coefficient $(D)$, fluid flux $\left(q_{z}\right)$, water content $(\theta)$, decay parameters $\left(\lambda_{1}\right.$ and $\left.\lambda_{2}\right)$ and adsorption parameters $\left(k_{1}\right.$ and $\left.\eta\right)$. The upper boundary is a specified mass or activity flux condition, calculated using the infiltration concentration $\left(C_{i}\right)$ and fluid flux $\left(\mathrm{q}_{\mathrm{I}}\right)$ from the atmospheric-unsaturated link (equation 9).

$$
q_{z} C-\theta D \frac{\partial C}{\partial z}=q_{1} C_{I}
$$

The initial conditions for the unsaturated transport model are specified concentration (equation 10).

$$
C(z, 0)=f_{2}(z)
$$


The lower boundary condition for the unsaturated transport model is a zero concentration gradient (equation 11).

$$
\frac{\partial C\left(z_{w t}, t\right)}{\partial z}=0
$$

It is assumed that diffusion across the lower boundary is negligible and advection is the dominant transport process at this boundary. Groundwater Flow and Transport

CATS uses three-dimensional groundwater flow and transport models. The MODFLOW code (McDonald and Harbaugh, 1988) was selected for the flow modeling because it is widely used, versatile, well tested, and utilizes a threedimensional saturated flow model. The governing equation for MODFLOW is based on Darcy's law and mass conservation (equation 12). The groundwater flow field is a function of the hydraulic conductivity $(\mathrm{K})$ distribution, hydraulic head distribution (h), the specific storage of the aquifer $\left(\mathrm{S}_{\mathrm{s}}\right)$ and fluid sources or sinks (W).

$$
\nabla \cdot \vec{q}=\nabla \cdot(K \nabla h)=-S_{s} \frac{\partial h}{\partial t}-W
$$

The input requirements for MODFLOW include a time invariant storage coefficient $\left(\mathrm{S}_{\mathrm{s}} \mathrm{b}_{\text {aquifer }}\right)$ for confined layers and specific yield $\left(\mathrm{S}_{\mathrm{y}}\right)$ for unconfined layers. This 
requires a simplifying assumption that the time variance of the storage in the unsaturated zone is negligible. The significance of this assumption will depend on how the specific yield is estimated, the temporal variation in the water content of the unsaturated zone and the fluctuations in the water table elevation. This problem is addressed in chapter 4 , using the ephemeral source example problem with a seasonally transient flow simulation.

The water table forms the upper boundary of the groundwater flow model and is simulated as a specified flux boundary (equation 13). The recharge flux $\left(\mathrm{q}_{R}\right)$ is determined by the downward flux at the lower boundary of the unsaturated zone flow model.

$$
\frac{\partial h}{\partial z} K_{s}=q_{R}
$$

The initial condition for the groundwater flow model is the head distribution in the aquifer (equation 14).

$$
h(x, y, z ; 0)=f_{3}(x, y, z)
$$

The bottom of the groundwater model is a no-flow boundary, representing an impermeable layer (equation 15).

$$
\frac{\partial h}{\partial z}=0 \text { at } z=\text { bottom }
$$


The sides of the model may be simulated using no-flow, specified head or specified flux conditions.

Zheng's (1991) MT3D code, simulates three-dimensional transport. MT3D was chosen because it utilizes the method of characteristics (MOC) and interfaces easily with MODFLOW. The MOC is a versatile solution technique that minimizes numerical dispersion (Konikow and Bredehoeft, 1978). The governing equation for MT3D contains a solute source (or sink) term $\left(\mathrm{q}_{\mathrm{s}} \mathrm{C}_{\mathrm{s}} / \mathrm{n} ; \mathrm{n}\right.$ is effective porosity) and chemical reaction terms to account for first order decay $\left(\lambda_{1} C+\lambda_{2} \rho_{b} k_{1} C^{\eta} / n\right)$ and equilibrium adsorption $\left(\rho_{b} k_{1} C^{\eta} / n\right)$ (equation 16).

$$
\frac{\partial C}{\partial t}=\nabla \cdot(D \nabla C)-\nabla \cdot \frac{\vec{q}}{n} C+\frac{q_{s} C_{s}}{n}-\frac{\partial p_{b} k_{1} C^{\eta}}{n \partial t}-\lambda_{1} C-\frac{\lambda_{2} \rho_{b} k_{1} C^{\eta}}{n}
$$

Specified flow and specified head boundaries in the model are simulated using specified concentration flux boundaries in the transport model. No flow boundaries may be treated as zero mass (or radioactivity) flux or diffusional mass flux boundary conditions using a specified concentration gradient. The upper boundary condition is specified mass (or radioactivity) flux, determined by the unsaturated flow and transport model (equation 17).

$$
q_{2} C=q_{R} C_{R}
$$

The initial conditions are specified concentrations (equation 18). 


$$
C(x, y, z ; 0)=f_{4}(x, y, z)
$$

The upper, flux boundary condition assumes that the contaminant is transported into the groundwater advectively with the recharge and that diffusion is negligible. For subsurface systems where diffusional transport is expected to dominate, specified gradient or a combination of specified advective and diffusional flux boundary conditions are used. All the CATS model simulations assume advective flux dominates at the upper boundary.

Summary

The CATS modeling technique utilizes existing numerical models of atmospheric and subsurface transport. These models are selected to fit the simulated system and the type and level of data available. The ability of CATS to mimic actual conditions is limited by the assumptions required by the individual numerical models and the assumptions made in implementing the model (e.g. normal distribution of mass in the atmosphere, Darcy flow in the subsurface, average conditions and parameter values).

The CATS modelling technique provides a framework for link individual transport models. This allows adaption of CATS to a wide variety of atmospheric releases and hydrologic conditions. The model links provide a mass accounting method and allow de-coupling of the models at the boundaries so that different time and spatial scales can be used for the individual numerical models. 


\subsection{MODEL LINKAGES}

Model linkages are developed to account for the transfer of mass from one transport system to the next and to allow for the storage of contaminants at the interface between the atmospheric and subsurface systems. These linkages allow coupling of systems with different time and spacial scales. The first link between the atmosphere and the ground surface is made using a deposition velocity to estimate the mass flux. Once the mass is deposited on the ground surface, all or part of the mass is partitioned into runoff and infiltration. Dissolution and suspension rate coefficients are used to simulate the transport of the contaminant into runoff and infiltration. First order decay is used to simulate radioactive or biological decay of the contaminant stored on the ground surface. The link between the unsaturated and groundwater systems uses the simulated concentration and water flux out from the bottom of the unsaturated column to simulate the recharge rate and concentration for the groundwater model. Currently, CATS requires manual iteration of the boundary and unsaturated zone conditions (recharge/discharge rates, water content or pressure distribution, contaminant concentration distribution and water table elevation) to simulate transient subsurface flow and transport.

\subsection{Atmospheric and Unsaturated Zone Link}

The atmospheric and unsaturated zone models are linked at their boundary, the ground surface. The concentration of mass or activity on the ground surface $\left(\mathrm{M}_{0}\right)$ due to dry deposition processes is simulated using the atmospheric 
concentration at a reference altitude $\left(z_{0}\right)$ and a deposition velocity $\left(v_{d}\right)$ (equation 19).

$$
M_{0}(x, y ; \Delta t)=C_{a}\left(x, y, z_{0} ; h^{\prime} ; \Delta t\right) v_{d} \Delta t
$$

The reference altitude, specific to the deposition velocity, is usually 1 meter (Sehmel, 1980). The total amount of mass deposited at a location $(x, y)$ over a specified time interval ( $t=0$ to $n$ ) is equal to the integral of the Gaussian function times the deposition velocity (equation 19), from the time that deposition began $(t=0)$ to time equal $n$ (equation 20 ).

$$
M_{n}=\int_{t=0}^{n} C_{a} v_{d}(t) d t
$$

Equation 20 is solved or approximated using simplifying assumptions (e.g., constant emission rates or approximate variable emission rates using step functions). In order to estimate the total mass deposited on a site from an ephemeral or chronic source, it is assumed that the average emission rates are constant over some time interval $(\Delta t)$ when the dispersive effects of the variability in the wind speed and atmospheric stability conditions can be described using constant dispersion coefficients and average wind parameter values. The total mass deposited is approximated as the sum of the mass deposited over the time interval modeled. 
Dry deposition is the first component of the link between the atmospheric model and the unsaturated transport model. Another part of the link accounts for dissolution of the aerosol. Dissolution may occur in the atmosphere. In that case the contaminant will reach the ground surface as a solute. Because the concentration and amount of precipitation are easily measured, the CATS model uses the measured or estimated concentration in precipitation $\left(C_{p}\right)$. The wet deposition component is assumed to have either a negligible or overwhelming impact on the atmospheric concentration. Aerosol particles trapped within the precipitation may be transported as colloids or they may be left behind at the soil surface as the precipitation becomes infiltration. Colloidal transport is not included in the CATS model.

For chronic atmospheric sources, episodic wet deposition is assumed to have a negligible effect on the average atmospheric concentration and dry deposition concentration. However, wet deposition may have a significant impact on the infiltration concentration. For ephemeral emissions, either wet or dry deposition is assumed to be the dominant process. In both cases, wet deposition is accounted for using the measured or simulated concentration $\left(\mathrm{C}_{\mathrm{p}}\right)$ in, and the amount of precipitation $(\mathrm{P})$ deposited during each time step.

For the particles stored on the ground surface, a dissolution term is necessary to complete the link between the atmospheric and unsaturated models. The dissolution of the aerosol will be a function of the amount and chemical composition 
of the precipitation, the amount, surface area and solubility of the contaminant and the contact time between the precipitation/infiltration and the contaminant relative to the dissolution rate. The amount of particulate contaminant stored at the surface at a specific time will be a function of the initial amount deposited and subsequent removal of the contaminant due to wash-off and transport with runoff or infiltration.

Several infiltration and dissolution schemes are implemented in the CATS model. All are based on a mass balance approach. Precipitation $(\mathrm{P})$ is partitioned into runoff $(R)$ and evapotranspiration (E) using dimensionless partitioning coefficients $\left(\mathrm{g}_{\mathrm{r}}\right.$ and $\left.\mathrm{g}_{\mathrm{e}}\right)$. Infiltration (I) is estimated using mass balance (equation 21). As with precipitation, the infiltration and runoff are in units of length.

$$
\begin{gathered}
P=I+R+E \\
I=P\left(1-g_{r}-g_{e}\right)
\end{gathered}
$$

The amount of water involved in dissolution of the contaminant (the solvent) is simulated as a function of the amount of precipitation added to the system (P) during the time step and a solvent partitioning coefficient $\left(\mathrm{g}_{1}\right)$. The solvent partitioning coefficient may be a constant or variable [e.g., a function of season (time), rain intensity, slope]. The infiltration concentration, the concentration of the contaminant entering at the upper boundary of the unsaturated transport model $\left(C_{i}\right)$ is a function of the amount of the dry deposited material that is dissolved $\left(g_{2} \Delta t M\right)$, the amount of solvent $\left(g_{1} P\right)$, and the concentration of the wet-deposited 
contaminant in the precipitation $\left(\mathrm{C}_{\mathrm{p}}\right)$ (equation 22).

$$
C_{i}=C_{P}+\frac{\varepsilon_{2} \Delta t M}{g_{1} P}
$$

Several dissolution options were tested using the CATS model. In one option, all of the mass deposited on the ground surface is dissolved $\left(g_{2} t=1\right)$ in and transported with the infiltrating water $\left(g_{1}=1-g_{r}-g_{e}\right)$. The other options simulate different amounts of solvent, using the solvent equal to the total precipitation $\left(\mathrm{g}_{1}=\right.$ 1) or the precipitation less evapotranspiration $\left(g_{1}=1-g_{e}\right)$. The solvent coefficient $\left(\mathrm{g}_{1}\right)$ controls the infiltration concentration but not the amount of mass partitioned into the subsurface. The amount of mass entering the subsurface is controlled by the leaching rate and runoff partitioning coefficients $\left(g_{2}\right.$ and $\left.g_{r}\right)$. When the leaching rate coefficient times time $\left(g_{2} \Delta t\right)$ is equal to one, all the mass deposited during the time step is dissolved and no mass is stored at the surface.

A mass balance approach is used to simulate the mass of contaminant stored at the surface (equation 23).

$$
M_{i+1}=M_{i} e^{-\lambda \Delta t}\left\{1-\Delta t\left(g_{2}(i)+g_{3}(i)+g_{4}(i)\right)\right\}
$$

The mass is partitioned into runoff (as solid and solute) and infiltration (solute). For the example simulations it is assumed that dissolution occurs rapidly and the solute concentrations of runoff and infiltration are equal. In this case, a single 
dissolution coefficient is used and the amount of mass transported in runoff is determined by the amount of the solvent lost to runoff. If a greater percentage of the dissolution occurs due to contact with infiltration, there are two modeling options. First, the solvent coefficient may be used to simulate the amount of water involved in dissolution, changing the concentration but not necessarily the amount of mass partitioned into runoff and infiltration. The second option requires the use of separate dissolution coefficients for the runoff $\left(\mathrm{g}_{4}\right)$ and infiltration $\left(\mathrm{g}_{2}\right)$ components. The suspension coefficient $\left(g_{3}\right)$ and dissolution coefficients can be constants, spatially variable or they may change step-wise at each time step. The sum of the suspension and dissolution rate coefficients times the length of the time step is always less than or equal to one. If the sum equals one, all the mass is removed from the surface.

The mass available to the subsurface system at the beginning of each time step $\left(M_{i+1}\right)$ is equal to the mass at the beginning of the last time step $\left(M_{i}\right)$ less the mass transported off of the surface in runoff and infiltration $\left(\mathrm{M}_{\mathrm{i}} \Delta \mathrm{t}\left(\mathrm{g}_{3}+\mathrm{g}_{4}\right)+\right.$ $\mathrm{M}_{\mathrm{i}} \Delta \operatorname{tg}_{2}$ ). Once the mass is partitioned into runoff (solute or solid), it is removed permanently from the model area. The model of the surface concentration over time (equation 23) is the governing equation for constant or discretely modeled dissolution and suspension coefficients. This is the form of the model link used in the example simulations.

The model link between the atmospheric and unsaturated zone models 
accounts for the mass deposited and stored at the ground surface. Mass is removed by first order decay, dissolution and transport as a solute in runoff and infiltration, and suspension and transport in runoff. The significance of the temporal variability in the suspension $\left(g_{3}\right)$ and dissolution $\left(g_{2}\right.$ and $\left.g_{4}\right)$ rate coefficients and the model used to simulate that variability are evaluated using constant, discrete, discontinuous linear and exponential function models of these coefficients. Equation 24 is the governing equation for the concentration of mass stored at the surface $(M)$ as a function of the initial amount of mass deposited $\left(M_{0}\right)$, using a single dissolution rate coefficient for runoff and infiltration, and discontinuous linear functions to describe the suspension and dissolution coefficients.

$$
\begin{gathered}
\text { let } g_{2}=c_{1} t+c_{2} \text { for } g_{2}>0 \text { and } g_{3}=c_{3} t+c_{4} \text { for } g_{3}>0 \\
{\left[g_{2}=0 \text { and } g_{3}=0 \text { otherwise }\right]} \\
M_{n}=M_{0} e^{-\lambda \Delta t}\left[1-\left(c_{1}+c_{3}\right) t^{2}+\left(c_{2}+c_{4}\right) t\right]
\end{gathered}
$$

The values for the constants $\left(c_{j}\right)$ are limited by the requirement that the sum of the dissolution and suspension coefficients times the length of the time step is always less than or equal to one.

The dissolution of the contaminant may increase with time as the particles deposited on the ground surface weather or are broken down by biological processes. This effect would be more noticeable with an ephemeral source than a chronic source of contaminant where the change in the dissolution rate would be 
obscured by continual replenishment of the contaminant at the surface.

Sedimentation, weathering and anthropogenic processes may bury the original ground surface (at the time of deposition) and cause the suspension rate to decrease over time. CATS does not account for changes in the elevation of the ground surface or the position of the depositional surface, consequently the dissolution and suspension rates must be used to account for the changes in the amount of mass available to the individual systems (surface and subsurface). Exponential functions are another way to simulate the changes in the dissolution and suspension coefficients. Equation 25 shows the governing equation for the mass stored at the ground surface using different models for the dissolution and suspension coefficients. In this model, the suspension coefficient decreases (to a limit of 0 ) and the dissolution coefficient increases (to a limit of 1) over time. The constants in this model must be selected such that the sum of the dissolution and suspension coefficients times the length of the time step is less than or equal to one.

$$
\begin{gathered}
M=M_{0} e^{-\lambda t}\left[1-\left(e^{-\left(c_{3} t+c_{4}\right)}+c_{1} t^{\frac{-1}{c_{2} t}}\right) t\right] \\
0<c_{3}<c_{4} \\
0<c_{1}<1 \\
0<c_{2}
\end{gathered}
$$

The effect of the different methods of simulating the dissolution and 
suspension coefficients on the simulated amount of mass stored at the ground surface is shown in figures 3 and 4 . Figure 3 shows the amount mass stored at the surface, relative to the amount of mass deposited during the time step, for a constant source of contamination simulated with various (constant) dissolution and suspension rates and with first order decay. If all the mass deposited is removed from the system $\left(g_{2} \Delta t+g_{3} \Delta t=1\right)$ at each time step, then the relative amount of mass at the surface is less than or equal to one for all time periods.

Figure 4 shows the effect of first order decay and using constant and different formulations of time dependant dissolution and suspension coefficients on the amount of mass stored at the ground surface from an ephemeral source. The discontinuous linear and exponential models of dissolution and suspension produce similar results with only slight differences in the time rate of change of the amount of mass at the surface when the initial $(t=0)$ and the final rates are set equal. The initial suspension and dissolution rates control how quickly the mass is removed from the surface and where the mass is stored. The differences in the rate at which mass is removed from the surface can be evaluated using the time derivative of the governing equations, these differential functions are listed in the appendix.

The dissolution coefficient influences the amount of mass remaining at the surface and the solute concentration in infiltration and runoff. The sensitivity of the simulated amount of mass stored at the ground surface over time is demonstrated using an exponentially increasing, discontinuously increasing and constant dissolution 


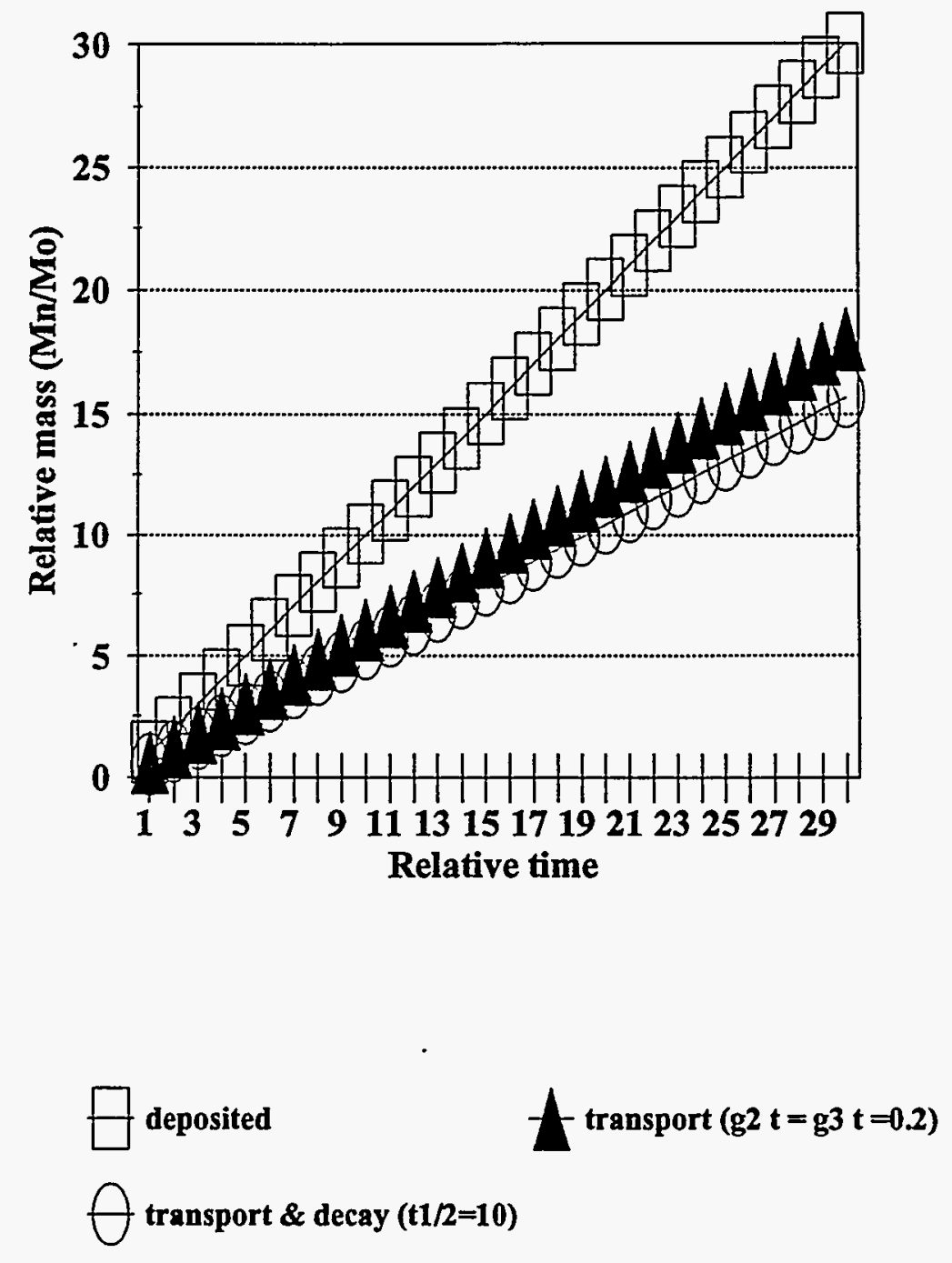

Figure 3 Amount of mass stored at the ground surface relative to the mass deposited from a constant chronic emission as a function of constant dissolution and decay over time (relative time is $t / \Delta t$ ) 


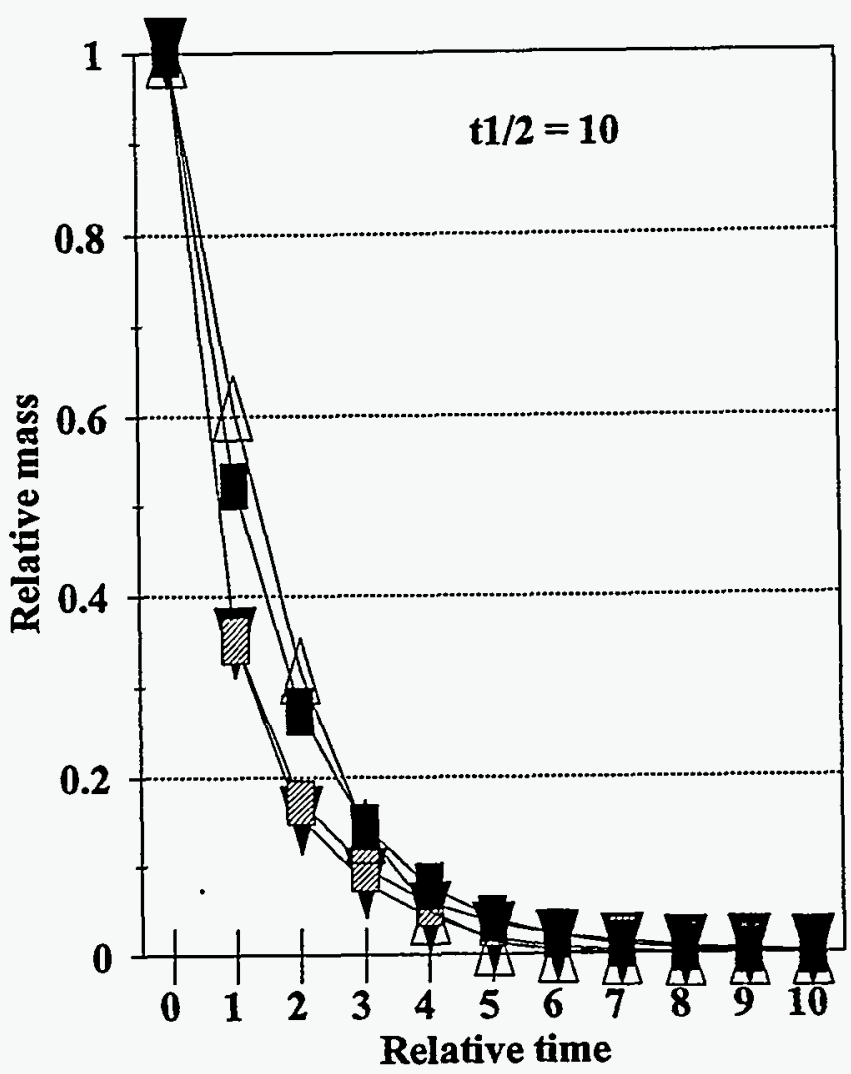

Fg2(t),g3(t) linear $g 2(t) \& g 3(t)$ exponential A $g 2(t)$ linear, $g 3(t)=0.2 \quad-g 2(t)=0.2, g 3(t)=0.2$

Figure 4 Amount of mass.stored at the ground surface relative to the mass deposited from an ephemeral emission as a function of dissolution of and suspension 
coefficients (Figure 5).

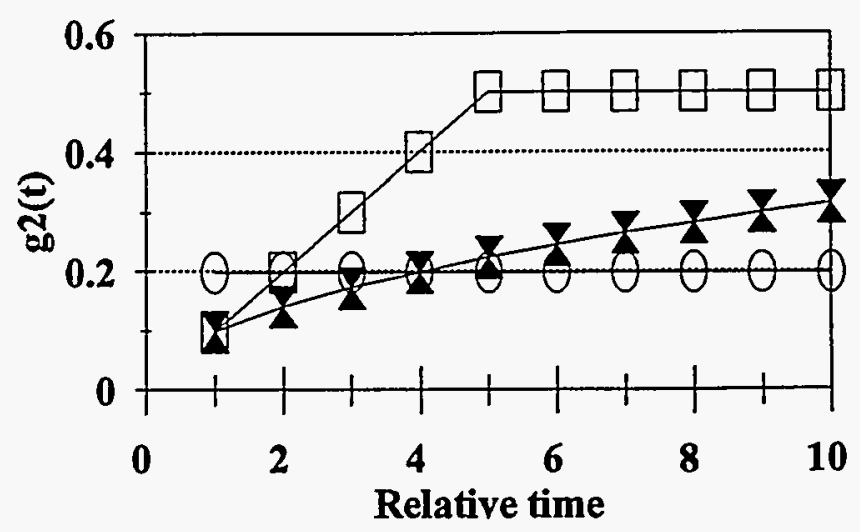

$\mathbf{Z}$ exponential $\square$ step function $\theta$ constant

Figure 5 Dissolution functions used in the sensitivity analysis of the simulated amount of mass stored at the ground surface

The simulated infiltration concentrations using the constant, discontinuous linear and exponential dissolution and suspension coefficient models are shown in figure 6. In the models with a constant dissolution rate, the amount of contaminant stored as a solute in the subsurface or runoff is directly proportional to the relative amount of water partitioned into each of those systems. Separate dissolution coefficients for runoff and infiltration can be used to change this proportion. Different models of dissolution produce changes in the timing and magnitude of the peak concentration and the duration of the contaminant pulse. Using a constant 


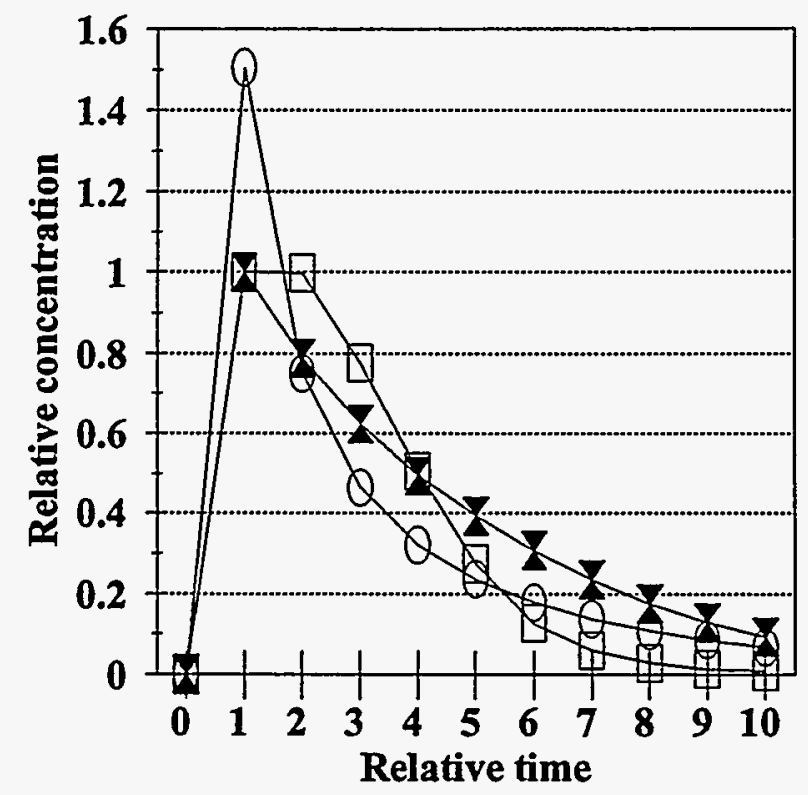

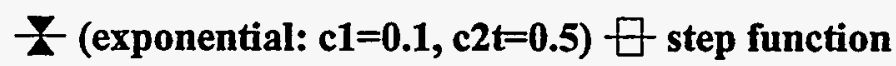
$\theta$ constant $(\mathrm{g} 2(\mathrm{t})=0.2)$

Figure 6 Infiltration concentration relative to the maximum concentration simulated using an exponential function, discontinuous linear and constant dissolution functions after an ephemeral emission 
dissolution coefficient to simulate the dissolution rate causes a narrower pulse, earlier peak and higher maximum concentration. A lower peak infiltration concentration can be produced if the dissolution rate is high enough to partition more of the mass stored at the surface into runoff during the early time steps. The mass stored at the surface is depleted faster with higher dissolution rates (Figure 7). If a constant leaching rate is used, the peak infiltration concentration occurs during the time step with the most mass at the surface. This is during the first time step for ephemeral sources. One way to revise the pattern of the infiltration concentration function is to make the leaching rate time dependent.

Figure 7 shows the effects of using linearly increasing and decreasing dissolution coefficients on the amount of mass stored at the ground surface and the infiltration concentration. The initial leaching rate could be set high to simulate the rapid dissolution of a more soluble component, then reduced to reflect the relative decrease in the amount of mass dissolved. In comparison to the simulations with constant dissolution coefficients, a linearly decreasing dissolution coefficient enhances the early peak in the infiltration concentration and causes an increase in the infiltration concentration. The increase in the infiltration concentration means that more mass will be transported to the subsurface. Another conceptual model of the dissolution and transport of mass at the ground surface is one where weathering and biological processes increase the solubility of the contaminant over time. Mass remains stored at the surface if the discontinuous linear functions used to describe 


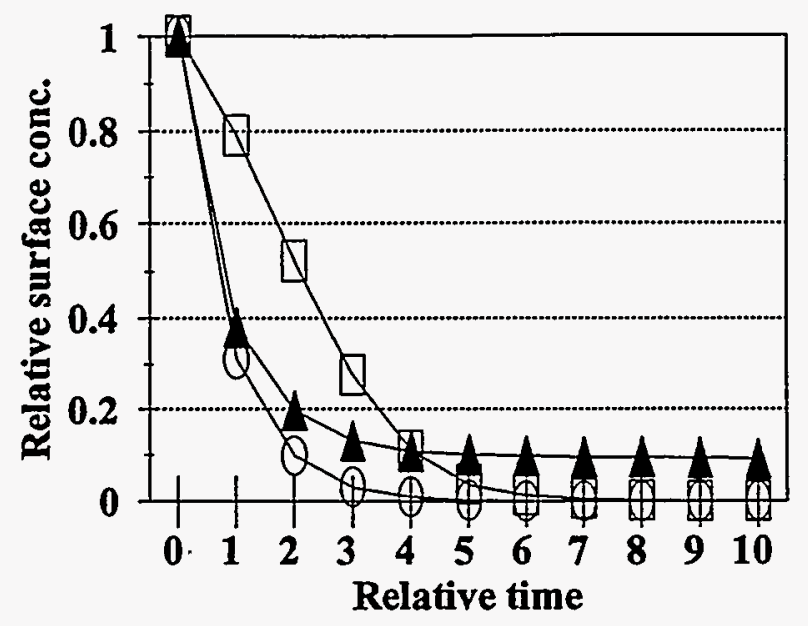

母 2 increasing (linear) $\theta$ g2 constant

t g2 (decreasing, linear)

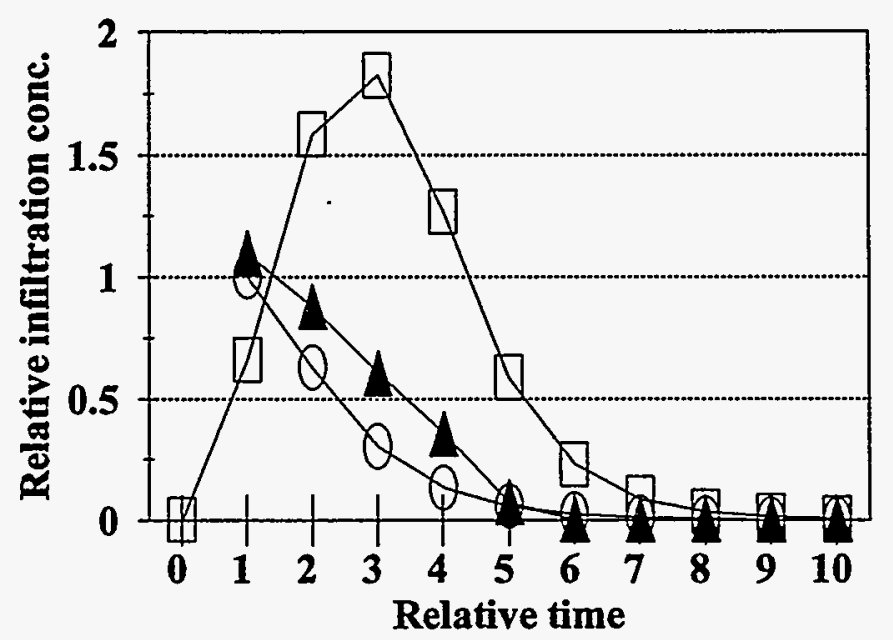

Figure 7 Sensitivity of the CATS model to the dissolution $\left(g_{2}\right)$ coefficient: mass stored at the surface and infiltration concentration over time 
the decreasing dissolution and suspension coefficients go to 0 before all the mass is transported off of the surface. In this case, the only removal pathways are first order decay and diffusion into the subsurface. The amount of mass available for transport by dissolution is decreased relative to the simulations with constant dissolution coefficients, but the amount of mass transported to the subsurface is increased because the amount of mass at the surface remains higher during the first four years (when $g_{2} \Delta t>0$ ).

When a linearly increasing dissolution coefficient is used to simulate a contaminant that becomes increasingly soluble over time, the maximum infiltration concentration is increased, the peak occurs later and the period with significant contamination concentrations is spread-out over a longer period of time. This simulation increases the amount of mass transported to the subsurface. Again, this is the simulation with the highest surface concentrations during the first four years of the simulation.

\subsection{Unsaturated Zone and Groundwater Link}

The link between the unsaturated and the groundwater transport models is more direct than the link between the atmospheric and unsaturated transport models because the transport mechanism is the same. In the subsurface, the contaminant is a solute transported in the liquid phase. The unsaturated flow and transport model provides the rate and concentration of the recharge to the saturated system. 
In steady-state simulations the lower boundary of the unsaturated flow and transport model is at a fixed depth. In transient simulations of unconfined groundwater systems, the water table elevation changes as does the unsaturated thickness and water content distribution. As a result, the recharge rate, contaminant concentration in the recharge and the storage term for transient simulations of the groundwater flow system vary and iterative solutions of the boundary conditions or relatively small time steps are required (Pikul et al., 1974). Water level fluctuations will change the distribution of the contaminant mass, causing vertical mixing of waters with different solute concentrations in the groundwater and unsaturated zones. The amount of mixing will influence the usefulness of specific emissions as tracers.

The CATS model uses iterations to determine the stable position of the water table and recharge rate for each time step of a transient simulation. Changes in the position of the water table are simulated by changing the elevation of the specified zero pressure node. To determine the stable position of the seasonal location of the boundary between the unsaturated and groundwater models the length of the unsaturated column is set to the maximum unsaturated thickness. The groundwater model results are used to estimate the average pressure head at the bottom node of the unsaturated zone model during each of the six periods in the annual cycle, then the unsaturated model is run to determine the revised recharge rate for the groundwater model. The groundwater model is run with the revised 
recharge rates and the length of the unsaturated column is updated.

The recharge concentration and rate are the concentration and water flux at the node representing the water table boundary. The position of the water table is considered stable if it stays within the bottom cell of the unsaturated zone model. The unsaturated model accounts for changes in the recharge rate due to temporal variations in the water stored in the unsaturated column. However, some error in the elevation of the water table estimated using the CATS model occurs because the groundwater flow code does not allow time variation of the specific yield. The example seasonal simulation for the ephemeral release is used to examine the significance of seasonal changes in the flow system and the effect different methods of simulating the flow conditions have on the predicted contaminant distribution. All modeling is an iterative process and the large number of parameters in the. CATS model make iteration essential. The CATS model provides a tool to evaluate which parameters are the most significant and what additional data will provide the most information about the system. 


\subsection{MODEL IMPLEMENTATION}

The CATS model is demonstrated by applying it to two test sites. The Sturgeon Falls simulation is used to illustrate how CATS is applied to a site with dry deposition from a chronic atmospheric source. The Sturgeon Falls simulation uses the chronic atmospheric emissions from the Sudbury nickel and copper smelters and the groundwater flow system described by Robertson and Cherry (1982) to examine the sensitivity of CATS to the atmospheric and groundwater parameters. The CATS model is used to determine, from a groundwater perspective, the appropriate time discretization for the source term.

The mapped, ground surface radionuclide distributions around the Chernobyl Nuclear Power Plant (CNPP) are used in a simulation of a hypothetical, basin scale, subsurface flow system to illustrate how the CATS atmospheric transport and deposition models work with an ephemeral source. The CATS model is used to simulate the CNPP site for two different time discretizations (seasonal and annual) to determine the effects of averaging the time dependent parameter values over different time scales on the modeled concentration distributions.

\subsection{Chronic Emission}

The Sturgeon Falls site investigated by Robertson, et al. (1989) is located 74 to 92 kilometers east to east-southeast of three nickel-copper smelters in the Sudbury Basin, Ontario, Canada (Figure 8). The geology of the site consists of 


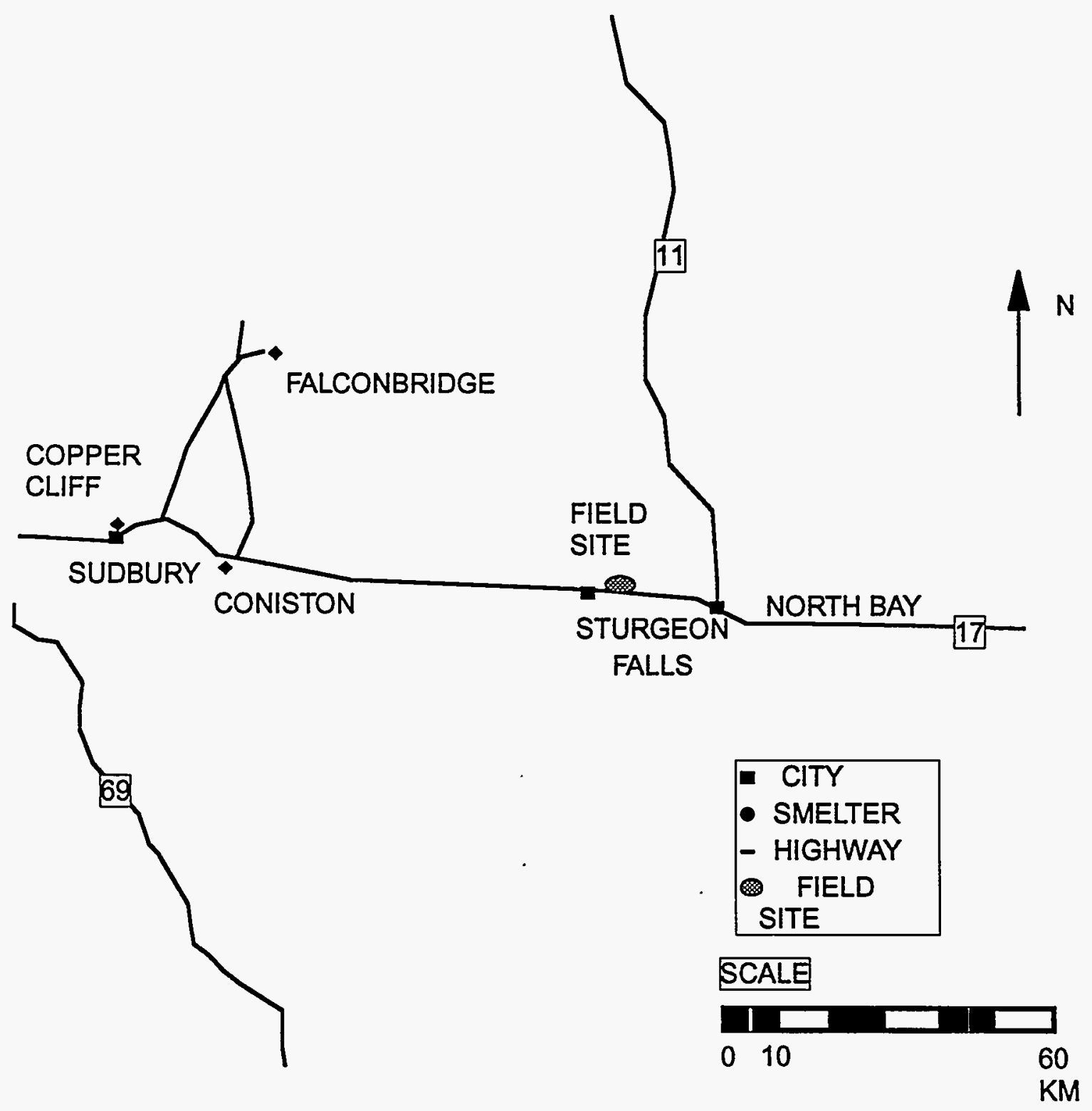

Figure 8 Sturgeon Falls site location map (after Energy, Mines and Resources Canada, 1983 a,b 
post-glacial deltaic deposits (silty sands to clays) deposited over glacial outwash (coarse to medium sands) (Robertson et al., 1989). The roasting and smelting operations in the basin have been a source of $\mathrm{SO}_{2}$ gas for more than 100 years. Mining of the Sudbury copper ore began in 1886 and open roasting of the ore was started in 1888 (INCO, 1946). The first smelter was built near the Copper Cliff mine and began production in 1892 . The smelter at Coniston was completed in 1913 and the Falconbridge smelter began production in 1930.

All the wind, emission, stack height history, ore production and groundwater concentration data for the Sturgeon Falls site are listed in the appendix. The data collected by Robertson et al. (1989) include field and lab derived aquifer hydraulic conductivities, water levels from water table wells, heads from a transect of multilevel wells and sulfate and tritium concentrations in the groundwater along the transect (appendix). The groundwater samples were collected between October 1986 and September 1987. Figure 9 shows the water table elevation for the site in August 1986 and the location of the transect of wells used for chemical sampling (as taken from Robertson and Cherry, 1989).

The $\mathrm{SO}_{4}{ }^{2-}$ distribution in groundwater at the Sudbury site is used to calibrate the CATS model of the site. The model results are compared to the conclusions of Robertson and Cherry (1989) and Robertson et al. (1989).

All the data for the site are from the groundwater system. This means the site specific atmospheric and unsaturated models are evaluated using the 


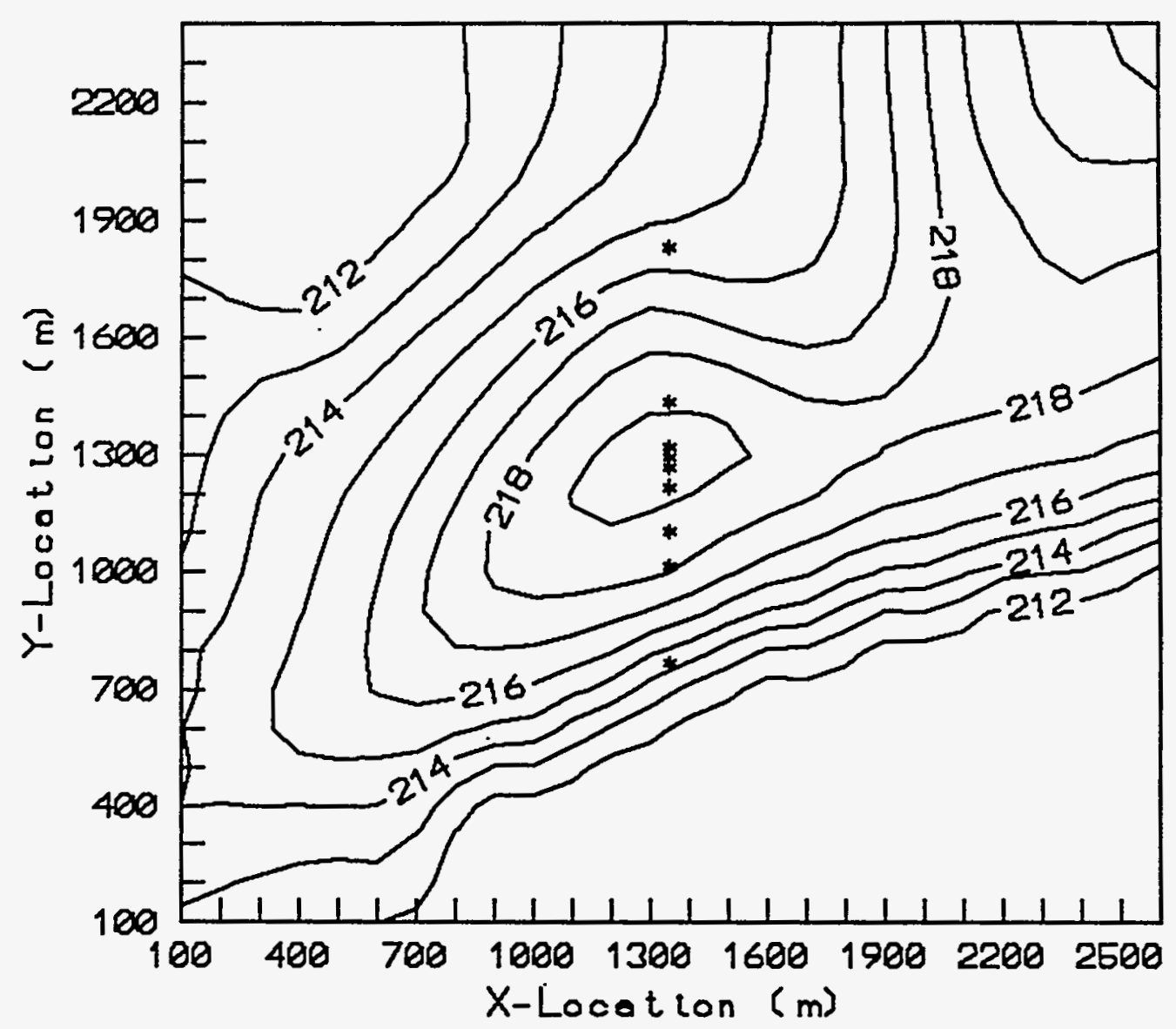

Figure 9 Sturgeon Falls site water table elevations (m above MSL) August, 1986, with monitoring well locations; river and escarpment are located along the $212 \mathrm{~m}$ contours, contour interval 1 meter (grid and water table elevations based on mapped values of Robertson and Cherry, 1989) 
groundwater data. The parameter values used in the model are restricted to the measured value or within a reasonable range of values as governed by published values for similar systems.

The modeling sequence for this site consists of simulating the subsurface flow system, estimating the contaminant mass deposited at the site, partitioning that mass into runoff, storage at the surface and infiltration, and simulating subsurface transport. The first step is to calibrate the three-dimensional groundwater flow model to the measured heads. The recharge rates determined by the calibrated flow model become the lower boundary condition for the unsaturated flow model. Then the subsurface transport simulations are run using the calibrated flow models. The model results are presented in the order they were completed: groundwater flow, atmospheric transport, unsaturated flow and transport, then groundwater transport. This illustrates one of the advantages of the CATS model. The linked models allow the modeler to use the available data to guide the modeling procedure.

Robertson, et al. (1989) show that the unsaturated zone thickness is a function of position in the flow system. Their data, along with the modeled position of the groundwater divide relative to the Sturgeon River and the escarpment are used to estimate the average unsaturated thickness for each model cell (Figure 10). Zones of minimum unsaturated thickness occur at the groundwater divide (0 to 0.25 $\mathrm{m})$, river $(0 \mathrm{~m})$ and beyond the escarpment $(0 \mathrm{~m})$. Zones of maximum unsaturated thickness occur north of the escarpment ( 3 to $6 \mathrm{~m}$ ) and between the groundwater 


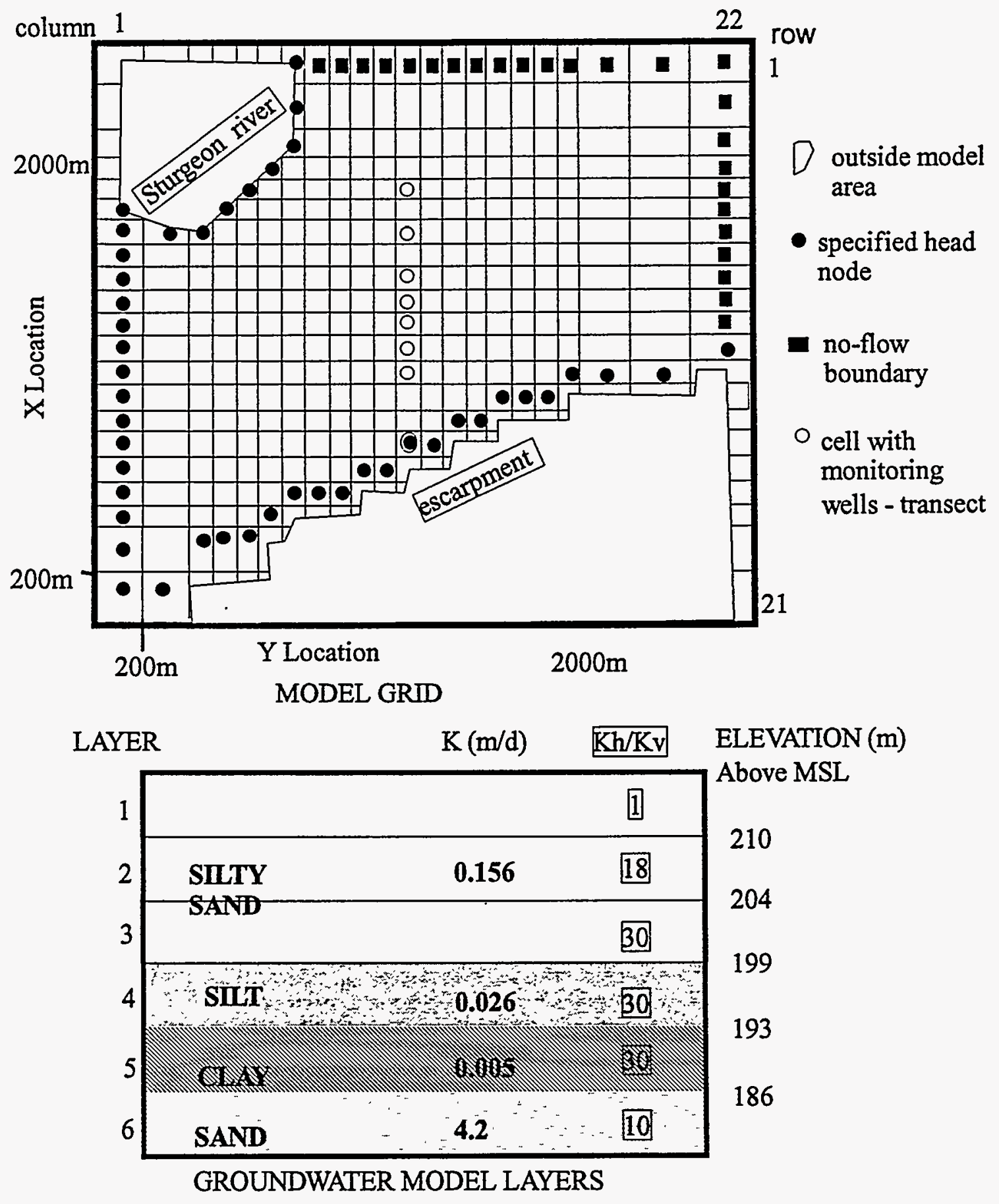

Figure 10 Sturgeon Falls site model grid and cross section 
divide and the river (1 to $3 \mathrm{~m}$ ). The unsaturated thickness is assumed to vary linearly between these zones.

The groundwater model for this site assumes steady state flow conditions and the recharge rate is determined by calibrating the groundwater flow model. Accordingly, the output required from unsaturated model is the recharge concentration over time. The atmospheric model and the model link to the unsaturated zone are used to estimate the amount of mass available to the subsurface system. Then contaminant transport through the unsaturated zone is modeled to simulate the recharge concentration history from 1892 through 1986. This provides the upper boundary condition for the groundwater transport model. Groundwater Flow Model

The groundwater system is simulated using six layers. The model discretization is shown in figure 10 and the parameter values used in the model simulations are listed in table 1 . The specified heads at the western and southern boundaries were estimated using Robertson and Cherry's (1989) water table map and the measured vertical gradients along their transect. Slight adjustments to the initial estimates of the specified head values were made during calibration to maintain outward fluxes at those boundaries. The no-flow boundaries are located along flow lines. These boundaries were positioned in areas where the groundwater flow is parallel or nearly parallel to the model boundary, based on the water table configuration (Figure 9) and the assumption that the groundwater potentials follow 
the same pattern with depth.

The model is calibrated to the August 1986 head values and water table elevations measured by Robertson et al. (1989). Calibration objectives include matching the water-table elevations along the transect (within $0.1 \mathrm{~m}$ ), water table configuration (Figure 9), and matching the direction and order of magnitude of the vertical gradients between layers. Head calibration values at each of the nodes in column 12, rows 6 through 15 and layers 1 through 6 are based on Robertson et al.'s (1989) interpretation of the measured head distribution (appendix). The head values are taken from the heads at the node position in the cross section presented by Robertson and Cherry (1989). These calibration values are based on the assumption that the head varies linearly between measurement points. The calibration values are used to compare different simulations and to assess the fit of the model to the field system. Base Case Simulation

The base case parameter values are listed in table 1 . These include the values of dispersivity (transport simulation), hydraulic conductivity and anisotropy in hydraulic conductivity used in the models by Robertson and Cherry (1989). The recharge distribution is estimated by calibrating the flow model to measured heads and the water table configuration (Figure 9). Calibration is by trial and error. The range of recharge rates is limited to the values estimated by Robertson and Cherry (1989) of 4 to $18 \mathrm{~cm}$ per year $\left(1\right.$ to $\left.5 \times 10^{-4} \mathrm{~m} / \mathrm{d}\right)$. The variations in the recharge 
rate are most likely due to variations in the runoff rate. The runoff rate is a function of differences in topography rather than heterogeneities in the unsaturated zone hydraulic conductivity or variations in the average evapotranspiration rate (Robertson and Cherry, 1989). Only small changes in the recharge rates are required to achieve calibration to water table elevations measured along the transect (Table 2). The water table closely resembles that of Robertson et al. (1989) (Figure 11). The largest calibration error (largest residual error) in the water table elevations occurs at the ends of the transect near the escarpment and toward the river. These errors exceed the $0.1 \mathrm{~m}$ calibration error limit, however they occur in areas with steep gradients in the water table elevation. The model reproduces this steep gradient reasonably well. The vertical gradients do not match the measured gradients as well as the water table targets. The model fit deteriorates with depth, especially between layers 3 and 5 where the calibration residual error is more than 10 meters between some nodes.

Several changes to the model produced little or no change in the vertical gradients (e.g., increasing the vertical gradients at the specified head boundaries, changes in the recharge rates). Changes in the vertical hydraulic conductivities were required to increase the vertical hydraulic gradients significantly. Decreasing the vertical conductance between layers 5 and 6 greatly improved the fit of the vertical hydraulic gradient with the minimum number of changes to the model [vertical conductance $=\left(0.5 \Delta z_{1} / K_{1}+0.5 \Delta z_{2} / K_{2}\right)^{-1}:$ base case $2.5 \times 10^{-4} 1 / d$, revised flow 

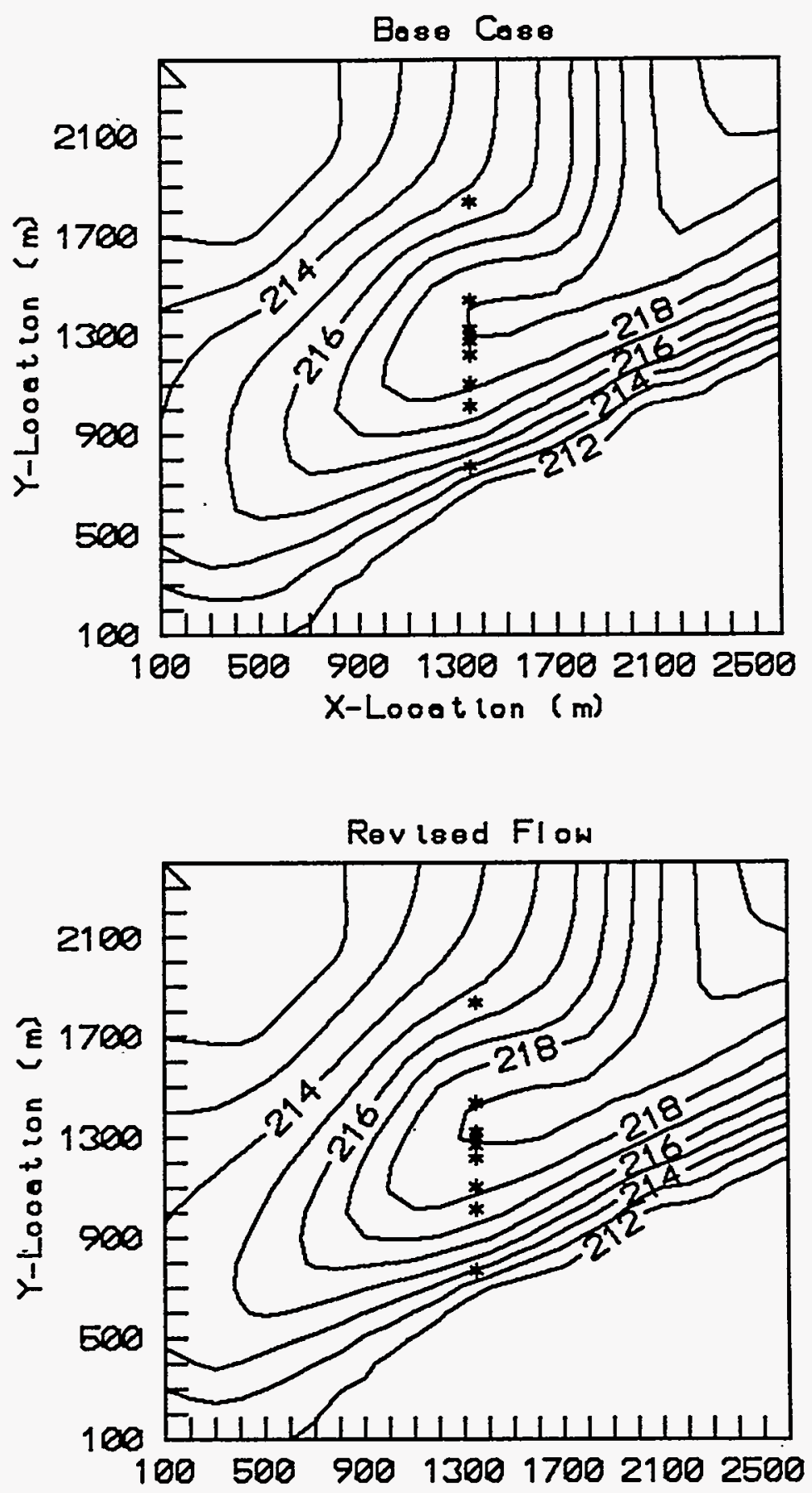

Figure 11 Sturgeon Falls site simulated water table elevations (m) above MSL: base case and revised flow 
$0.5 \times 10^{-4} 1 / \mathrm{d}$ ). The presence of clay lamellae toward the bottom of layer 5 provides a physical basis for increasing the anisotropy in the hydraulic conductivity.

Table 2 Flow Model Calibration: Residual Errors in Water Table Elevation

\begin{tabular}{lllc} 
Y-Location & Water Table Elev. & Residual Error (model-measured) \\
$(\mathrm{m})$ & $(\mathrm{m})$ & Revised & Base Case \\
750 & 215.2 & 0.8 & 0.7 \\
850 & 217.2 & 0.0 & -0.1 \\
950 & 218.3 & 0.0 & 0.0 \\
1050 & 219.1 & -0.1 & -0.1 \\
1150 & 219.1 & 0.0 & 0.0 \\
1250 & 219.0 & 0.0 & -0.1 \\
1350 & 218.3 & 0.0 & 0.0 \\
1450 & 218.0 & 0.0 & 0.0 \\
1550 & 217.1 & 0.0 & 0.0 \\
1650 & 215.8 & -0.1 & -0.1 \\
1750 & 213.0 & 0.5 & 0.4 \\
& & & \\
\hline
\end{tabular}

Revising the vertical hydraulic conductivity necessitated recalibrating the model to water-table elevations, and resulted in significant changes to the simulated recharge (Table 3). The calibration errors for the base case and revised flow model are compared in figure 12. The revised flow model matches the measured heads better than the base-case model in all the layers except layer 6 . The base case flow model results in a better head calibration for this layer because of the low heads in layers 4 and 5 . The revised flow system model matches the measured vertical gradients better than the base case flow system, especially between layers 3 and 5 (Figure 13). The calibration values for vertical gradient and the results of the 
Table 3 Sturgeon Falls Site Simulated Recharge Distributions $(0.00001 \mathrm{~m} / \mathrm{d})$

BASE CASE
\begin{tabular}{|c|c|c|c|c|c|c|c|c|c|c|c|c|c|c|c|c|c|c|c|c|c|c|}
\hline RIC & 1 & 2 & 3 & 4 & 5 & 6 & 7 & 8 & 9 & 10 & 11 & 12 & 13 & 14 & 15 & 16 & 17 & 18 & 19 & 20 & 21 & 22 \\
\hline 1 & 0 & 0 & 0 & 0 & 0 & 0 & 0 & 0 & 0 & 0 & 0 & 0 & 5 & 5 & 5 & 5 & 10 & 25 & 30 & 35 & 35 & 38 \\
\hline 2 & 0 & 0 & 0 & 0 & 0 & 0 & 0 & 0 & 0 & 0 & 0 & 0 & 5 & 5 & 5 & 5 & 10 & 25 & 30 & 35 & 35 & 38 \\
\hline 3 & 0 & 0 & 0 & 0 & 0 & 0 & 0 & 0 & 0 & 0 & 0 & 0 & 5 & 5 & 5 & 5 & 10 & 25 & 30 & 35 & 40 & 30 \\
\hline 4 & 0 & 0 & 0 & 0 & 0 & 0 & 0 & 0 & 0 & 0 & 0 & 0 & 0 & 0 & 0 & 0 & 10 & 25 & 30 & 35 & 40 & 25 \\
\hline 5 & 0 & 0 & 0 & 0 & 0 & 0 & 5 & 0 & 0 & 0 & 0 & 0 & 0 & 0 & 0 & 0 & 15 & 30 & 35 & 45 & 35 & 20 \\
\hline 6 & 0 & 0 & 0 & 0 & 0 & 5 & 5 & 0 & 0 & 0 & 0 & 0 & 0 & 0 & 0 & 0 & 15 & 35 & 35 & 45 & 35 & 20 \\
\hline 7 & 0 & 0 & 0 & 0 & 0 & 5 & 10 & 10 & 15 & 20 & 20 & 25 & 20 & 20 & 0 & 0 & 35 & 40 & 45 & 45 & 35 & 20 \\
\hline 8 & 0 & 0 & 0 & 0 & 5 & 10 & 10 & 15 & 15 & 35 & 40 & 45 & 40 & 40 & 40 & 40 & 45 & 45 & 48 & 40 & 35 & 20 \\
\hline 9 & 0 & 5 & 5 & 5 & 10 & 10 & 10 & 15 & 20 & 45 & 45 & 55 & 50 & 45 & 45 & 45 & 48 & 48 & 45 & 35 & 30 & 20 \\
\hline 10 & 0 & 10 & 10 & 10 & 10 & 15 & 20 & 20 & 30 & 45 & 50 & 45 & 45 & 50 & 48 & 48 & 45 & 45 & 35 & 30 & 20 & 10 \\
\hline 11 & 0 & 15 & 15 & 15 & 15 & 20 & 20 & 30 & 45 & 50 & 48 & 48 & 45 & 45 & 45 & 45 & 35 & 35 & 25 & 20 & 10 & 0 \\
\hline 12 & 0 & 15 & 15 & 15 & 20 & 20 & 25 & 40 & 48 & 45 & 35 & 20 & 35 & 35 & 35 & 35 & 20 & 20 & 10 & 10 & 0 & 0 \\
\hline 13 & 0 & 15 & 15 & 20 & 20 & 25 & 30 & 48 & 45 & 45 & 45 & 48 & 45 & 30 & 30 & 20 & 20 & 10 & 0 & 0 & 0 & 0 \\
\hline 14 & 0 & 15 & 15 & 20 & 25 & 30 & 45 & 40 & 40 & 40 & 40 & 45 & 40 & 20 & 20 & 10 & 10 & 0 & 0 & 0 & 0 & 0 \\
\hline 15 & 0 & 15 & 15 & 20 & 25 & 45 & 30 & 30 & 30 & 30 & 40 & 40 & 35 & 15 & 15 & 0 & 0 & 0 & 0 & 0 & 0 & 0 \\
\hline 16 & 0 & 15 & 15 & 15 & 40 & 30 & 25 & 20 & 20 & 15 & 10 & 0 & 0 & 0 & 0 & 0 & 0 & 0 & 0 & 0 & 0 & 0 \\
\hline 17 & 0 & 15 & 15 & 40 & 25 & 25 & 15 & 15 & 15 & 10 & 10 & 0 & 0 & 0 & 0 & 0 & 0 & 0 & 0 & 0 & 0 & 0 \\
\hline 18 & 0 & 15 & 35 & 15 & 15 & 20 & 10 & 10 & 10 & 0 & 0 & 0 & 0 & 0 & 0 & 0 & 0 & 0 & 0 & 0 & 0 & 0 \\
\hline 19 & 0 & 35 & 15 & 10 & 10 & 10 & 10 & 0 & 0 & 0 & 0 & 0 & 0 & 0 & 0 & 0 & 0 & 0 & 0 & 0 & 0 & 0 \\
\hline 20 & 0 & 10 & 10 & 10 & 10 & 0 & 0 & 0 & 0 & 0 & 0 & 0 & 0 & 0 & 0 & 0 & 0 & 0 & 0 & 0 & 0 & 0 \\
\hline 21 & 0 & 0 & 0 & 0 & 0 & 0 & 0 & 0 & 0 & 0 & 0 & 0 & 0 & 0 & 0 & 0 & 0 & 0 & 0 & 0 & 0 & 0 \\
\hline
\end{tabular}

REVISED FLOW

\begin{tabular}{|c|c|c|c|c|c|c|c|c|c|c|c|c|c|c|c|c|c|c|c|c|c|c|}
\hline R C & 1 & 2 & 3 & 4 & 5 & 6 & 7 & 8 & 9 & 10 & 11 & 12 & 13 & 14 & 15 & 16 & 17 & 18 & 19 & 20 & 21 & 22 \\
\hline 1 & 0 & 0 & 0 & 0 & 0 & 0 & 0 & 0 & 0 & 0 & 0 & 0 & 1 & 1 & 1 & 1 & 1 & 10 & 15 & 20 & 25 & 30 \\
\hline 2 & 0 & 0 & 0 & 0 & 0 & 0 & 0 & 0 & 0 & 0 & 0 & 0 & 1 & 1 & 1 & 1 & 1 & 10 & 15 & 20 & 25 & 30 \\
\hline 3 & 0 & 0 & 0 & 0 & 0 & 0 & 0 & 0 & 0 & 0 & 0 & 0 & 1 & 1 & 1 & 1 & 1 & 10 & 15 & 20 & 30 & 25 \\
\hline 4 & 0 & 0 & 0 & 0 & 0 & 0 & 0 & 0 & 0 & 0 & 0 & 0 & 0 & 0 & 0 & 0 & 1 & 10 & 15 & 20 & 30 & 15 \\
\hline 5 & 0 & 0 & 0 & 0 & 0 & 0 & 1 & 0 & 0 & 0 & 0 & 0 & 0 & 0 & 0 & 0 & 5 & 10 & 20 & 35 & 25 & 15 \\
\hline 6 & 0 & 0 & 0 & 0 & 0 & 1 & 1 & 0 & 0 & 0 & 0 & 0 & 0 & 0 & 0 & 0 & 5 & 10 & 20 & 35 & 25 & 15 \\
\hline 7 & 0 & 0 & 0 & 0 & 0 & 1 & 1 & 1 & 5 & 15 & 15 & 15 & 15 & 15 & 0 & 0 & 25 & 30 & 35 & 35 & 25 & 10 \\
\hline 8 & 0 & 0 & 0 & 0 & 1 & 1 & 1 & 5 & 5 & 25 & 30 & 35 & 30 & 30 & 30 & 30 & 35 & 35 & 38 & 30 & 25 & 10 \\
\hline 9 & 0 & 1 & 1 & 1 & 1 & 1 & 1 & 5 & 10 & 35 & 38 & 40 & 40 & 35 & 35 & 35 & 38 & 38 & 35 & 25 & 20 & 5 \\
\hline 10 & 0 & 1 & 1 & 1 & 1 & 5 & 10 & 10 & 20 & 35 & 40 & 30 & 32 & 40 & 38 & 38 & 35 & 35 & 25 & 20 & 10 & 1 \\
\hline 11 & 0 & 5 & 5 & 5 & 5 & 10 & 10 & 20 & 35 & 40 & 35 & 35 & 32 & 35 & 35 & 35 & 25 & 25 & 15 & 10 & 1 & 0 \\
\hline 12 & 0 & 5 & 5 & 5 & 10 & 10 & 15 & 30 & 38 & 35 & 20 & 5 & 20 & 30 & 25 & 25 & 10 & 10 & 1 & 1 & 0 & 0 \\
\hline 13 & 0 & 5 & 5 & 10 & 10 & 15 & 20 & 38 & 35 & 35 & 35 & 35 & 35 & 25 & 20 & 10 & 10 & 1 & 0 & 0 & 0 & 0 \\
\hline 14 & 0 & 5 & 5 & 10 & 15 & 20 & 35 & 30 & 30 & 30 & 30 & 30 & 30 & 25 & 10 & 1 & 1 & 0 & 0 & 0 & 0 & 0 \\
\hline 15 & 0 & 10 & 10 & 10 & 15 & 35 & 25 & 25 & 25 & 30 & 30 & 30 & 30 & 1 & 1 & 0 & 0 & 0 & 0 & 0 & 0 & 0 \\
\hline 16 & 0 & 10 & 15 & 15 & 30 & 20 & 15 & 10 & 10 & 10 & 1 & 0 & 0 & 0 & 0 & 0 & 0 & 0 & 0 & 0 & 0 & 0 \\
\hline 17 & 0 & 10 & 15 & 30 & 15 & 15 & 5 & 5 & 5 & 1 & 1 & 0 & 0 & 0 & 0 & 0 & 0 & 0 & 0 & 0 & 0 & 0 \\
\hline 18 & 0 & 10 & 25 & 10 & 10 & 5 & 5 & 1 & 1 & 0 & 0 & 0 & 0 & 0 & 0 & 0 & 0 & 0 & 0 & 0 & 0 & 0 \\
\hline 19 & 0 & 25 & 10 & 1 & 1 & 1 & 1 & 0 & 0 & 0 & 0 & 0 & 0 & 0 & 0 & 0 & 0 & 0 & 0 & 0 & 0 & 0 \\
\hline 20 & 0 & 10 & 1 & 1 & 1 & 0 & 0 & 0 & 0 & 0 & 0 & 0 & 0 & 0 & 0 & 0 & 0 & 0 & 0 & 0 & 0 & 0 \\
\hline 21 & 0 & 0 & 0 & 0 & 0 & 0 & 0 & 0 & 0 & 0 & 0 & 0 & 0 & 0 & 0 & 0 & 0 & 0 & 0 & 0 & 0 & 0 \\
\hline
\end{tabular}




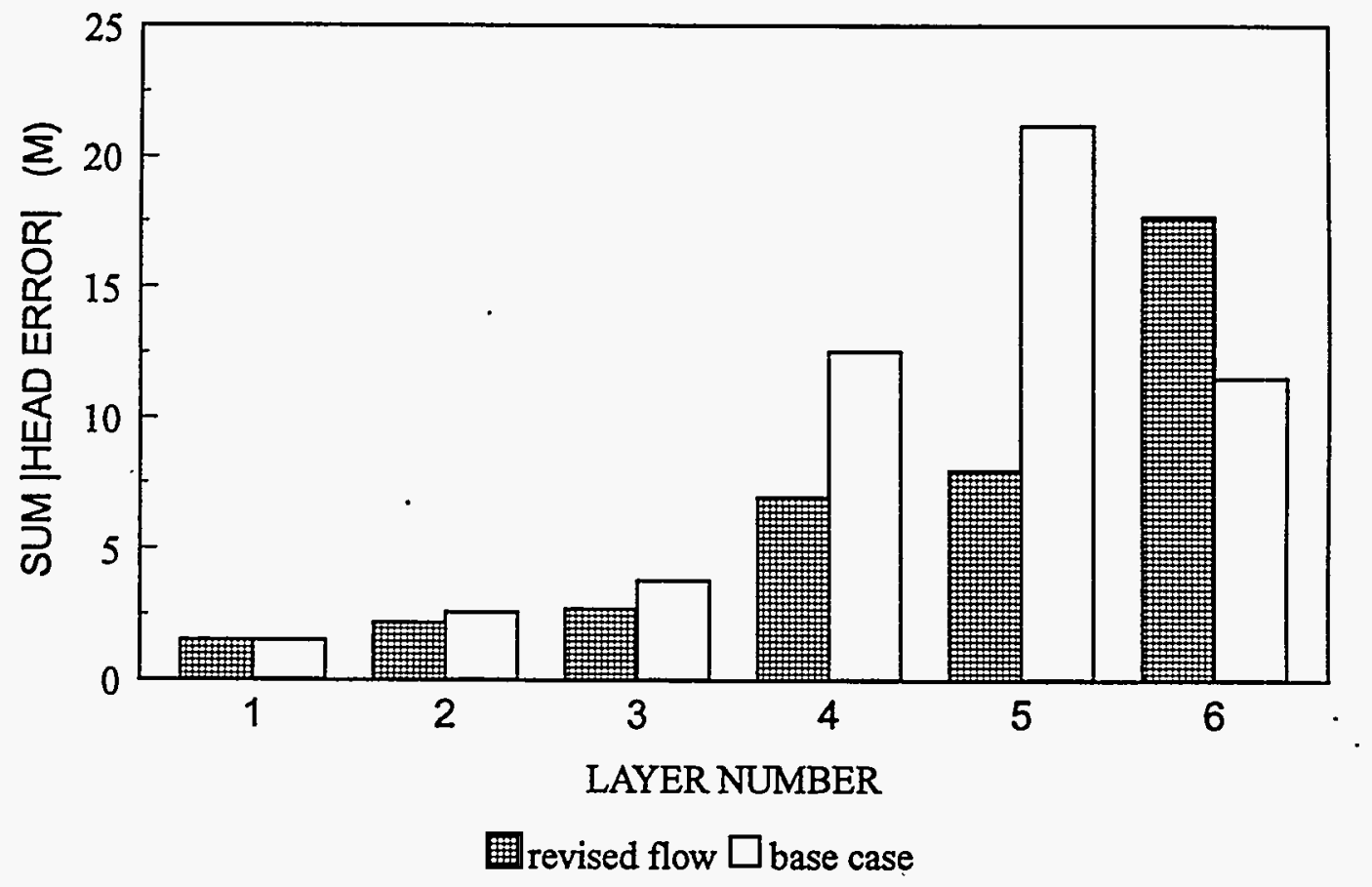

Figure 12 Sturgeon Falls site base case and revised flow model calibration errors in simulated head distribution, sum of the absolute residual error by layers 


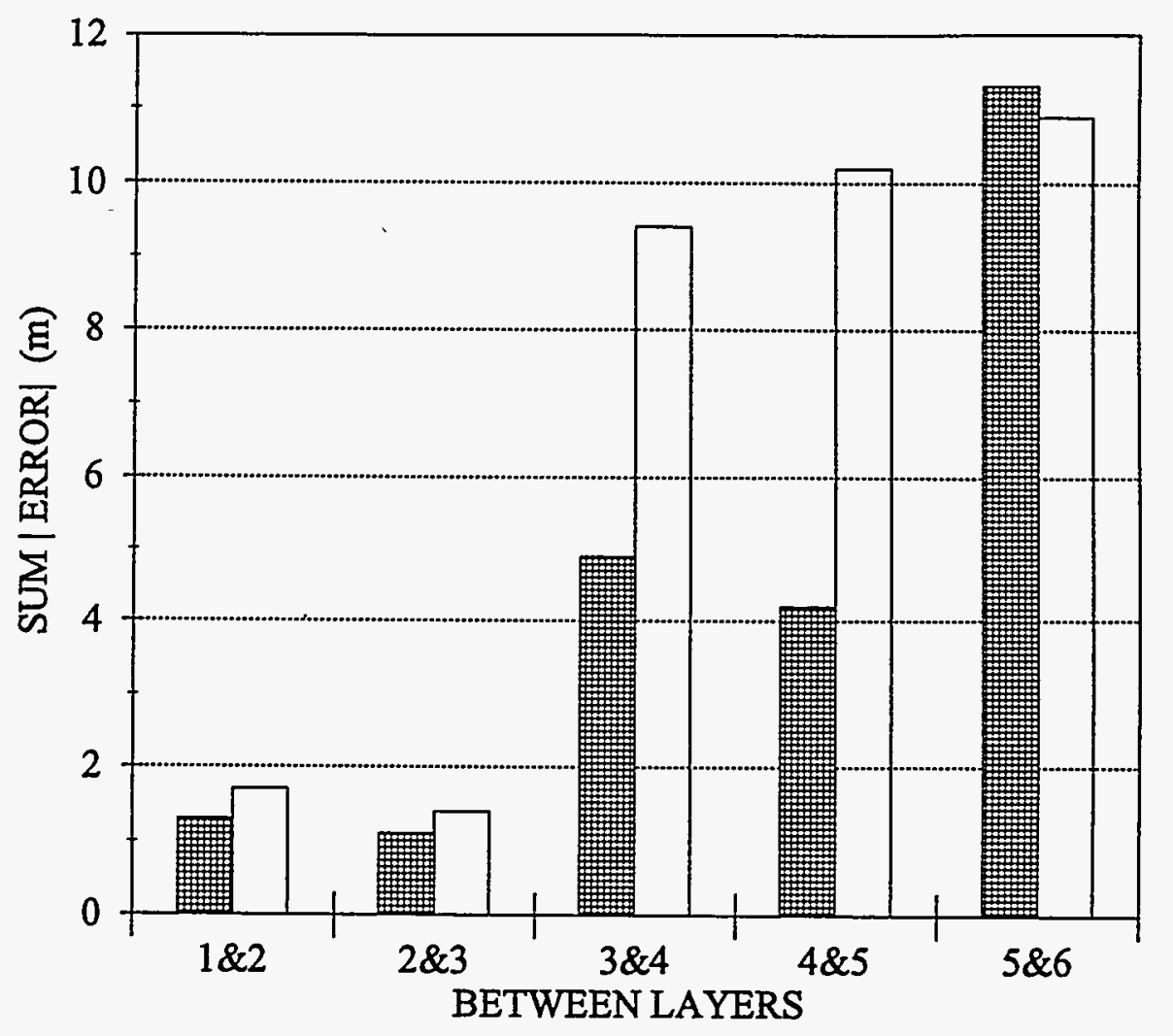

REVISED FLOW $\square$ BASE CASE

Figure 13 Sturgeon Falls site base case and revised flow model calibration errors in the vertical gradients along the transect (model column 12) 
revised flow model calibration are listed in the appendix. As with the base case, the largest residuals are in the zones with the steepest gradient and are less significant.

Both of the flow models are used to simulate transport and the results are compared as part of the sensitivity analysis of the CATS model to the parameters that describe the groundwater flow system. If the CATS model is producing realistic simulations, the revised flow system should yield a sulfate and tritium distribution that is closer to the measured distribution than the base case flow system. The input files for these models are on computer disk (back pocket).

Robertson, et al. (1989) assume the differences in recharge rates are due to slight differences in slope and that overall the top layer is homogeneous. The recharge rate required at one cell $(\mathrm{R} 12, \mathrm{C12})$ does not fit the general recharge pattern. The local topography (steeper slope) and the presence of a low conductivity zone at the ground surface are the possible controlling factors (Robertson and Cherry, 1989; Solomon et al., 1993). The CATS model for this site assumes that the surficial low conductivity and steep slope zones can be treated in the same manner. The model cell covering these zones is treated as an area of increased runoff. This assumes that the low conductivity zone at the surface is thin and limits the amount of infiltration but does not affect the hydraulic properties of the unsaturated column. 
Atmospheric Transport

The source term $\left(\mathrm{Q}_{0}\right)$ is the single most important parameter in the CATS model because it determines the timing of the emission and the magnitude of the atmospheric concentration. The atmospheric sources for the dry deposition model are assumed to be the three copper smelters in the Sudbury Basin. Other sources of sulfur are assumed negligible. A model of the atmospheric source term has been developed based on the methods of the U.S. EPA (Pope, 1990; U.S. EPA, 1977). In this model, $\mathrm{Q}_{0}$ is a function of the amount of ore roasted and smelted and the methods used to process the ore. Records of the total ore processed exist, but they are not consistent (Barrow, 1902; Royal Ontario Nickel Commission, 1917; INCO, 1946; Culliford, 1982). There are several long-term and consistent records of the amount of nickel produced in the Sudbury region (Ontario Ministry of Natural Resources, 1983; Kirk, 1990; Kuck, 1991). The nickel production records coupled with the average grade of the ore mined are used to estimate the total amount of ore processed annually (equation 26).

$$
\text { Ore }_{\mathrm{T}}=\frac{\mathrm{Ni} \text { Production }}{\text { Fraction Ni in Ore }}
$$

The parameter values for the atmospheric source term model are listed in the appendix. The results of the source term model show the importance of the nickel production history on the emission rate (Figure 14). This is most evident in the 


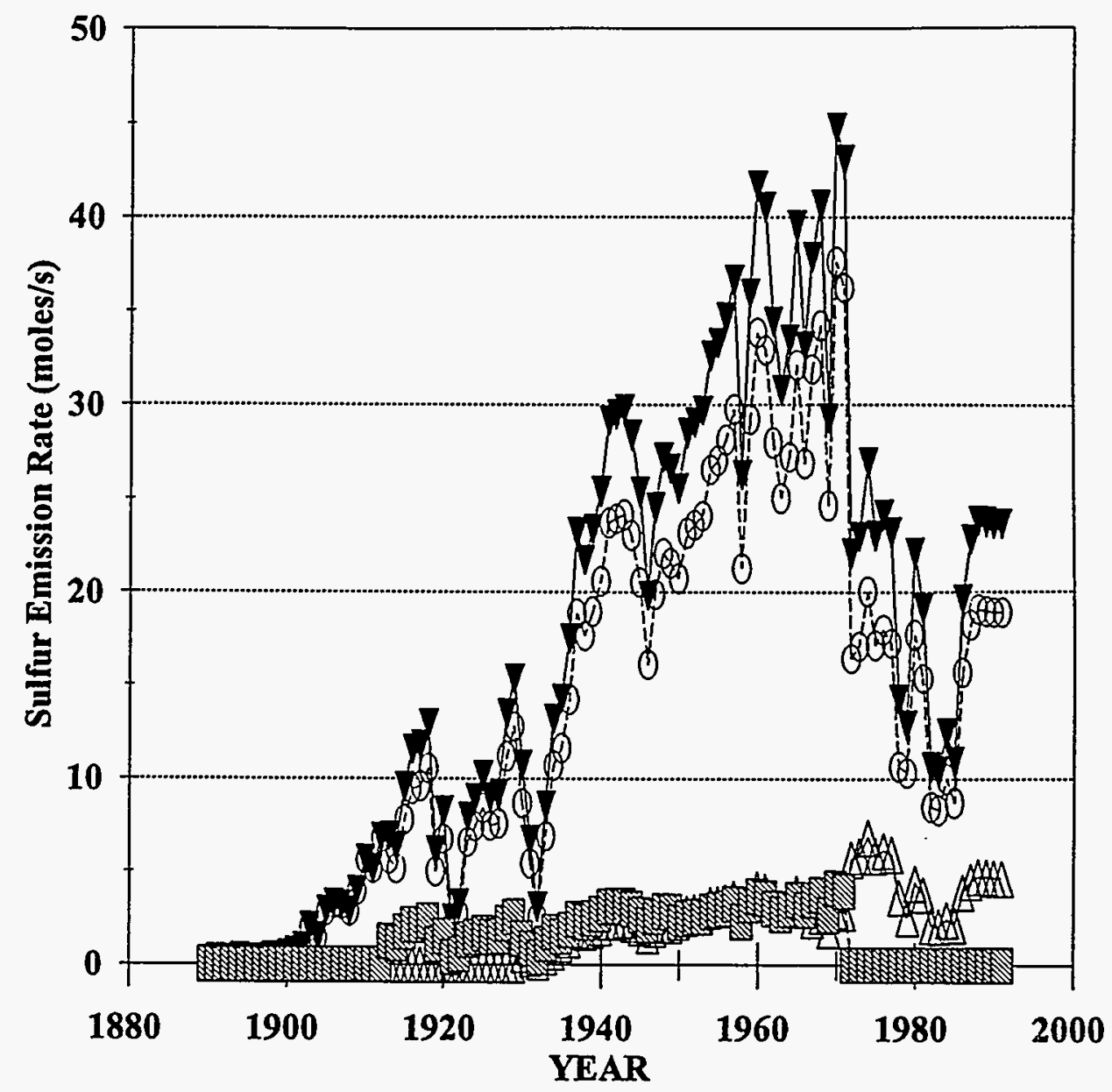

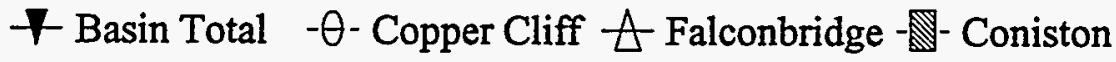

Figure 14 Sudbury Basin estimated average annual sulfur emission rates (moles/s): basin total and individual smelter contributions 
Falconbridge emission history. In this case, the emission rate increases in 1973, after sulfur removal is implemented, due to increased production. The Coniston smelter shows the most distinct change in emissions because it was closed in 1972 . This coincides with the implementation of sulfur removal at the Copper Cliff smelter and the increase in emissions at Falconbridge. Decreased production in 1978 through 1979 and 1982 through 1985 dropped the emission rates to pre 1940 levels. If the source terms are averaged over ten year periods, the annual variations are smoothed. Figure 15 is a bar graph showing the total average emission rates for ten year periods.

The CATS model can be used to determine whether or not the short-term changes in the estimated emission rate are preserved in the recharge concentration and the appropriate time periods for the subsurface simulations.

The significance of the uncertainty in the atmospheric transport parameter values on the predicted atmospheric concentration was evaluated using the ten year averaged emission rates presented in figure 15 . The parameter ranges used in the sensitivity analysis are summarized in table 1.

The distance (x) and the direction ( $\omega)$ of the site relative to the smelters are fixed. This assumes that the distances between the open roasting beds, previous smelters and the current smelter locations are negligible.

The average effective emission height ( $h$ ') for each smelter is assumed to be equal to the top of the stack. This assumes no net rise above the top of the stack 


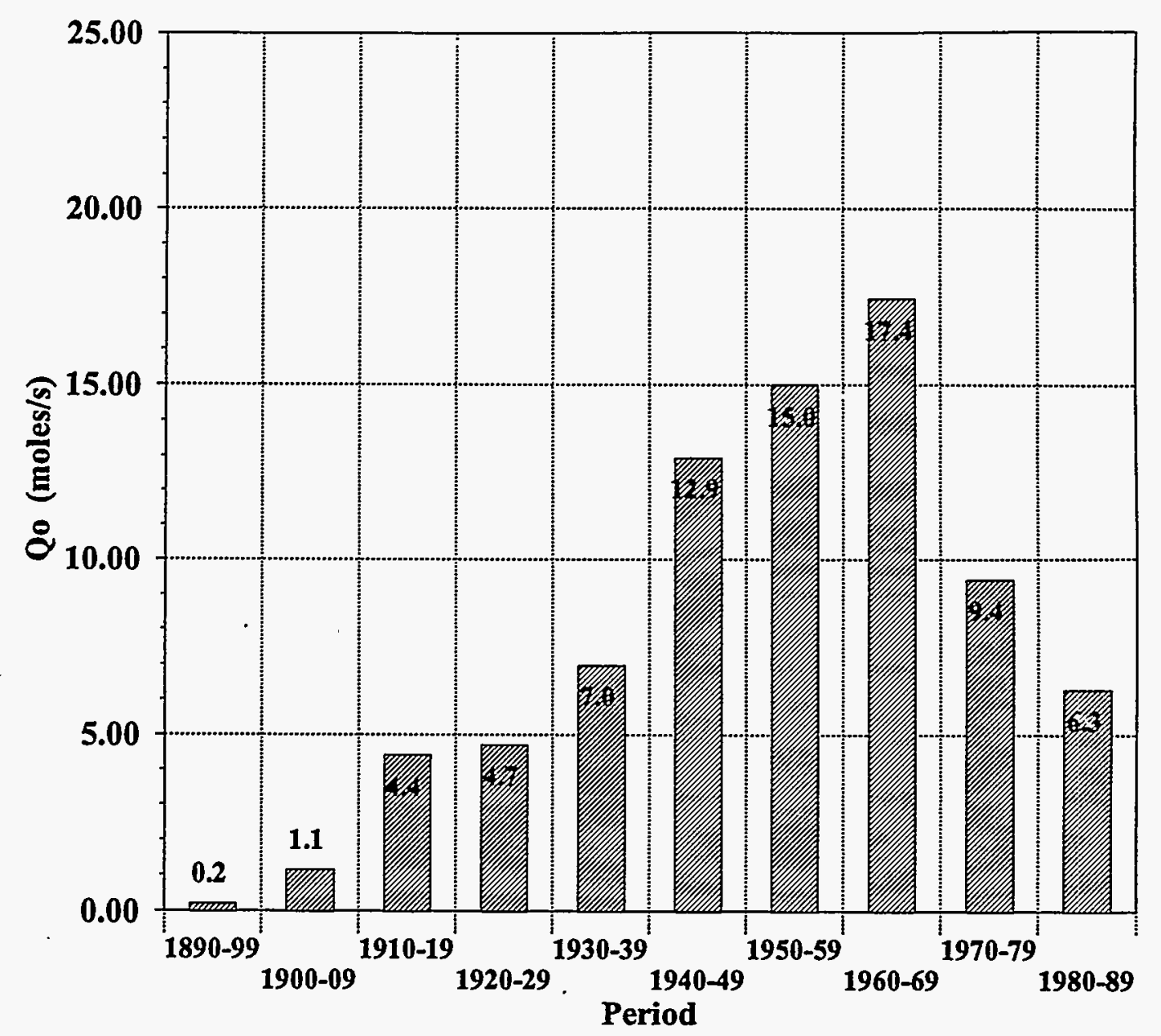

Figure 15 Simulated combined, ten year average sulfur emission rates (moles/s) for the Sudbury Basin 
due to buoyancy. The assumption of no net plume rise yields the highest simulated atmospheric concentrations. The effects of this assumption on the simulated concentration are examined in the sensitivity analysis where the effective stack heights are increased up to 50 meters above the top of the stacks. Changes in the stack heights over time result in changes in the emission height. The smelter stack height histories and other parameter values are listed in the appendix.

Average annual wind data from the long term records at the Sudbury and North Bay airports are used for the model wind speed $(u)$ and frequency function $(F(\omega))$ (Environment Canada, 1982). The Sudbury data give the average conditions for the source area and the North Bay data are for conditions near the field site. These two cases do not represent the potential extreme values of $u$ and $F(\omega)$, but they do show the uncertainty in the average conditions.

Since the field site is located so far from the source area $(70-90 \mathrm{~km})$, the average vertical dispersion coefficient $\left(\sigma_{z}\right)$ is approximated as 80 percent of the mixing layer depth. This vertical dispersion requires the assumption that the plume extends beyond the mixing layer. If the plume is restricted to the mixed layer, then the dispersion coefficient would be equal to 40 percent of the mixed layer depth and the ground level concentrations would be doubled. If the model is calibrated to mass concentrations at the surface, the deposition velocity would be lower than the velocity used in the simulation with greater vertical dispersion. The ranges of parameter values used in the sensitivity analysis are listed in table 1. 
Sensitivity Analysis Results

The ranges of values listed in table 1 were used with the ten-year average emission rates (Figure 15) to demonstrate the sensitivity of the atmospheric model to parameter uncertainty. The maximum and minimum simulated atmospheric concentration functions from the sensitivity analysis of parameter uncertainty are shown in figure 16. The maximum atmospheric concentrations are predicted using the North Bay wind data (minimum wind speed) and minimum release height. The North Bay data show a lower frequency of wind from the east-northeast (the Falconbridge direction) than the Sudbury data, reducing the sulfur contribution from the Falconbridge smelter. Data from the North Bay and Sudbury meteorological stations show approximately the same frequency for winds from the east (Copper Cliff and Coniston direction). The Sudbury wind speed data are higher on average than the North Bay data for winds from the east and east-northeast.

The maximum difference in the simulated atmospheric concentration at the field site, for this range of parameter values, changes the predicted concentration by a factor of three. The order of magnitude of the predicted concentration is not affected by the uncertainty in the average parameter values.

The North Bay wind data, average annual mixing depth and emission heights equal to stack height were used to generate the atmospheric concentration function for CATS model simulations of the Sturgeon Falls site. Slightly lower atmospheric concentrations would be calculated if the Sturgeon Falls wind data or greater 


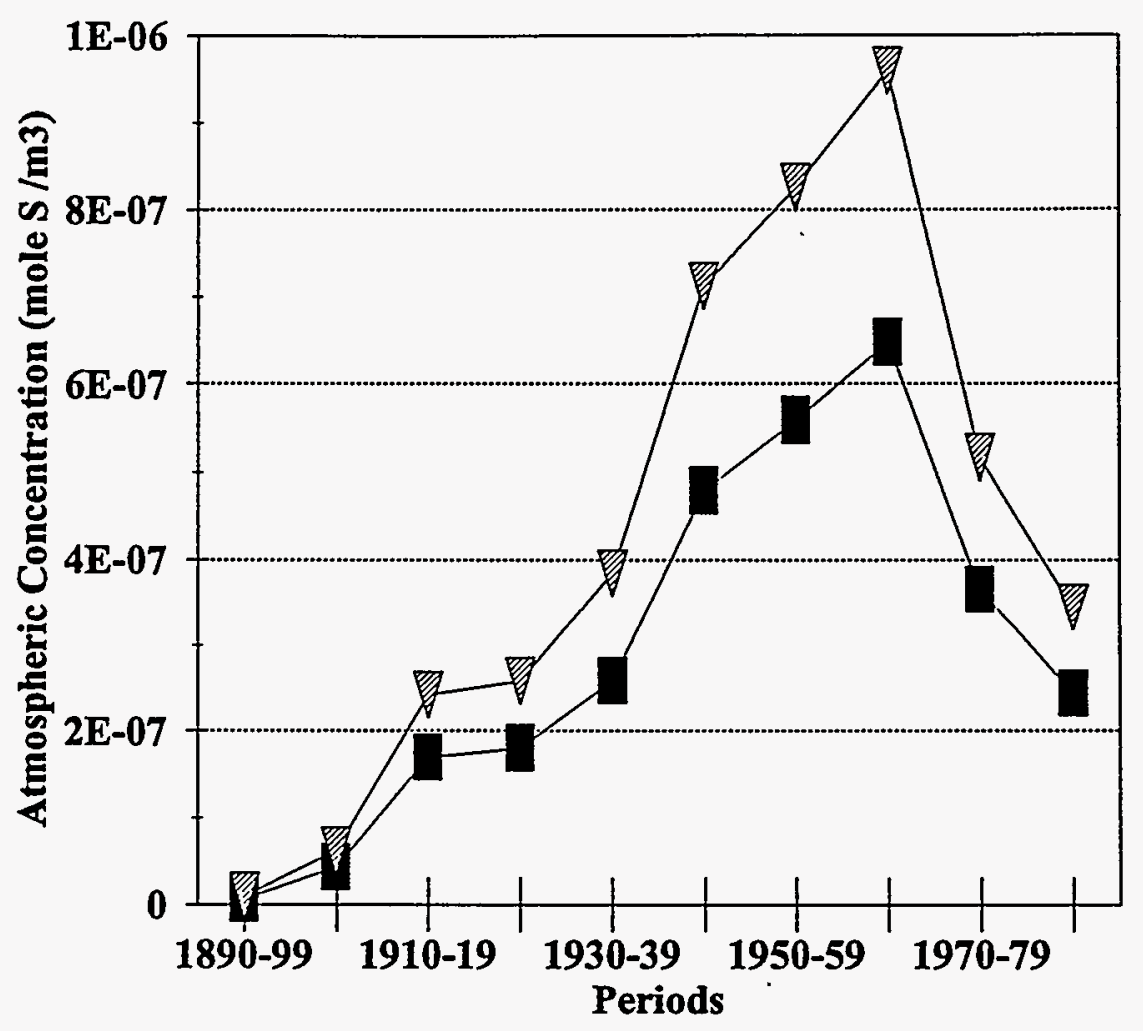

Sudbury $(\mathrm{u}, \mathrm{F})$; h' elevation North Bay $(\mathrm{u}, \mathrm{F})$; h' height

Figure 16 Sturgeon Falls site atmospheric model sensitivity analysis: extreme atmospheric concentration functions using wind parameters $(u, F)$ and effective source release height $\left(h^{\prime}\right)$ 
emission heights were used. The total atmospheric concentration above the site is equal to the sum of the concentrations for the individual smelters. The atmospheric model and output are on disk (back pocket).

Atmospheric-Unsaturated Link

Published dry deposition velocities for $\mathrm{SO}_{2}$ were used to estimate the reasonable range of average dry-deposition mass flux of sulfur to the surface (appendix). From the equation for this link (equation 3) it can be seen that the deposition velocity controls the magnitude of the estimated mass deposited, and that order of magnitude changes in the deposition velocity will result in order of magnitude changes in the predicted deposition mass. The long-term average deposition rates for $\mathrm{SO}_{2}$ over a variety of sites and ground cover are generally within the same order of magnitude $(0.001$ to $0.009 \mathrm{~m} / \mathrm{s})$. Since the Sturgeon Falls site is covered with the same plant type (trees) over most of its surface area, a single deposition rate for the entire site is appropriate. The model produces a uniform deposition of mass over the site for each annual period. The reasonable range of $\mathrm{SO}_{2}$ deposition velocities $(0.001$ to $0.009 \mathrm{~m} / \mathrm{s})$ results in an estimated deposited concentration $\left(\mathrm{M}_{0}\left[\mathrm{M} / \mathrm{L}^{2}\right]\right)$ of one to nine times the atmospheric concentration $\left(\mathrm{C}_{0}\right.$ $\left.\left[\mathrm{M} / \mathrm{L}^{3}\right]\right)$ every one thousand seconds (16.7 minutes).

When an average value of the deposition velocity $(0.006 \mathrm{~m} / \mathrm{s})$ is used to simulate the link between the atmospheric and unsaturated zone models for the Sturgeon Falls site, the maximum calculated infiltration concentration is higher than 
the maximum measured concentration in groundwater. Consequently, a lower deposition velocity of 0.004 meters per second is used in the base case simulation. The lower deposition velocity is still within the range of reasonable values for this site.

The mass of sulfur deposited on the surface is converted from moles of sulfur to grams of sulfate to allow comparison of the measured and modeled concentrations (Figure 17). A stacked bar graph is used to show the contribution of the total sulfur deposited from each smelter for the base case simulation. The total simulated amount of sulfur emitted from 1890 to 1986 by smelters in the Sudbury Basin is equivalent to 158 teragrams of sulfate $\left(10^{12} \mathrm{~g}\right)$. In the base case simulation $\left(v_{d}=0.004 \mathrm{~m} / \mathrm{s}\right)$ the cumulative amount of mass deposited on the model area is 2.1 gigagrams $\left(10^{9} \mathrm{~g}\right)$ of sulfate, approximately 0.0013 percent of the total emission. The deposition velocity does not exceed the vertical rate of mass spreading due to dispersion $(0.8 \mathrm{~m} / \mathrm{s})$ and thus does not remove mass faster than it is being replaced by dispersion.

It is assumed that distant atmospheric sources of sulfur influence only the wet-deposition mass flux. This assumption is based on the conceptual model that wet deposition is an episodic process that removes mass from the entire thickness of the atmosphere penetrated by precipitation while dry deposition is a continuous process and the amount of mass deposited is a function of the ground-level atmospheric concentration. Pollutants transported over long distances are more 


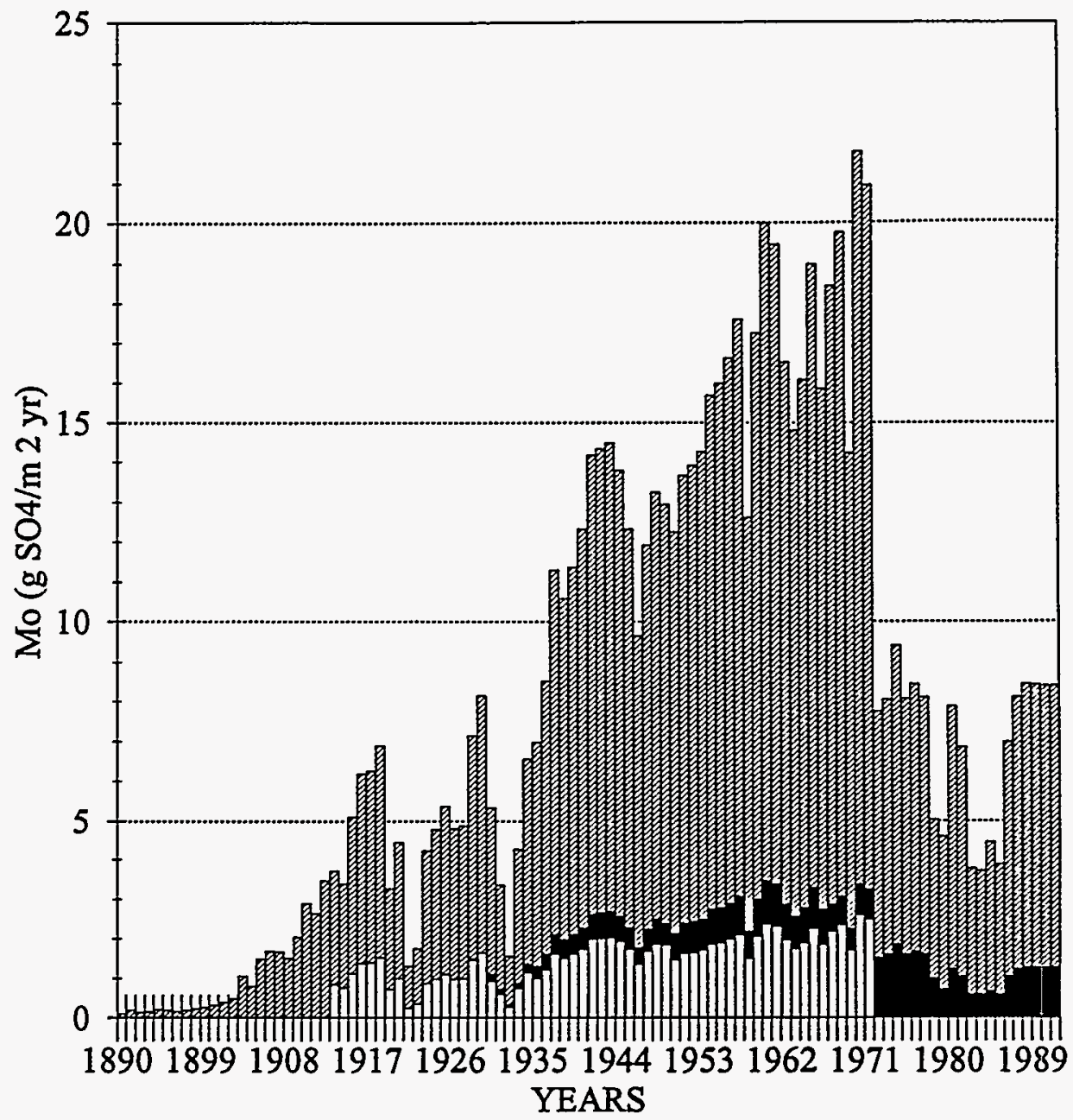

$\square$ CONISTON $\square$ FALCONBRIDGE

Figure 17 Sturgeon Falls site simulated average annual dry deposition of sulfate using base case parameter values (North Bay wind data, $h^{\prime}=$ stack height, $\mathrm{v}_{\mathrm{d}}=$ $0.004 \mathrm{~m} / \mathrm{s})$ 
dispersed and have much lower concentrations than pollutants from a more local source. The lower concentrations do not necessarily mean less mass and the total amount of mass in the atmosphere above a specific site may be controlled by distant sources. Since wet deposition removes pollutants from the entire thickness of the atmosphere penetrated by the precipitation, while the dry-deposition flux is a function of the ground-level pollutant concentration the two processes may result in very different source term functions for the subsurface model.

In this simulation, since the average annual wet deposition concentration is unknown for most of the 96 year simulation period, only dry deposition is modeled. The average measured concentrations in precipitation could increase the infiltration concentration by 2.7 to $5.8 \mathrm{mg}$ of sulfate per liter of water in the post 1980 simulations, depending on how much evaporative enrichment of the precipitation concentration occurs (Robertson et al., 1989; Ministry of the Environment, 1986).

The concentration of the water infiltrating the unsaturated zone is estimated using three different solvent functions $\left(g_{1}\right)$. The results are compared in figure 18 . In all three methods, all the mass deposited during the annual time step is assumed to be dissolved and transported, none of the mass is stored at the surface beyond the end of the time step $\left(\mathrm{g}_{2} \Delta t=1\right)$. In one of the functions, the mass is dissolved in the total volume of precipitation added to the system during the time step $(0.94 \mathrm{~m} / \mathrm{yr})$. This simulation assumes that the evapotranspiration at the ground surface is negligible and that there is no evaporative enrichment of the infiltration 


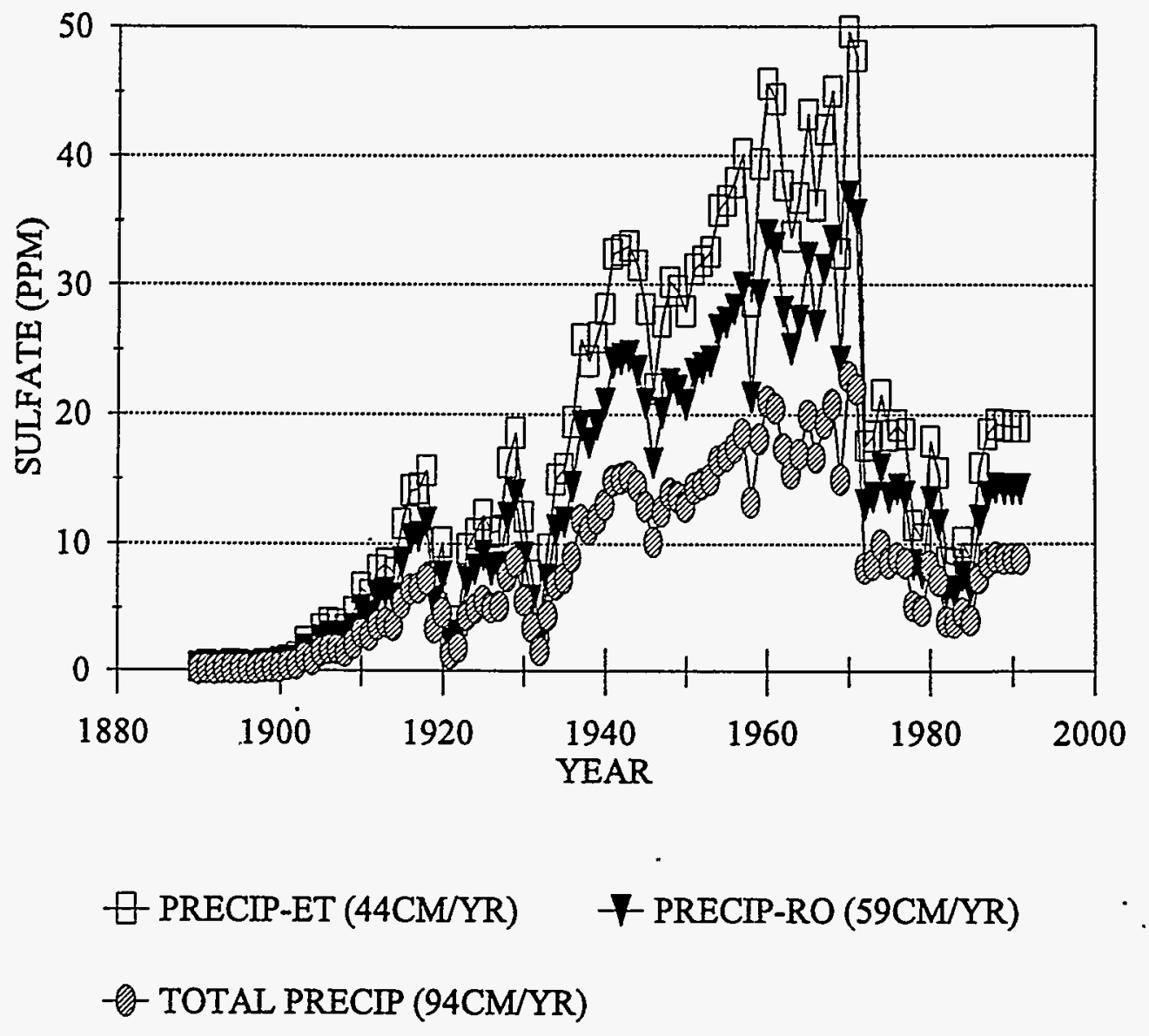

Figure 18 Sturgeon Falls site simulated infiltration concentration as a function of the amount of solvent (solvent equals all precipitation, precipitation less runoff and precipitation less evapotranspiration) 
concentration at the ground surface. This method could be used if all evapotranspiration is simulated using the subsurface flow models. In the second function the mass is dissolved in the volume of water involved in infiltration and runoff, precipitation less evapotranspiration $(0.44 \mathrm{~m} / \mathrm{yr})$. This simulation allows for evaporative enrichment at the ground surface. It assumes that all evapotranspiration occurs at the soil surface. The solvent function controls the concentration of the infiltration and runoff solutions, but the amount of mass in those systems is controlled by the amount of water moving into that system. In both the first and second functions, the percent of the total mass deposited that is transported as a solute by runoff is equal to the percent of the precipitation removed as runoff. In the third function the mass is dissolved in the volume of water involved in infiltration and evapotranspiration, precipitation less runoff $\left(\mathrm{g}_{1}=0.59 \mathrm{~m} / \mathrm{yr}\right)$. The third function is useful only if the mass transported as a solute in runoff is negligible and evapotranspiration is negligible or modeled using the unsaturated or groundwater flow model.

The infiltration partitioning function controls the magnitude of the infiltration concentration. Since the second solvent function $\left(g_{1}=0.44 \mathrm{~m} / \mathrm{yr}\right)$ accounts for evapotranspiration it should produce infiltration concentrations that are the closest to the measured groundwater concentrations. This provides a method to check the results of the atmospheric model and the first model link. When a deposition velocity of 0.006 meters per second is used the peak concentrations are significantly 


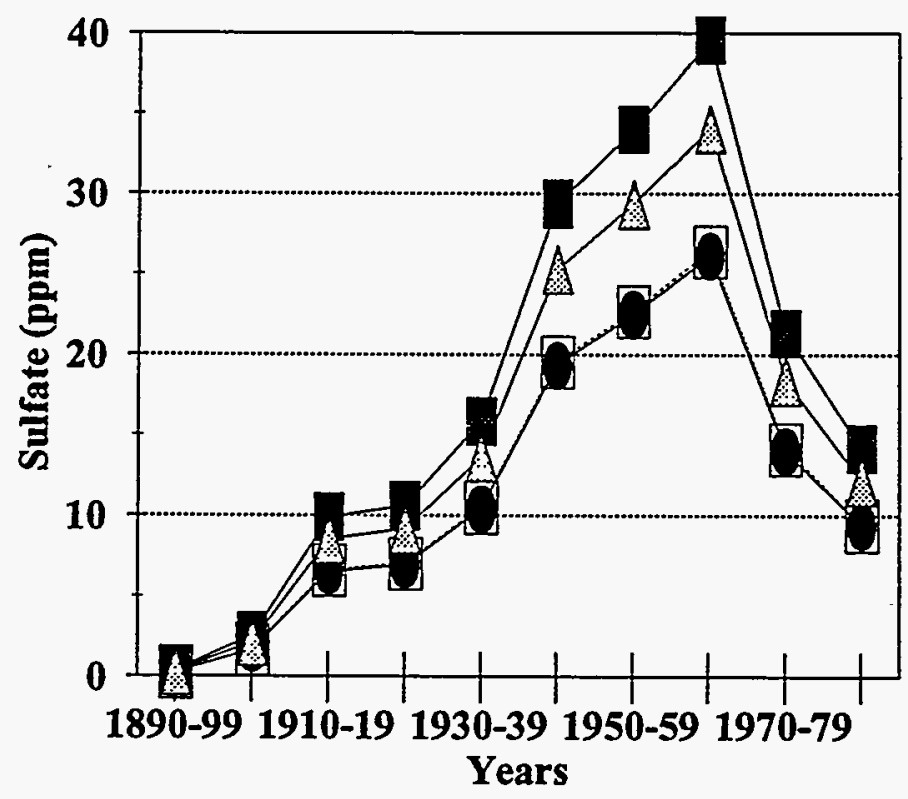

$V d=0.006 \mathrm{~m} / \mathrm{s}, \mathrm{g2t}=0.66, \mathrm{~g} 3 \mathrm{t}=0.34 \square \mathrm{Vd}=0.004 \mathrm{~m} / \mathrm{s}, \mathrm{g} 2 \mathrm{t}=1$

$\mathrm{Vd}=0.006 \mathrm{~m} / \mathrm{s}, \mathrm{g} 2 \mathrm{t}=1$

$-\mathrm{Vd}=0.006 \mathrm{~m} / \mathrm{s}, \mathrm{g2t}=0.66$

Figure 19 Simulated infiltration concentration sensitivity to the atmosphericunsaturated zone model link (dissolution coefficient, suspension coefficient and deposition velocity) 
the simplest change is made. The deposition velocity is reduced to 0.004 meters per second and the infiltration concentration is simulated using an amount of solvent equal to 0.44 centimeters per year.

Unsaturated Transport

The unsaturated zone parameter values are, for the most part, unknown. The data from Robertson et al. (1989) provide certain limits to the range of values for the unsaturated zone parameters. The unsaturated zone is composed of the same silty fine sand as the upper aquifer. The unsaturated zone is assumed to have a saturated hydraulic conductivity on the order of $10^{-4}$ centimeters per second (approximately $10 \mathrm{~cm} / \mathrm{d}$ ) and a saturated water content of 0.33 to 0.35 . Of the average values for various soil textural groups, as determined by Rawls and Brakensiek (1982), sandy clay loam fits the sediment type (silty fine sand with clay) and saturated parameter values $\left(\mathrm{K}_{\mathrm{s}}\right.$ and $\left.\boldsymbol{\theta}_{\mathrm{s}}\right)$ for the unsaturated zone at this site (Table 1). The unsaturated parameter values $\left(\theta_{\mathrm{r}}, \alpha\right.$ and $\left.\beta\right)$ for sandy clay loam were used in the initial unsaturated transport simulation. Other textural groups fit the sediment type and magnitude of the saturated hydraulic conductivity, but they have higher average saturated water contents. The parameter values for these groups (silt loam, loam and sandy loam) and other average parameter values for sandy clay loam (Carsel and Parish, 1988) provided the range of parameter values used in the sensitivity analysis of the unsaturated zone model.

HYDRUS and MT3D calculate the coefficient of hydrodynamic dispersion 
(D) using the longitudinal dispersivity $\left(\alpha_{L}\right)$ and an effective molecular diffusion coefficient $\left(D_{d}\right)$. The same dispersivity and effective molecular diffusion coefficient are used in the unsaturated and groundwater simulations.

In this model the only variations within the unsaturated zone are the thickness, flow rate and initial water content distribution. The unsaturated zone model is run for every combination of unsaturated thickness and recharge rate used in the model. The recharge rates determined from the calibration of the groundwater flow model are used to determine the flux boundary conditions at the bottom of the soil columns and the calibrated water table elevations are used to estimate the lengths of the soil columns. The upper boundary condition is specified flow, equal to the lower boundary flow condition. The initial conditions are specified using the water content distribution determined by setting the lower boundary to a zero pressure head condition in separate runs of the unsaturated model. This is the water content profile necessary to sustain the specified flow rate and maintain saturated conditions at the bottom of the column. The resulting, steady-state water content profile determines the pressure head distribution, effective hydraulic conductivity of the soil column and the advective transport rate.

The water content profiles and recharge concentration results for several model runs are shown in figures 20 and 21 . For columns of equal length and different flow rates the water content increases with increasing flow. Columns with the same flow rate maintain higher water contents in the shorter columns. 


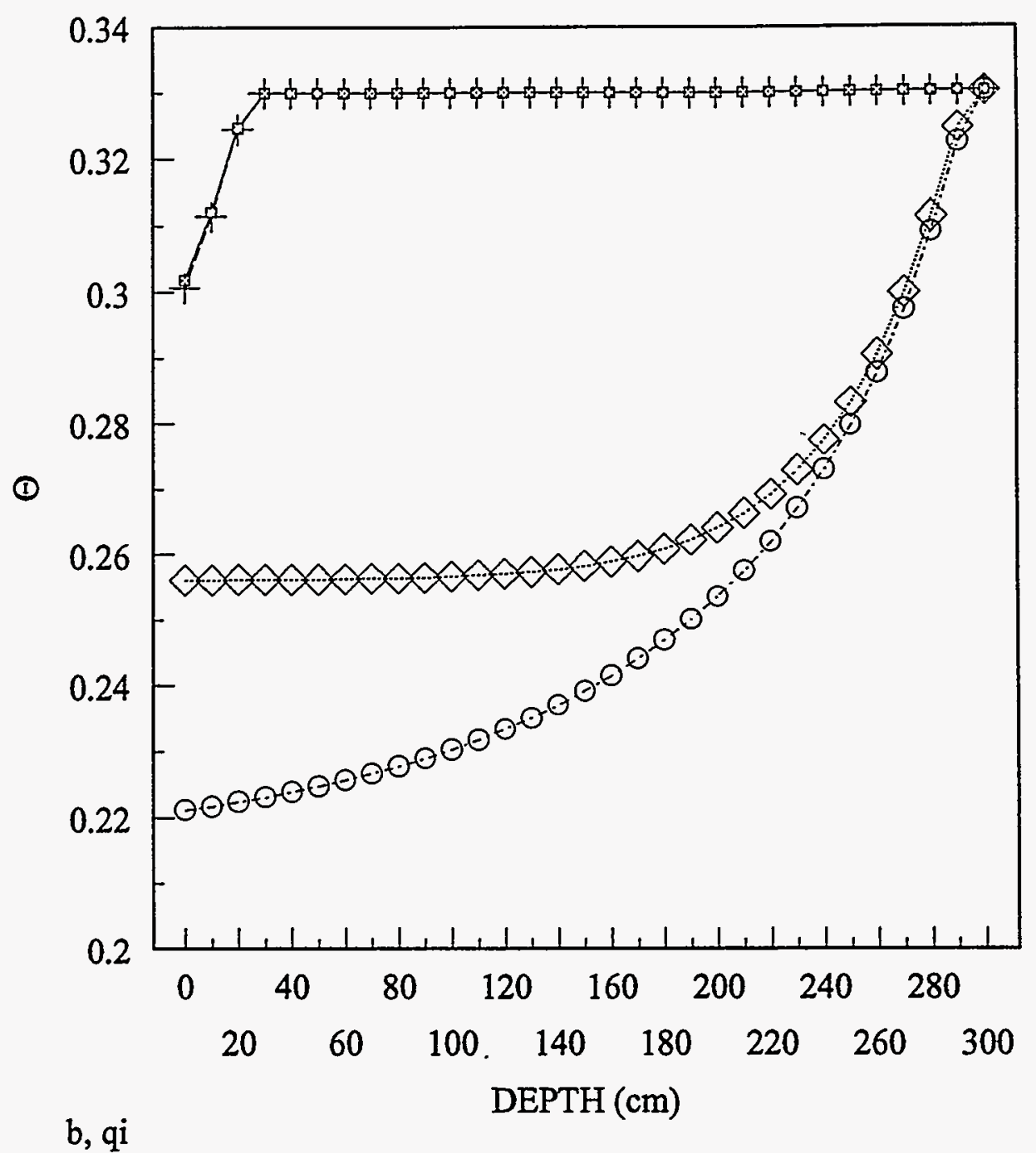

$300 \mathrm{~cm}, 0.01 \mathrm{~cm} / \mathrm{d} 300 \mathrm{~cm}, 0.015 \mathrm{~cm} / \mathrm{d} 25 \mathrm{~cm}, 0.03 \mathrm{~cm} / \mathrm{d} 25 \mathrm{~cm}, 0.05 \mathrm{~cm} / \mathrm{d}$ $-\odot-$ $\cdots$ -十$\rightarrow$

Figure 20 Sturgeon Falls site simulated steady state water content distributions for different unsaturated thicknesses (b) and infiltration rates $\left(q_{i}\right)$ 


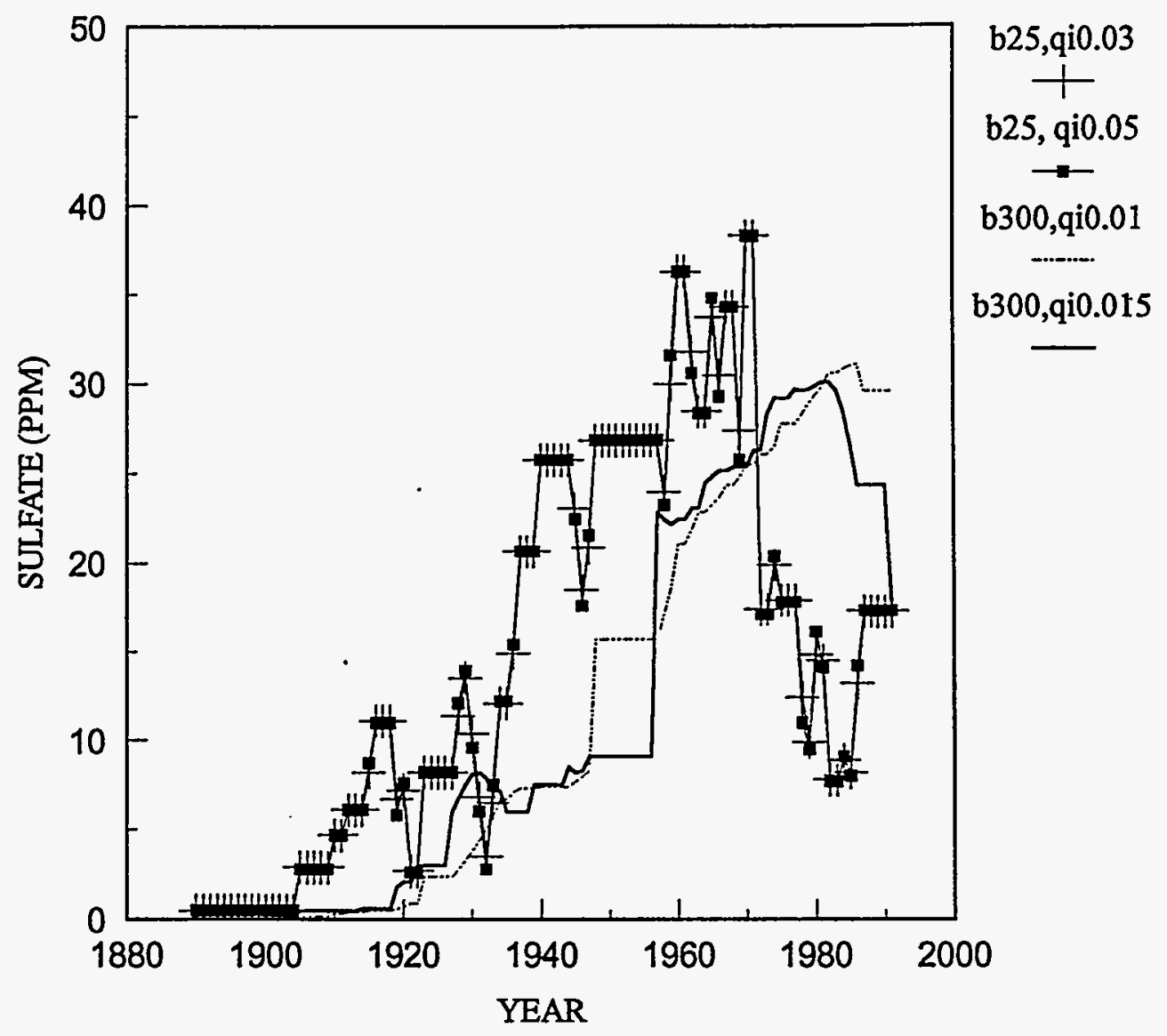

Figure 21 Sturgeon Falls site simulated recharge concentration functions for $25 \mathrm{~cm}$ and $300 \mathrm{~cm}$ unsaturated thicknesses $(b[\mathrm{~cm}])$ and various infiltration rates $\left(\mathrm{q}_{\mathrm{i}}\right.$ $[\mathrm{cm} / \mathrm{d}])$ 
Conditions that are favorable for rapid transport (shorter pathway, higher flow rate) maintain higher water contents and as a result have higher unsaturated hydraulic conductivities. However, for the range of recharge rates and soil hydraulic parameters used in this model, the enhanced hydraulic conductivities do not result in significant differences in the simulated recharge functions for unsaturated thicknesses less than 200 centimeters. For the longer columns $(>100 \mathrm{~cm})$ with lower recharge rates $(<0.02 \mathrm{~cm} / \mathrm{d})$ where the water content drops below 0.30 at the ground surface, small differences in the recharge rate change the hydraulic conductivity significantly.

Since all the cells have the same infiltration concentration during the same time step, the amount of mass entering the subsurface is a function of the recharge rate. The 300 centimeter long columns with a recharge rate of 0.015 centimeters per day show a significant lag in the arrival time for the sulfate and a damping of all the small concentration fluctuations compared to the 25 centimeter column (Figure 21). The damping and time lag are significantly greater with a slightly lower recharge rate $(0.01 \mathrm{~cm} / \mathrm{d})$ as seen in the delay in and spreading out of the period of peak concentration.

The longer the column, the more the fluctuations in the predicted recharge concentrations are damped, but the damping is minimal for infiltration rates greater than 0.01 centimeters per day. The maximum predicted recharge concentration is changed by a factor of less than two for all the simulated soil column lengths and 
recharge rates.

Testing the sensitivity of the predicted recharge concentration to the soil hydraulic parameters $\left(\alpha, \beta, \theta_{\mathrm{r}}\right)$ also results in slight changes in the predicted recharge concentration. The range of $\alpha$ values $(0.02$ to 0.09$)$ yields slight differences in the predicted recharge concentration and no delay in the predicted arrival time of the peak concentration. The unsaturated flow simulation is more sensitive to the $\beta$ parameter and creates the greatest variation in the predicted recharge. Using the maximum $\beta$ value slightly lowered all the predicted concentrations, maintaining the magnitude of the fluctuations in the predicted recharge concentration with no delay in the predicted arrival time of the peak concentration. The extreme recharge concentration functions for unsaturated thicknesses of 25 and 200 centimeters are shown in figure 22 .

The results of these simulations show that the only zone in the model with a recharge concentration function that does not resemble the atmospheric source function (Figure 14) is near the escarpment (Figure 10) where there is a band of thick unsaturated zone and low recharge rates (Table 3 ). The revised groundwater flow model has more cells with low recharge rates $(<0.05 \mathrm{~cm} / \mathrm{d})$ and a lower average recharge rate than the base case groundwater flow model, putting less mass into the groundwater system. The larger zone of low recharge changes the contaminant distribution.

The unsaturated zone model uses the units centimeters, micrograms and days. 


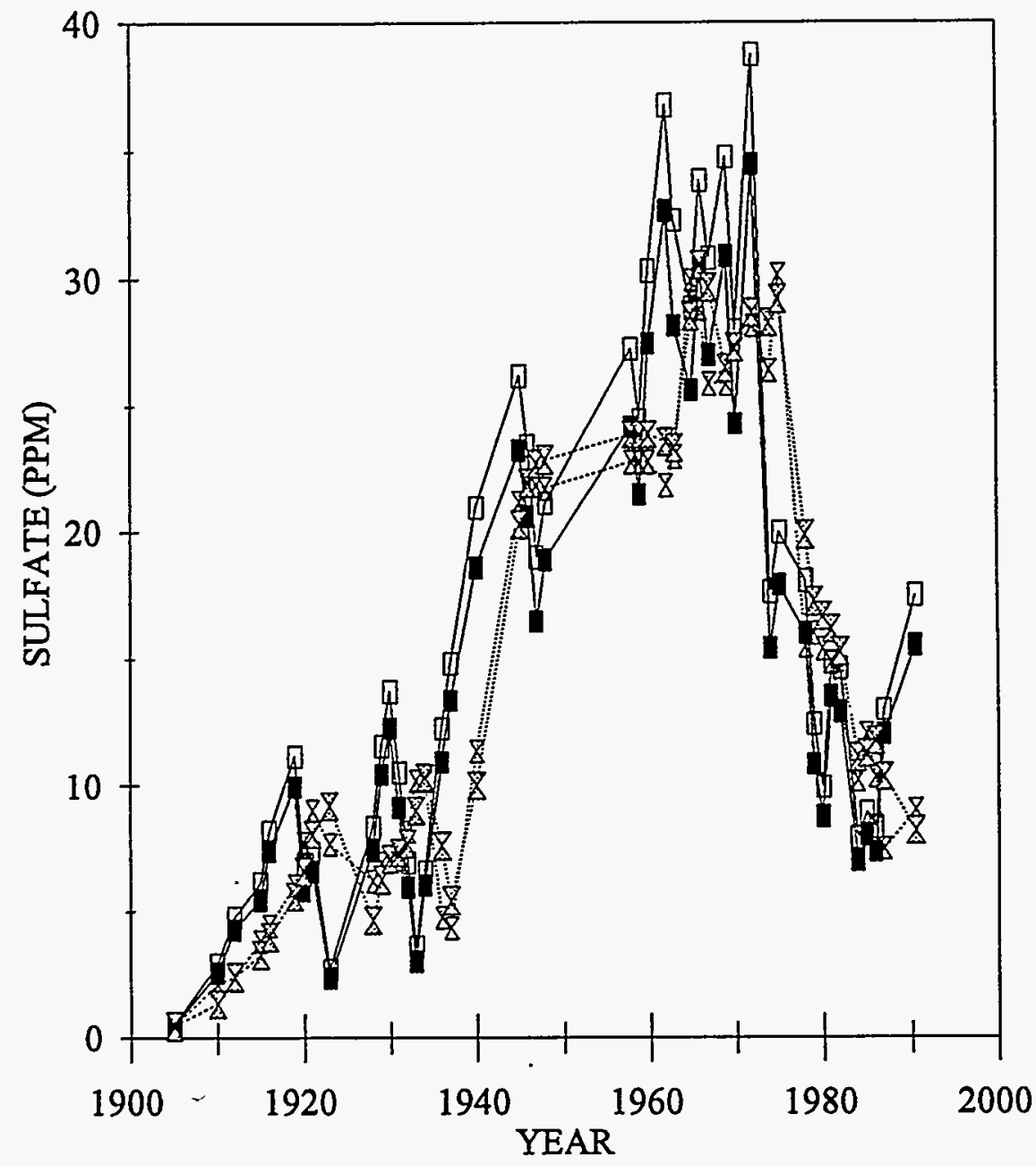

$$
b=25 \mathrm{~cm} \quad b=200 \mathrm{~cm}
$$

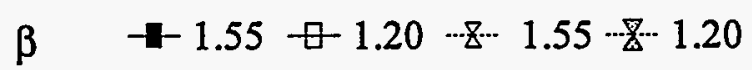

Figure 22 Sensitivity of the Sturgeon Falls simulated recharge concentration function to unsaturated zone thickness and soil hydraulic fitting parameter $\beta$ 
The unsaturated model concentration output is in micrograms per cubic centimeter. The units used in the groundwater transport model are meters, grams and days. There is no correction factor needed for the recharge concentration between the two models $\left(1 \mu \mathrm{g} / \mathrm{cm}^{3}=1 \mathrm{~g} / \mathrm{m}^{3}\right)$. However, the flow and transport parameter values must be converted to the correct units (Table 1). Groundwater Transport

The base case and revised flow system models are used to simulate sulfate and tritium transport in the groundwater system. The predicted distributions of these two contaminants are compared to the measured values. Since the variations in the atmospheric source function (timing and magnitude of fluctuations) are reflected in the recharge concentration functions for the model, annual time steps are used in the groundwater transport model.

Sulfate Transport

The sulfate distribution in the groundwater system is simulated using the concentration in recharge as the source term and transporting it in a steady-state flow system with the same dispersivity and effective molecular diffusion coefficient used in the unsaturated zone model (Table 1). The simulated concentrations are compared to averaged concentrations in wells located near the nodes in the model. The estimated average recharge rate and unsaturated zone thickness for each cell in the model grid determines which recharge concentration function is used for the cell. The input files for the base-case and revised-flow transport simulations are 
located on disk (back pocket). The base-case and revised-flow transport models were run using both the MOC and HMOC solution options, different particle tracking options available in MT3D (e.g., number of particles, Euler particle tracking algorithm, fixed and random particle positions) as well as different computers. Changes in the solution technique, particle tracking and computer used for the simulation resulted in slight differences in the predicted concentrations, but did not change the predicted contaminant distribution or the fit of the model to measured concentrations.

The differences in the contaminant distributions can be seen using contour maps of the simulated sulfate concentrations in layers 1 and 4 (Figure 23). The base case simulation results in a more uniform distribution of mass in layer 1 than the revised flow system simulation. The larger zone of low recharge in the revised flow model produces a more gradual concentration gradient between the center of the model flow system and the river and escarpment boundaries. However these cells are all located away from the transect of measured sulfate values and cannot be used to support the use of one flow system realization over another.

The fit of the model to measured sulfate concentration depends on the flow system used in the simulation. The revised flow system gives a much closer fit to the measured concentrations, because the downward movement of sulfate is limited by the flow. This is evident in cross-sections of the modeled concentration (Figure 24) and even more obvious in a map of the simulated concentrations for layer 4 

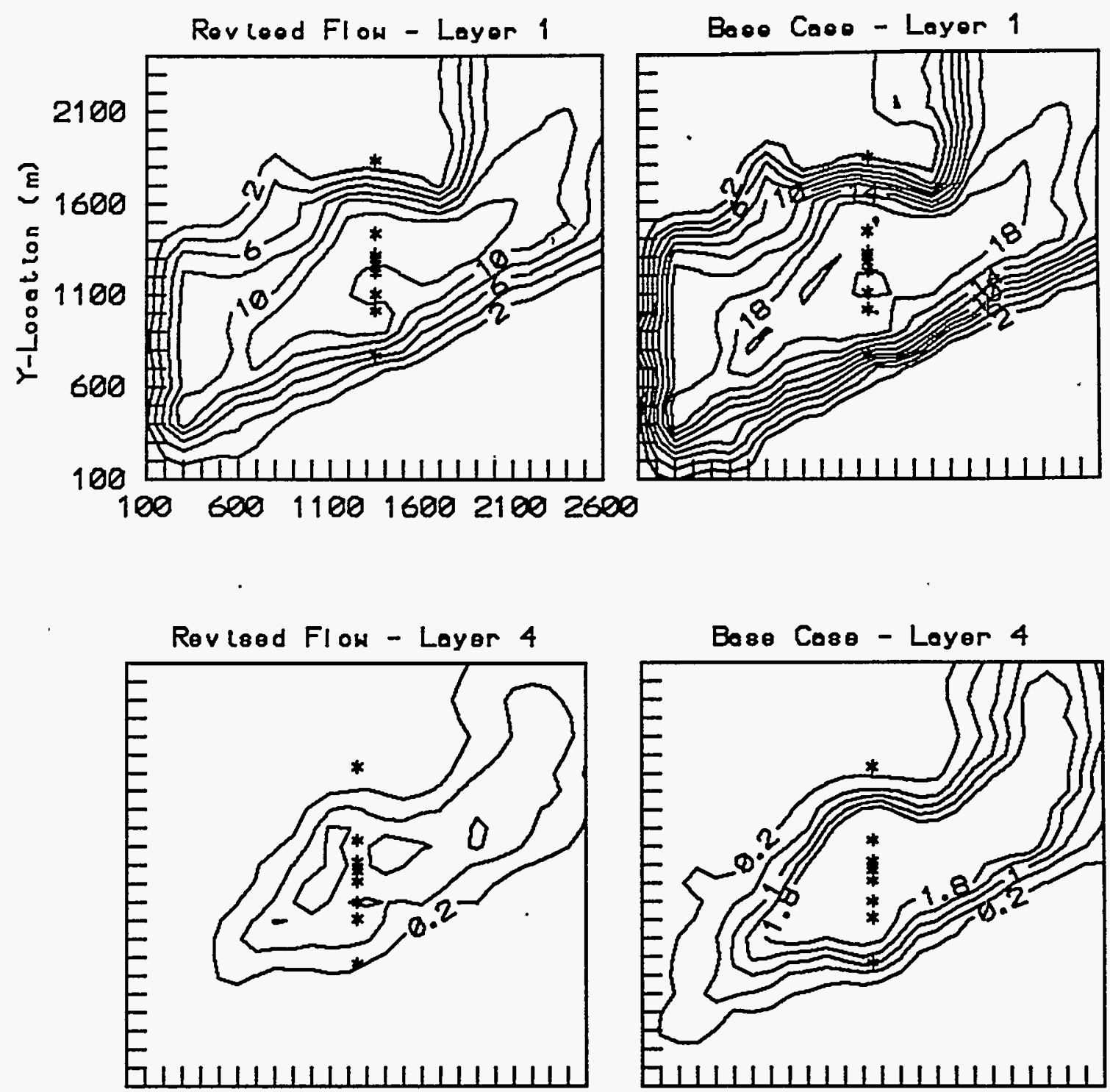

Figure 23 Map views of sulfate distribution in layers 1 and 4 for the base case and revised flow simulations for the Sturgeon Falls site (contour interval $2 \mathrm{ppm}$ for layer 1 and $0.4 \mathrm{ppm}$ for layer 4) 

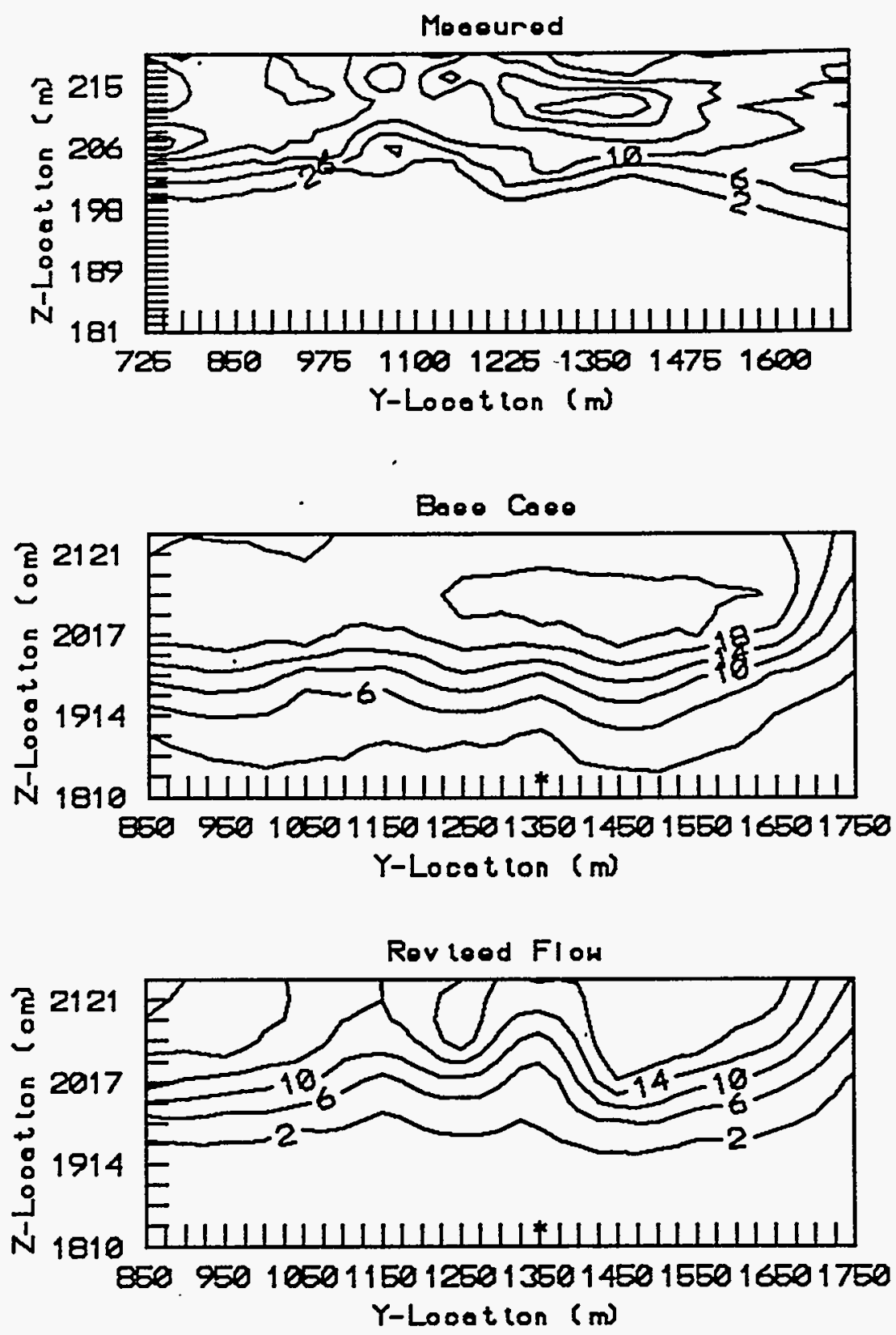

Figure 24 Sturgeon Falls site measured and simulated sulfate concentrations (ppm) along the transect (model column 12) (vertical exaggeration $=10 x$; contour interval $=4 \mathrm{ppm})$ 
(Figure 23).

Robertson et al. (1989) suggest that sulfate reduction may explain the lack of sulfate lower in the aquifer (with one exception near the $1550 \mathrm{~m}$ grid location). The CATS modeling results indicate another possibility, that the flow system is limiting the downward migration of the contaminants. Even with decay to reduce the sulfate concentration in the lower layers (below $199 \mathrm{~m}$ elevation), the base case simulation would estimate a depth to the maximum concentration that is too great. There is one exception, the base case simulates the depth to peak concentration better near the escarpment $(y=725 \mathrm{~m})$.

Another significant difference between the two simulations is the amount of mass in the subsurface. An area graph of the cumulative amount of mass stored in runoff, the unsaturated zone and groundwater shows how much more mass is transported to the subsurface in the base case simulation (Figure 25). The revised flow simulation shows a smoother change in the total amount of mass deposited than the base case simulation because shorter (annual) time steps were used. Summary

The CATS model is applied to the Sturgeon Falls site to demonstrate how the model is used to simulate dry deposition from chronic atmospheric emissions and subsequent subsurface transport. The conceptual and numerical models provide a framework for analyzing the differences between the wet and dry deposition components. The wet deposition is episodic and may or may not occur on a day 


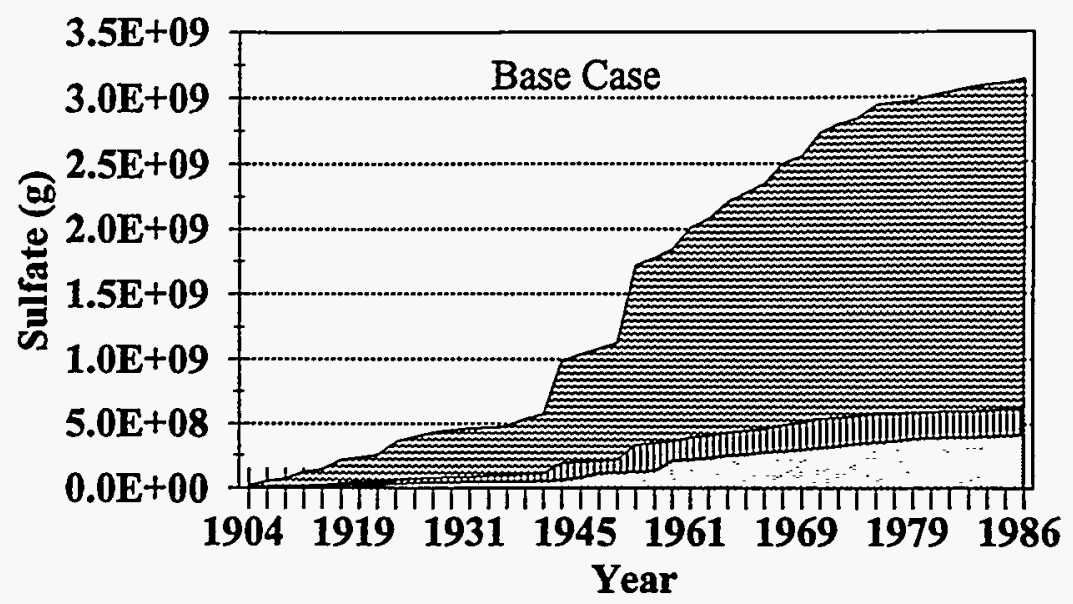

groundwater

unsaturated zone runoff

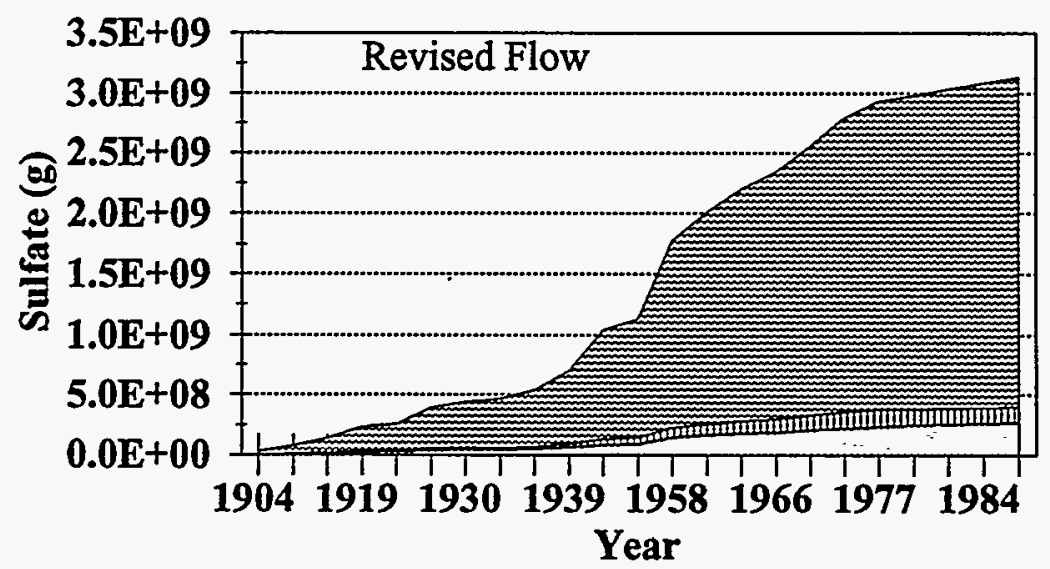

Figure 25 Mass distribution for the base case and revised flow simulations of the Sturgeon Falls site 
when the wind is blowing the Sudbury emissions over the field site. Dry deposition is a more consistent (less episodic) deposition process that should preserve the signature (as fluctuations in the amount of sulfur deposited) of the Sudbury Basin emissions. The atmospheric transport and deposition model provides a means of estimating the amount of mass deposited from dry deposition processes, analyzing the significance of modeling assumptions and estimating the reasonable range of infiltration concentrations as a function of uncertainty in the model parametervalues.

CATS provides a method to account for the impact of one small change in the flow system, in this case the vertical conductance between two layers, on the distribution of mass in the system. A decrease in one of the vertical conductance values limited the vertical transport of the contaminant and reduced the amount of mass stored in the subsurface. The CATS simulation indicates that additional data on the amount and type (solid or solute) of sulfate transported in runoff and the amount of mass stored at the ground surface would provide the information necessary to refine and support a narrower range of deposition velocities to determine the amount of mass entering the system. The total amount of sulfur in the groundwater system, especially in the lower layers, would indicate the amount of mass in the groundwater system and indicate whether or not sulfate reduction is occurring, providing support for the base case or revised flow simulation. The threedimensional groundwater transport simulation indicates that mixing will obscure the 
differences in the recharge concentration history caused by increasing unsaturated thickness. In this case, the most information about the recharge rate will be provided by the distribution of the mass in the unsaturated zone.

The most important considerations for this site are accurate representations of the atmospheric source term and the groundwater flow system. The atmospheric source function controls the magnitude and timing of changes in the contaminant's concentration in recharge, while the groundwater flow system controls the vertical distribution of the contaminant.

The CATS simulation shows how the dry deposition of sulfur from the Sudbury sources maintains the fluctuations in the source term and these variations are sufficient to produce the present groundwater sulfate concentration distribution. The CATS simulation also demonstrates that the dry deposition component of the total sulfur deposition may be as high as fifty percent. If the evaporative-enriched wet deposition concentration is added to the model, infiltration concentrations increase by 2 to $5 \mathrm{mg} / \mathrm{L}$ in the post 1980 water. The resulting increase almost doubles the modeled groundwater concentrations compared to simulations without wet deposition. There is enough uncertainty in the atmospheric model parameter values to compensate for this increase without changing the reasonable ranges for parameter values established in the conceptual model for this site. The uncertainty in the parameters used to describe the atmospheric and subsurface systems is great enough to allow calibration of the model to measured sulfate concentrations, but not 
so great that the model would produce disparate results (varying several orders of magnitude). The cumulative mass balance error for the revised and base case simulations is less than one percent (Figure 26).

CATS model results support Robertson and Cherry's (1989) assumption that the unsaturated zone does not delay the contaminant pulse or significantly alter the infiltration concentration over the region sampled. However, CATS model results indicate the unsaturated zone significantly alters the timing and fluctuation in the recharge concentration in areas with thicker unsaturated zones $(>2 \mathrm{~m})$ or low recharge rates $\left(<5 \times 10^{-5} \mathrm{~m} / \mathrm{d}\right)$. At this site, zones with low recharge rates and thick unsaturated zones are generally located above groundwater zones of horizontal flow where the sulfate concentration is influenced by mixing. Mixing with water that has retained the atmospheric source signature (the pattern of variation in the sulfate concentration) reduces the impact of the recharge concentration function (for that cell) on the groundwater concentration distribution in the cell. The threedimensional flow and transport model used in CATS provides a means to simulate the effects of mixing on the concentration distribution.

Robertson et al. (1989) and Robertson and Cherry (1989) conclude that sulfate reduction and lower cosmic tritium concentrations are required to reduce the concentration of these contaminants below layer two. The CATS model provides a framework to compare the transport of these two contaminants. As a result, the model shows that a slightly revised groundwater flow system from Robertson and 


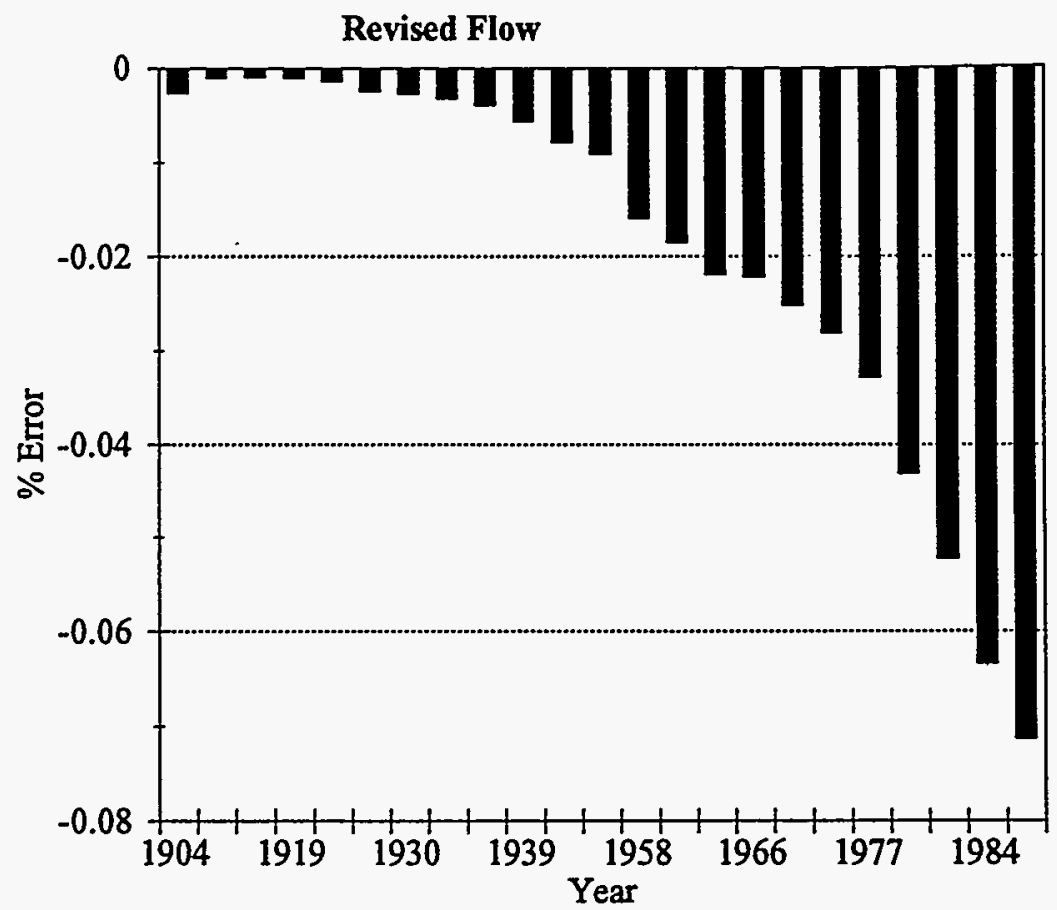

Figure 26 Cumulative mass balance error in the Sturgeon Falls site simulation 
Cherry (1989) results in a better simulation of the hydraulic heads and contaminant distribution.

The CATS model simulations show that lower long-term average recharge rates than the rates estimated by Robertson and Cherry (1989) and Solomon et al. (1993) for this site are possible. The studies by Robertson and Cherry (1989) and the Solomon et al. (1993) were focused on the top two layers, in the zone located at and above the maximum tritium concentration. The CATS simulations are designed for a slightly larger scale. The CATS simulations using the revised flow system reproduce the vertical distribution of hydraulic head, sulfate and tritium concentration better than Robertson and Cherry's model. One possible problem with the CATS model simulations is the assumption that the August 1986 water table elevations represent the long-term average position of the water table. The elevations at the end of summer, a period of high evapotranspiration and low recharge, are probably lower than the annual average position. If the average annual position of the water table is higher but the magnitude and direction of the hydraulic gradients remain constant, then the recharge rates required for the CATS simulations would be greater. Simulating the groundwater system with a lower vertical conductance (revised model) and the base case recharge rates (Robertson and Cherry (1989) and Solomon et al. (1993) rates) raises the water table elevation approximately one meter $(0.7 \mathrm{~m}$ to $1.3 \mathrm{~m})$. The total seasonal fluctuation in water table elevations at the site is only about $1.3 \mathrm{~m}$ (Solomon et al., 1993). Assuming the 
average annual position is half way between the minimum and maximum elevations, the average annual position of the water table is about 0.6 to 0.7 meters above the minimum (August) position of the water table. Hence, the average annual recharge rate is probably greater than the recharge rate estimated with the revised flow model but less than the recharge rate estimated by the Robertson and Cherry (1989) model. The CATS simulations indicate that the average annual recharge rate predicted using the depth to the tritium peak are probably higher than the long-term rate. The depth to the tritium peak may be a function of seasonal effects (e.g., increased vertical gradient during periods of greater recharge) as well as the average conditions in the flow field. The effects of seasonal flow conditions on CATS model simulations are demonstrated using the model of a hypothetical groundwater flow system in the CNPP 30 kilometer zone.

\subsection{Ephemeral Emission}

The large ephemeral release due to the 1986 fire at the Chernobyl nuclear power plant (CNPP) illustrate how the CATS model is applied to an ephemeral radionuclide emission. The storage and decay of the contaminant at the ground surface is modeled using parameter values based on data from sites in the area around the CNPP. A hypothetical subsurface flow system, based on a composite of data for several sites in and around the $\mathbf{3 0}$ kilometer zone, is used to simulate the potential radionuclide storage and transport in the subsurface. The groundwater 
flow system is generated using no flow boundaries around three sides and bottom of the aquifer, specified flux (recharge) boundary for the upper surface, and specified heads along the remaining side. The sensitivity of the model to reasonable ranges of the transport model parameter values, model links and seasonal changes in the flow system are examined. The hydrogeologic and atmospheric emission data used to create the hypothetical transport system are listed in the appendix. Atmospheric Transport and Deposition

The wind direction shifted several times during the emission period as evidenced by the deposition pattern of the radionuclides on the ground surface (Figure 27). For the hypothetical site, the CATS model uses a standard Gaussian plume model, without adjustment for plume depletion due to dry deposition between the source and site, to simulate the ground level atmospheric ${ }^{137} \mathrm{Cs}$ concentration. The model site shown in figure 27 was selected because a small relatively distinct plume covers the site. The mapped surface activities are used to calibrate the atmospheric transport and deposition model by setting targets at several down-wind and cross-wind distances. The ranges in parameter values allowed during the calibration are listed in table 4. Single values for the atmospheric emission rates $\left(Q_{0}\right)$ are assumed because they will control the magnitude of the deposited concentration but not the distribution. In addition, changes to the emission rate will result in proportional changes in the deposition velocity $\left(v_{d}\right)$ in order to match the magnitude of the surface activity concentration. 


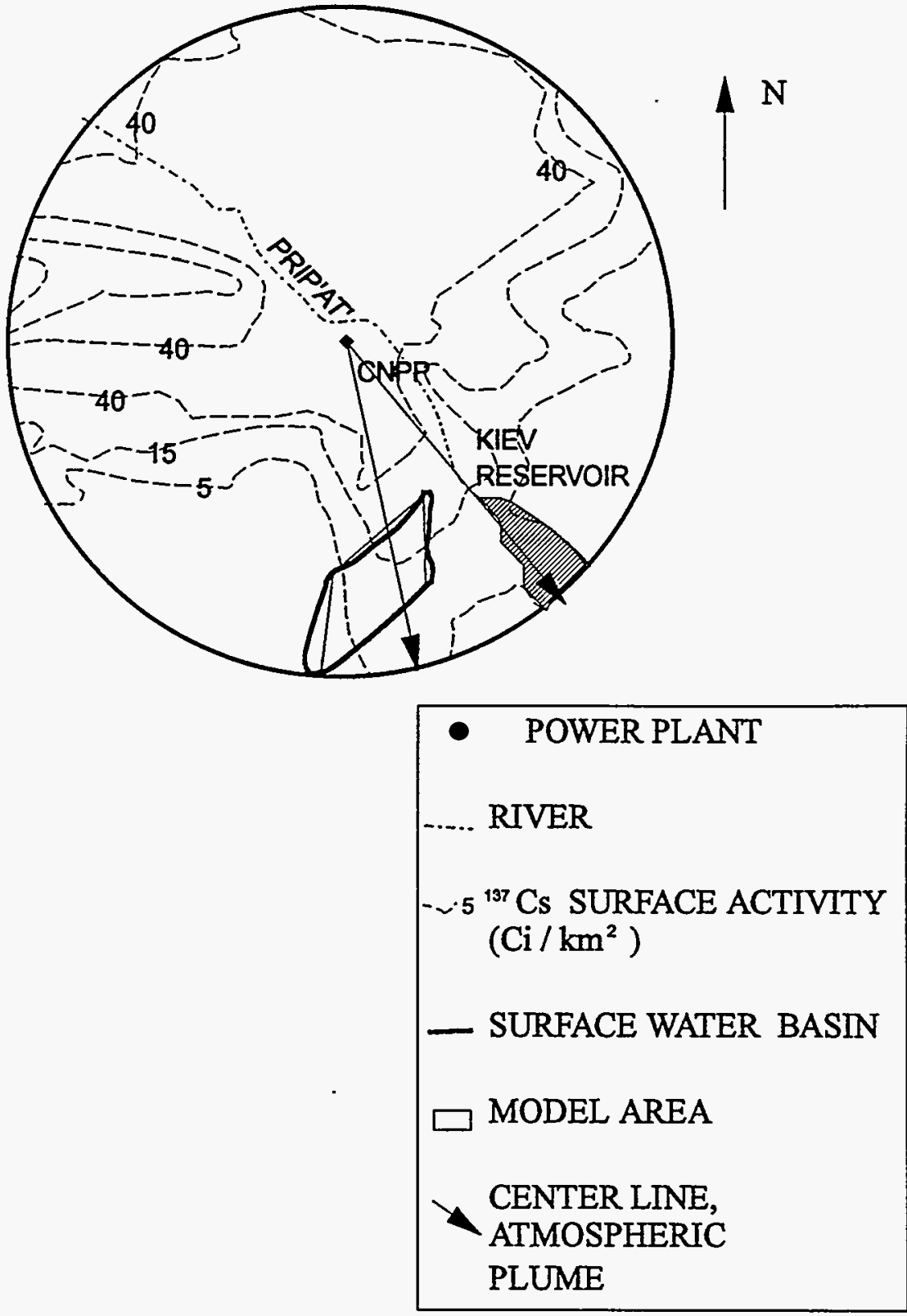

Figure 27 CNPP 30 kilometer zone location map, surface cesium concentration, inferred plume centerlines and model area 
Table 4 CNPP Site Base Case and Range of Parameter Values

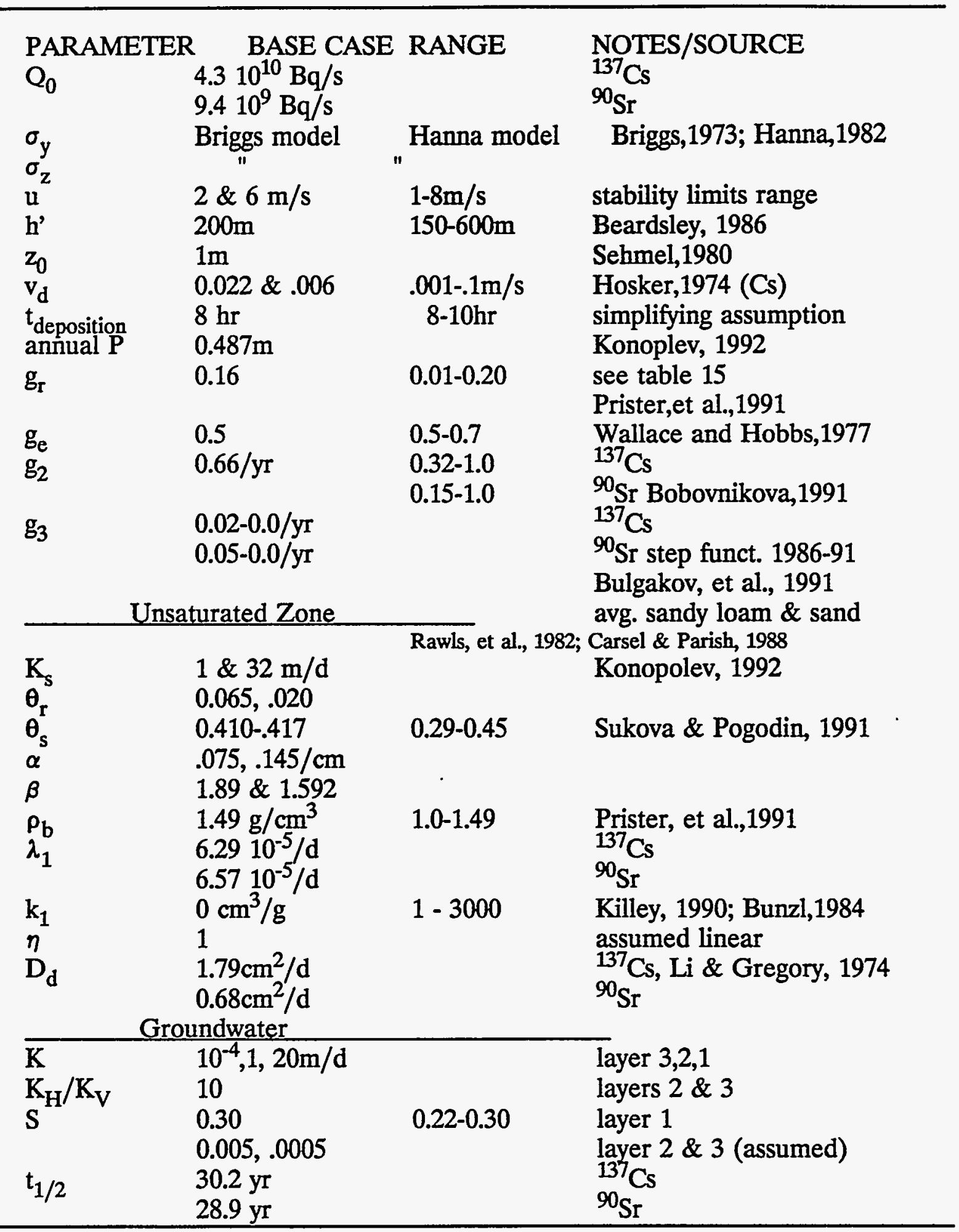


The effective release height $\left(h^{\prime}\right)$, wind parameters $\left(u, \sigma_{y}, \sigma_{z} S^{\prime}, F(\omega)\right)$ and deposition velocities $\left(v_{d}\right)$ are varied to calibrate the modeled plume shape. Two sets of dispersion coefficients are used during model calibration, one set from Briggs (1973) and the other from Hanna (1982). The release height, and dispersion parameters control the plume shape. The deposition velocity is used to match the magnitude of the surface concentrations. The large number of unknown parameter values indicates the possibility of a non-unique calibration.

In addition to varying the dispersion, wind speed, deposition and release height parameter values, the atmospheric concentration and deposition are modeled using single and double plume realizations. The pattern of cesium and strontium deposition on the field site (Figure 27) indicates that a second plume to the southeast of the site may influence the contaminant distribution at the site.

The atmospheric model was used to simulate a single plume using the parameter ranges for each of Pasquill's (1962) atmospheric stability categories. These simulations were used to narrow the range of possible parameter values. Sensitivity plots for these simulations (Figures 28 and 29) show that consistently better fits to the measured surface concentrations are obtained using the parameter ranges for the stability categories A and B with the dispersion coefficients of Briggs (1973). The sensitivity plots also show that there is an optimum combination of parameter values for each stability category. Figure 28 shows the sensitivity of the calibration to wind speed and the dispersion parameters. The best fit is obtained 


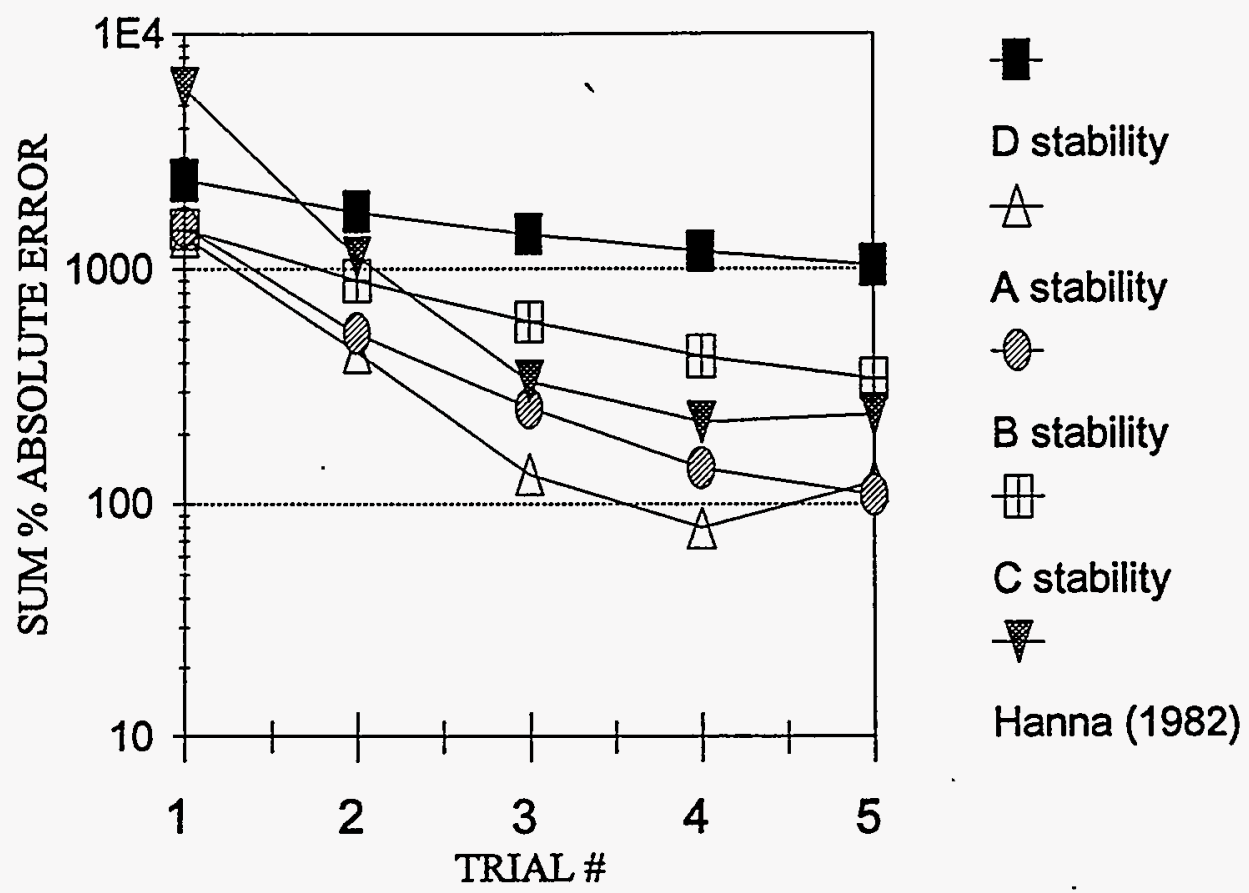

\begin{tabular}{|lcllll|}
\hline trial \# & 1 & 2 & 3 & 4 & 5 \\
& & & & & \\
D & 3 & 4 & 5 & 6 & 7 \\
A & .5 & 1 & 1.5 & 2 & 2.5 \\
B & 1 & 2 & 3 & 4 & 5 \\
C & 2 & 3 & 4 & 5 & 6 \\
Hanna & 1 & 2 & 3 & 4 & 5 \\
\hline
\end{tabular}

wind speed $\mathrm{m} / \mathrm{s}$

Figure 28 CNPP atmospheric model calibration to mapped surface concentrations using wind speed with Pasquill's dispersion model for four stability categories and Hanna's dispersion model for longer distances 

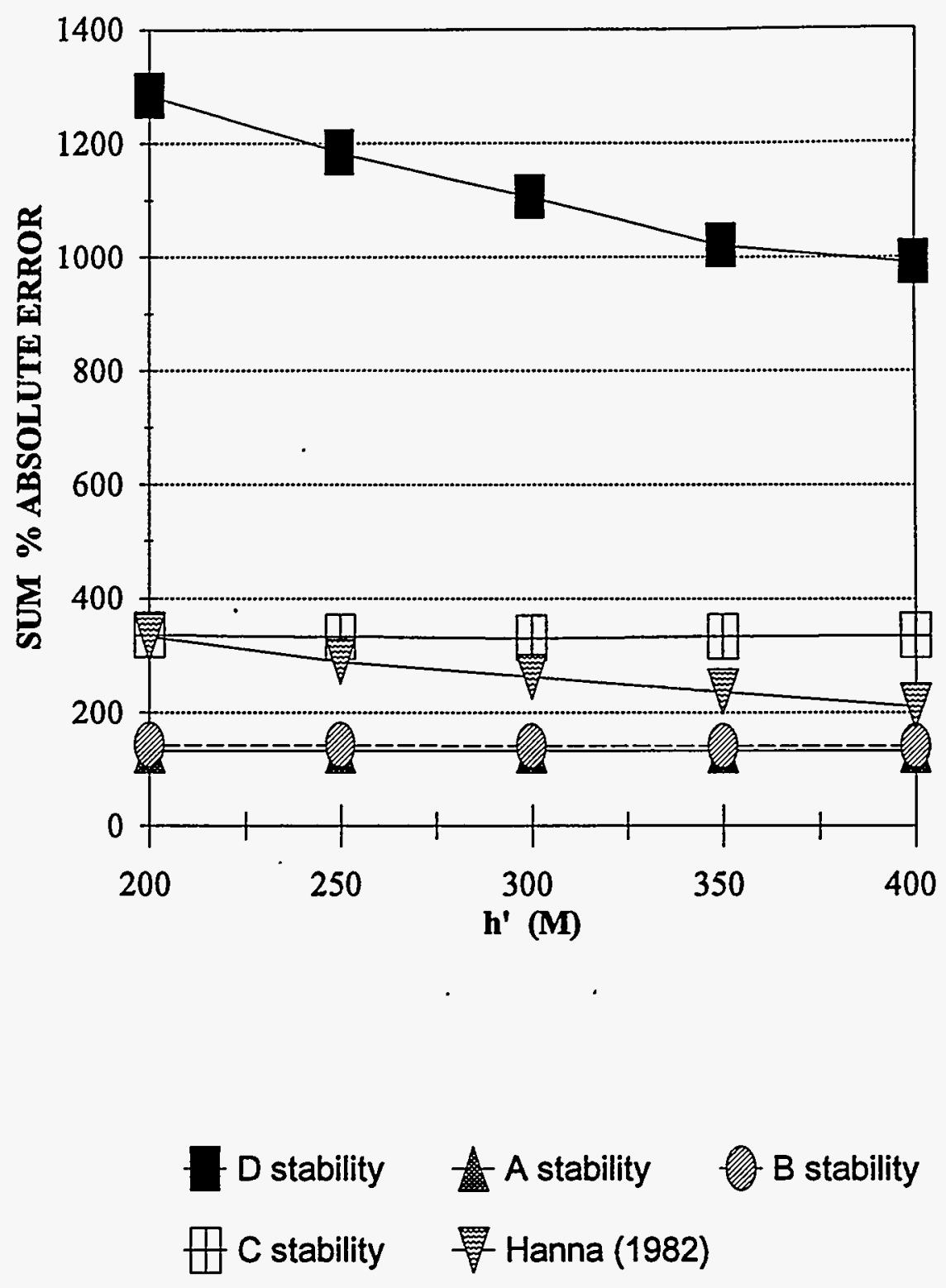

Figure 29 CNPP atmospheric model calibration using effective release height with the best wind speed simulations for each dispersion simulation 
with the A stability, Briggs dispersion model, a wind speed of 2 meters per second and a deposition velocity of 0.05 meters per second. The wind speed ranges are limited by the atmospheric stability category (Pasquill, 1982). The model used in this simulation utilizes cross-wind dispersion parameters that are corrected for sampling times longer than 10 minutes (the standard period over which the measurements for the dispersion coefficients are made). The actual period of deposition is unknown. A deposition period of eight hours is assumed and the modeled horizontal dispersion coefficients are increased by a factor of 2.1.

The plume models with the lowest overall calibration error are relatively insensitive to the release height (Figure 30). The absolute value of the relative error in the model simulation is used to measure the fit of the simulation to the . field concentrations. The relative error [(simulated - measured)/measured] is used to prevent the high concentration calibration values from dominating the calibration. Consequently, a better overall fit of the plume to the field concentrations is obtained.

Of the single plume simulations, the A-stability parameter values yield the best simulation of the deposited mass because they produce a wider plume, possibly accounting for the effect of having two or more superimposed plumes.

The wind field parameter values from the three best ${ }^{137} \mathrm{Cs}$ simulations are used to simulate ${ }^{90} \mathrm{Sr}$ transport. The deposition velocity is used to calibrate the simulations. The deposition velocities required to calibrate the simulations of ${ }^{90} \mathrm{Sr}$ 
deposition should be higher than those for ${ }^{137} \mathrm{Cs}$, because the ${ }^{90} \mathrm{Sr}$ was emitted as larger particles. As with the ${ }^{137} \mathrm{Cs}$ simulations, the A-stability parameter values yield the best fit to the mapped concentrations. As expected, all the strontium simulations require a higher deposition velocity for calibration than the same stability simulation for cesium.

For the double-plume models, two plumes are simulated and the concentrations summed to estimate the total surface concentration of cesium and strontium. Each plume has a separate coordinate system where the "x" position is the down-wind distance along the centerline of the plume and the "y" position is the cross-wind distance from the centerline of the plume. A third coordinate system is required for the groundwater model and conversion factors are used to link all three systems together (appendix). Since the two plumes have similar shapes the same stability conditions are assumed for both plumes.

The double-plume, A-stability model results in plumes that are too wide, but about the right length. The double, B-stability plumes are about the right width, but a little short. The single-plume, A-stability model and the double-plume, B-stability model are applied to the field site by calculating the activity deposited at each node (Figure 30). Comparison of these results to the mapped surface activities over the field site indicates that the single-plume, A-stability model yields the best simulation. This is because the double-plume models only change the modeled surface activity along the north-east side of the field site. The single-plume, A-stability model 
1 Plume - A Stab ll ity

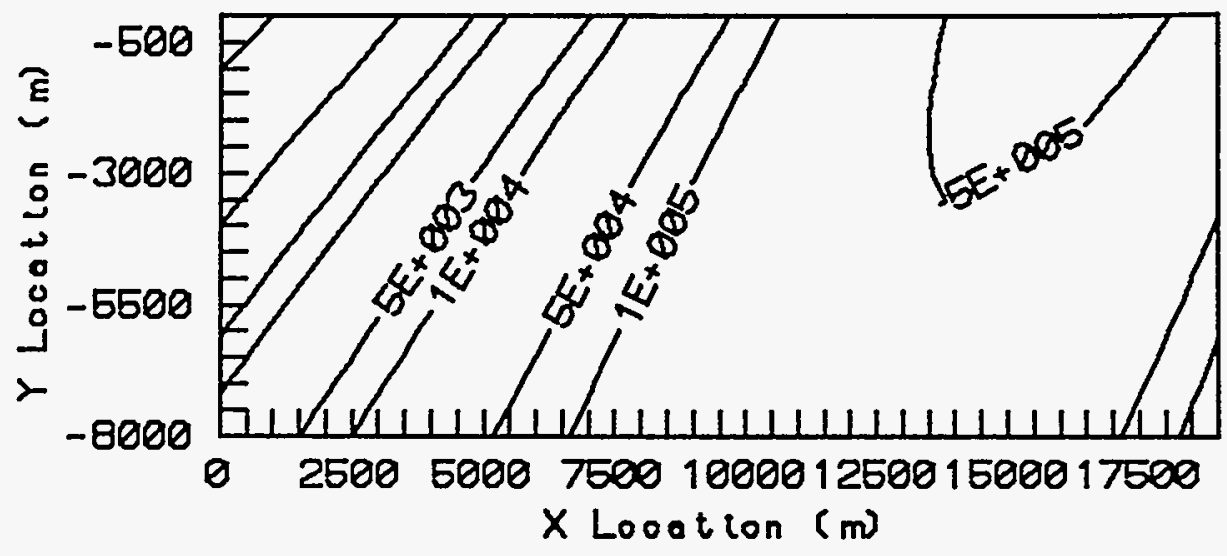

2 Plumes - B Stab ll tty

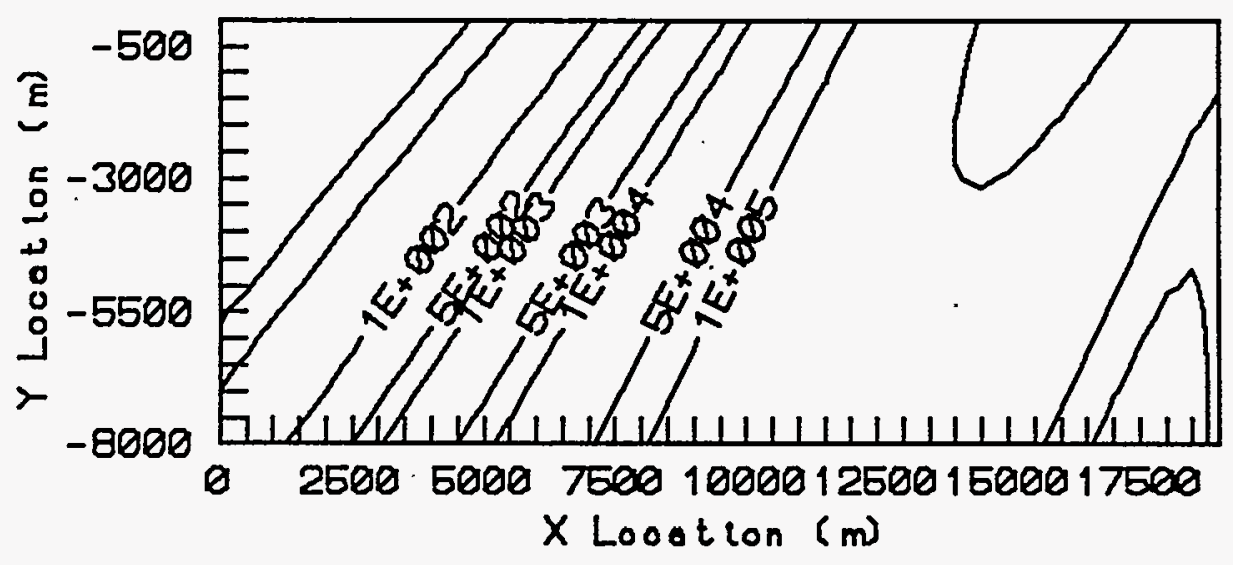

Figure $30 \mathrm{CNPP}$ site simulated cesium surface concentration $\left(\mathrm{Bq} / \mathrm{m}^{2}\right)$ using base case atmospheric parameters with single and double plumes (A stability single plume $u=2 \mathrm{~m} / \mathrm{s}, v_{d}=0.05 \mathrm{~m} / \mathrm{s} ;$ B stability double plume $u=5 \mathrm{~m} / \mathrm{s}, v_{d}=0.055 \mathrm{~m} / \mathrm{s}$ ) 
results are used as the input for the subsurface transport model.

Dissolution, Runoff and Infiltration

The Chernobyl simulation requires storage and dissolution of the fuel particles and aerosols. In order to simplify the problem, wet and dry deposition of resuspended surface contamination, remedial activities and plant uptake are ignored. The range of values used for the parameters in the surface-subsurface link are listed in table 4. In the CNPP simulations, the runoff suspension rate coefficient $\left(g_{3}\right)$ is a function, decreasing step-wise with time, to a value of 0 by the fifth year after deposition occurred. The decrease in the activity partitioned into runoff (as a solid) is based on data from the CNPP 30 kilometer zone and the assumption that over time the contaminated surface is buried under plant matter and other sediments, eventually moving the original ground surface below the runoff zone. For this model, the increase in unsaturated thickness due to these sedimentation processes is considered negligible and the initial depositional surface is assumed to be the top of the unsaturated column.

The amount of activity transported as particulates in runoff is small compared to the activity transported as a solute in runoff and infiltration in this model. Unlike the suspension coefficient, the leaching rate coefficient is assumed constant. The model link is calculated for a steady-state flow system, using the long-term average precipitation rate, annual time steps and the extreme and average leaching and evaporation coefficient values (Table 4). For the range of values used in this 


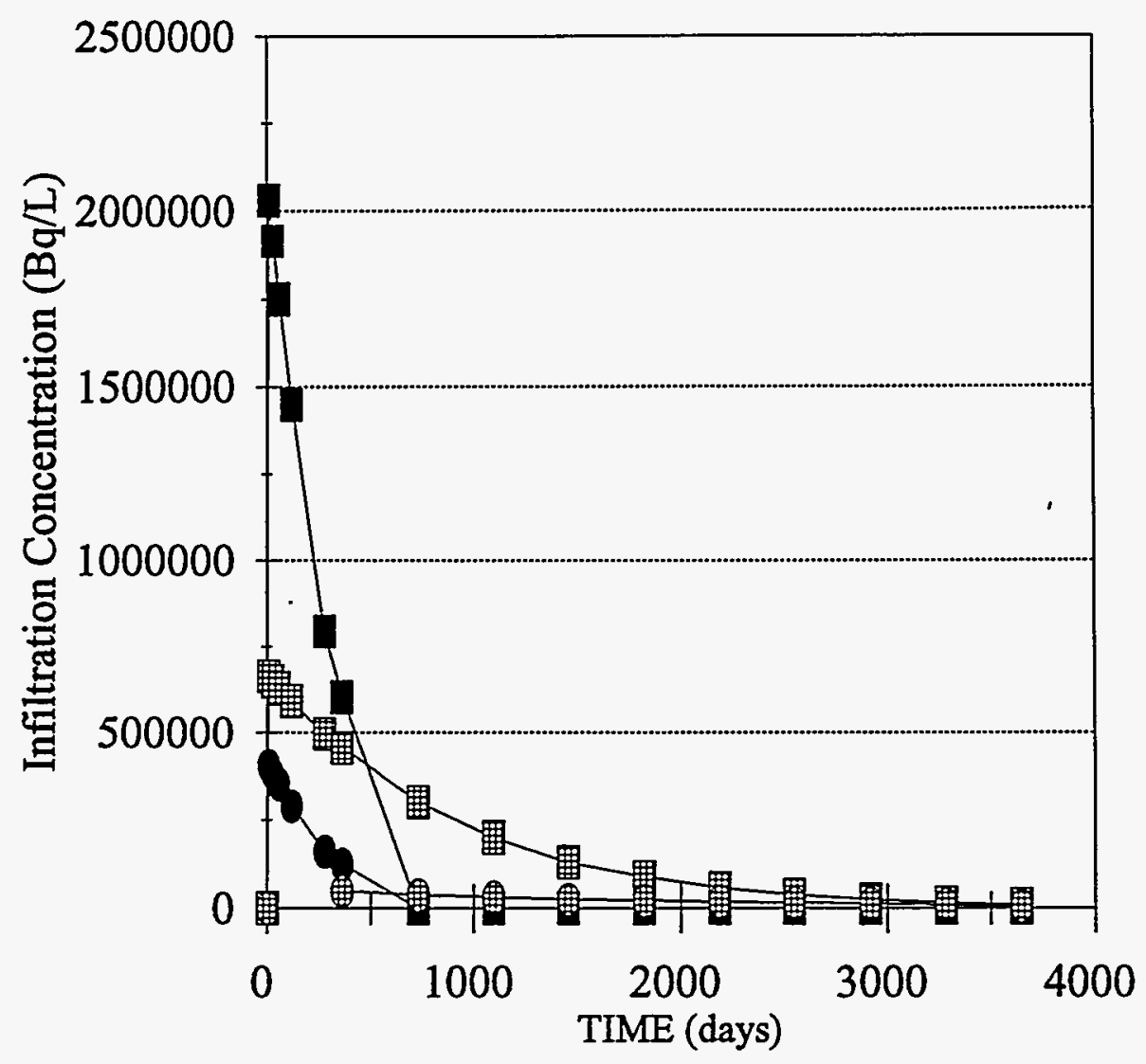

- $\mathrm{Cs}, \mathrm{g} 2 \mathrm{max}-\mathrm{Sr}, \mathrm{g} 2 \mathrm{max}$ 界 $\mathrm{Cs}, \mathrm{g} 2 \mathrm{~min}-\mathrm{Sr}, \mathrm{g} 2 \mathrm{~min}$

Figure 31 Sensitivity of CNPP site simulated cesium and strontium infiltration concentrations to dissolution coefficient $\left(\mathrm{g}_{2}\right)$ extreme values 
simulation, the uncertainty in the solvent coefficient has little effect on the infiltration concentration. Figure 31 shows the effect of the extreme values of the dissolution coefficients on the infiltration concentration. The maximum dissolution coefficient values produce the maximum infiltration concentration while the minimum dissolution coefficients produce a longer period of elevated concentrations. The current model assumes that rapid dissolution, storage of the contaminant near the surface and rapid diffusion keep the infiltration and runoff concentrations equal.

The effects of seasonal inputs on the predicted infiltration concentration were estimated by partitioning the precipitation into runoff and evapotranspiration using six periods for every annual cycle. The periods and the ranges for the partitioning coefficients during each period are listed in table 5. For convenience, the periods are based on 30 day months and the annual cycle is 360 days. The annual cycle is divided into a winter period (December - March) with no liquid precipitation; spring melt period (April) with the total precipitation equal to the amount of melt water plus the monthly rainfall; late spring period (May); summer period (June - July); summer to fall transition period (September), and the fall period (October November). The spring period is assumed to be a period of high runoff and low evapotranspiration. Summer is assumed to be a period where all the precipitation is lost to evapotranspiration. Fall is assumed to be a period with no evapotranspiration. The transition periods are assumed to have some average rate 
of precipitation, evapotranspiration and runoff.

Figure 32 compares the amount of infiltration modeled with the extreme seasonal evapotranspiration and runoff parameter values (Table 5). The largest differences in the amount of water infiltrating the unsaturated zone occur during the spring snow melt period. This would cause significant changes in the predicted infiltration concentration and could significantly alter the predicted transport rate. Summing the total infiltration for each annual cycle and computing the average daily flow rate indicates that the minimum infiltration (seasonal) model is within the range of reasonable values for the average annual steady-state infiltration rate.

To compare the seasonal and steady-state models, both are run using the same average annual infiltration rate $(0.045 \mathrm{~cm} / \mathrm{d})$. The modeled seasonal infiltration concentration, using a constant dissolution rate, discontinuously ' . decreasing suspension rates and the minimum infiltration model with 30 day time steps, is shown in figure 33. The seasonal simulation starts with the May, 1986 period (\#3) of the annual cycle.

Unsaturated Flow and Transport

The site is divided into 18 zones based on unsaturated thickness, soil type, and surface contaminant concentration (Figure 34). Unsaturated transport under steady and seasonal infiltration is simulated. In both models the time steps are set equal to 30 days, the unsaturated thickness is assumed constant with time and a lower boundary condition of constant pressure head $(0 \mathrm{~cm})$ is used. The steady-state 


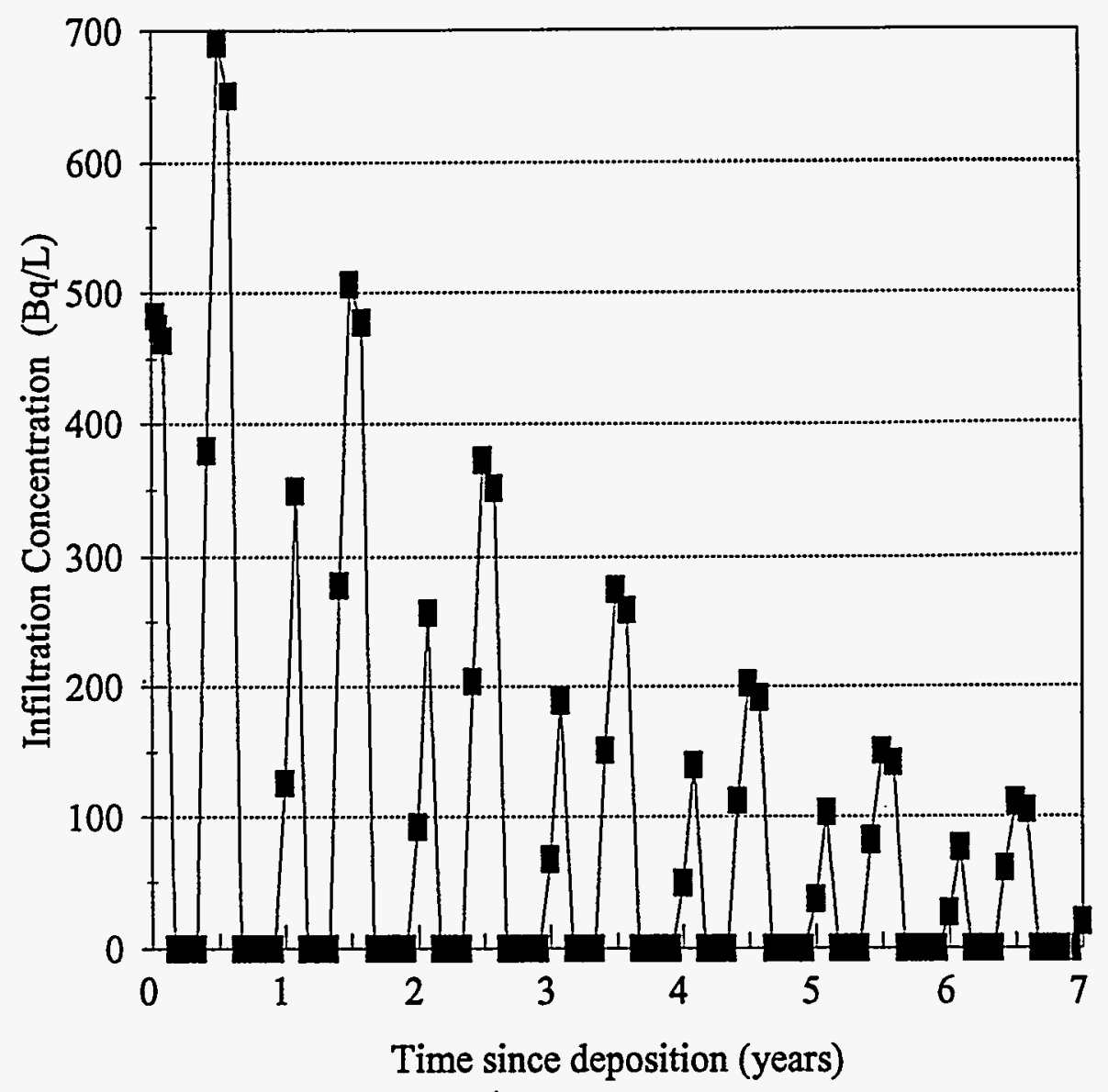

Figure 33 CNPP site simulated seasonal infiltration concentrations in the zone of maximum cesium deposition (base case) 


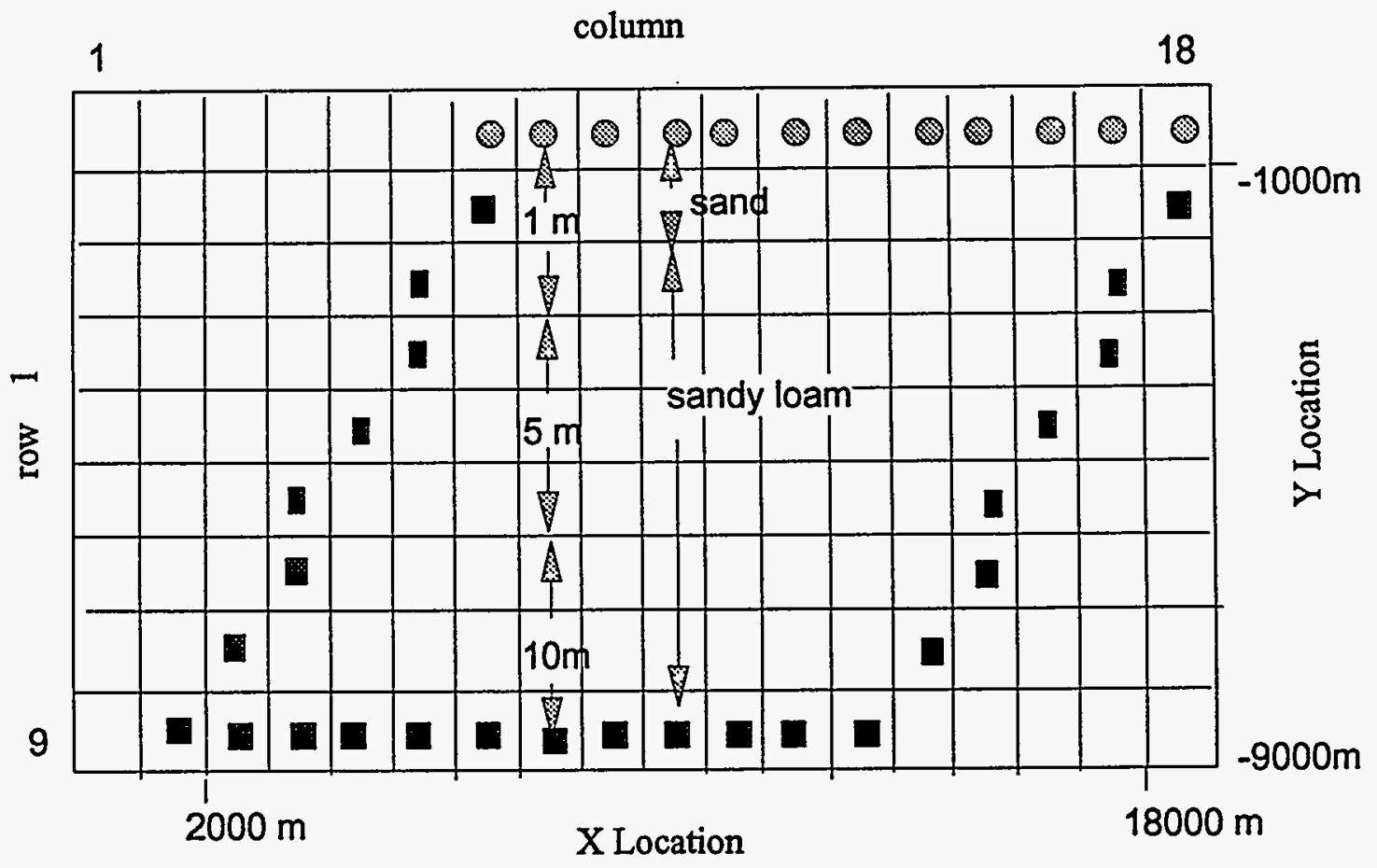

- Specified Head Boundary Node

No-Flow Boundary Node

Figure 34 CNPP site model grid, sediment types, unsaturated thickness, and groundwater model boundary conditions 
water content distribution is used for the initial conditions for the seasonal flow model and then the seasonal flow model is run for one annual cycle before starting the transport simulation.

The recharge concentration functions for the zone of maximum deposition and each of the unsaturated column types produced by the steady-state model are shown in figure 35 . The model is run without any chemical retardation. The unsaturated zone delays the arrival of the peak concentration from 1 year $(100 \mathrm{~cm}$ thick sand column) to more than 10 years $(1000 \mathrm{~cm}$ sandy loam).

Comparing the steady-state results (Figure 35) to the seasonal simulation (Figure 36) shows the effects of the hydraulic properties of the sandy loam. In the seasonal simulation, the same thickness of sand and sandy loam produce very similar recharge concentration functions. The time of the peak recharge concentration is reduced in the sandy loam and the rate of decline in the recharge concentration for the sand and the sandy loam are lower than in the steady-state simulation. These effects are a result of differences in the hydraulic conductivity fields over time and the amount of mass stored at the ground surface. The dissolution and suspension coefficients are set to 0 during periods when there is no infiltration or runoff. Since the values of these coefficients (when they are not set to 0 ) are kept the same as the steady-state simulation values and they are time dependant, the amount of mass stored at the surface is higher. This has the effect of moving more mass into the subsurface and less into runoff because most of the runoff occurs during a single 


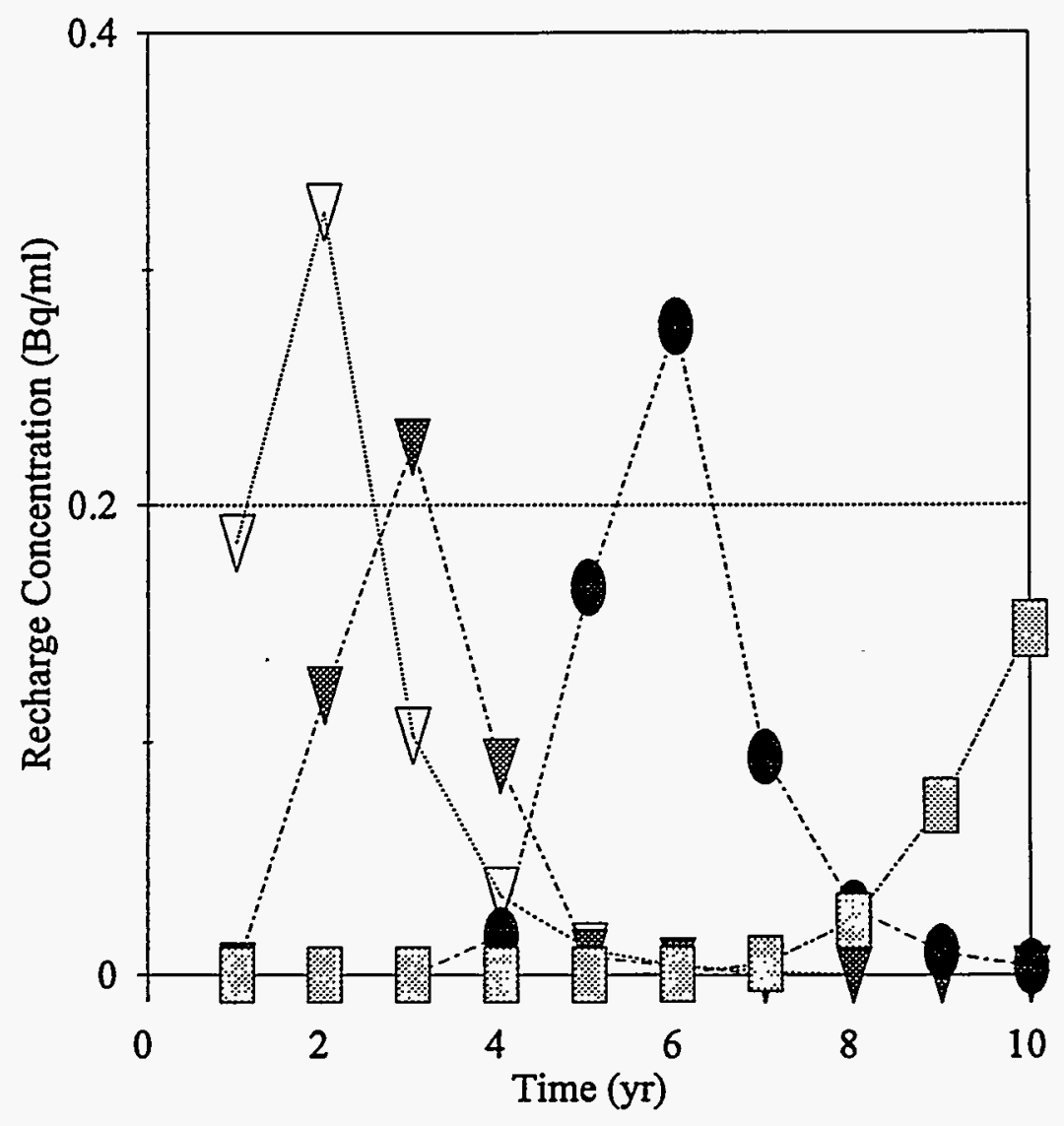

$\because$ Sand $1 \mathrm{~m} \quad-$ sandy loam $1 \mathrm{~m}$ sandy loam $5 \mathrm{~m}$ sandy loam $10 \mathrm{~m}$

Figure 35 Steady state flow simulation: maximum recharge concentration functions for the four soil type/thickness zones 


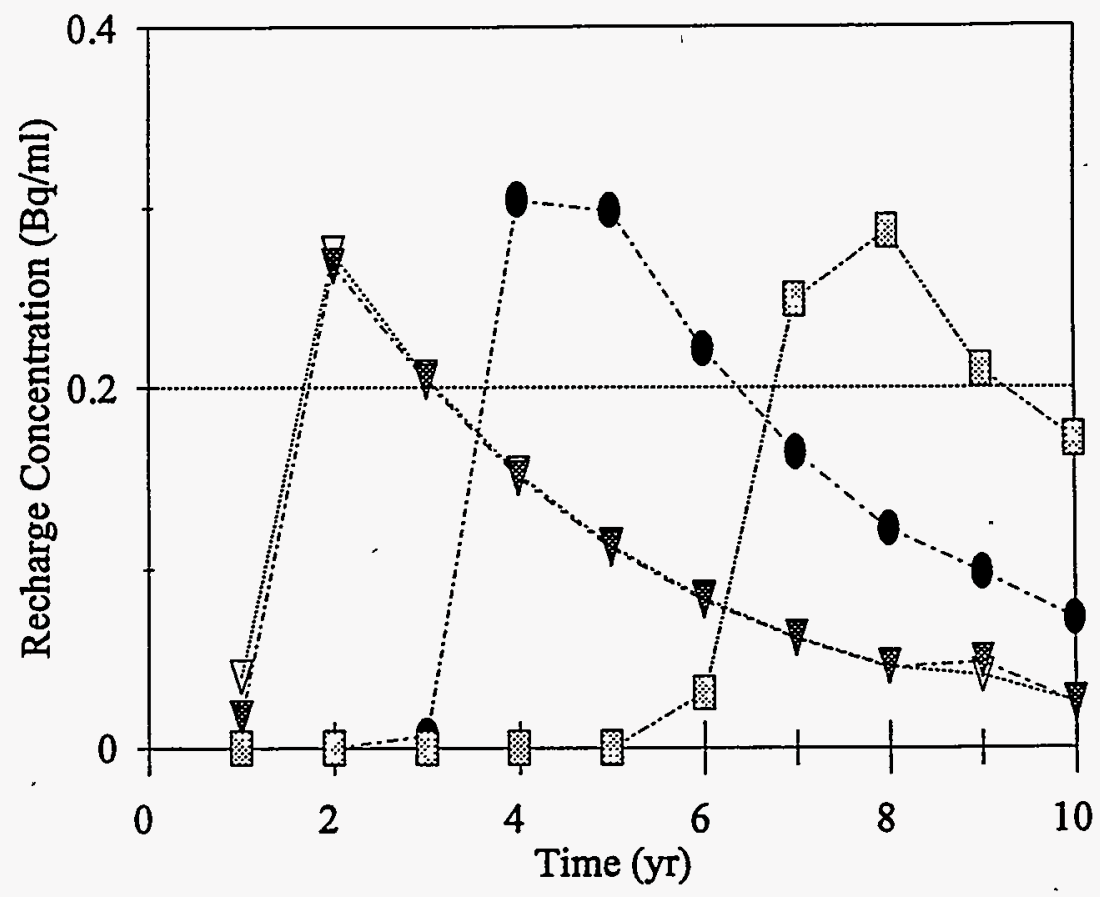

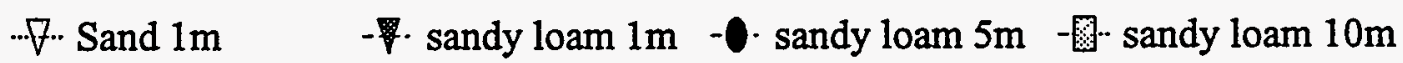

Figure 36 Seasonal flow simulation: maximum recharge concentration functions for the four soil type/thickness zones 
annual period (April). In order to maintain the same amount of mass at the surface and in runoff as the steady-state simulation, the dissolution and runoff coefficients have to be increased.

Plots of the seasonal changes in the water content profile indicate the sandy loam maintains a more uniform hydraulic conductivity field over the annual cycle than the sand. The differences in the seasonal recharge rates for the sand and sandy loam are slight.

The sensitivity of the unsaturated transport model to adsorption is tested using steady flow simulations for the 100 centimeter thick sand and sandy loam models. Figure 36 shows the results of the sensitivity analysis for the sand and sandy loam columns using a distribution coefficient of 1 milliliter per gram. In the previous simulations (steady state and seasonal without decay) the peak recharge concentrations and arrival times are similar $(0.2$ to $0.4 \mathrm{~Bq} / \mathrm{ml}$ and 1 to 2 years) for the one meter long soil columns. As expected, the simulations using equilibrium adsorption are very different. Using a $\mathbf{K}_{\mathbf{d}}$ of 1 milliliter per gram delays the arrival time by ten to fifteen years and reduces the peak recharge concentration by an order of magnitude $(0.04 \mathrm{~Bq} / \mathrm{ml})$. Simulations with higher values of the distribution coefficient (100 to $1000 \mathrm{~g} / \mathrm{ml}$ ), in the range from the literature for cesium (Bunzl et al., 1989; Fruchter et al., 1985; Killey et al., 1990), indicate that the cesium never reaches the groundwater in significant quantities. Since cesium has entered the groundwater system in more than one location (Prister et al., 1991; Buravlev et al., 


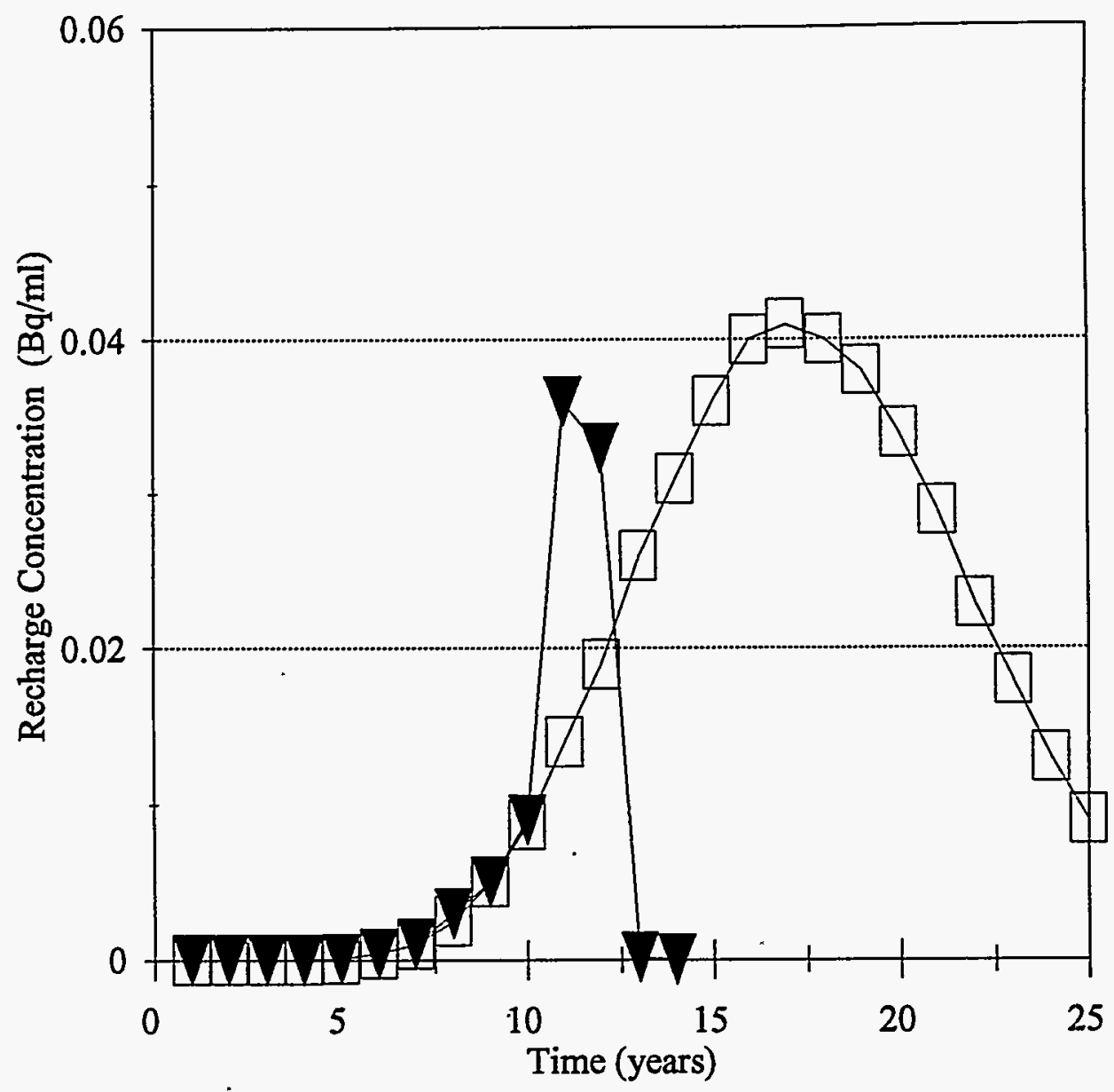

F Sand (1m) $\quad \square$ Sandy Loam (1m)

Figure 36 Simulated cesium recharge concentration (maximum) for 2 soil types with adsorption $\left(\mathrm{k}_{\mathrm{d}}=1 \mathrm{ml} / \mathrm{g}\right)$ 
1992; Lukashev, 1993), either the effects of equilibrium adsorption are not significant or the effects of preferential flow paths or colloidal transport are controlling transport through the unsaturated zone. Although the advectiondispersion model used to simulate unsaturated flow and transport in the CATS model does not simulate the physical processes causing funnel or finger flow, the influence of a small zone of high hydraulic conductivity on the average recharge concentration for a single cell of the groundwater model can be simulated using a single high hydraulic conductivity column. The significance of the high conductivity zone and the percentage of the groundwater model cell covered by higher unsaturated conductivity is estimated by using the recharge weighted concentration for the groundwater model.

Groundwater Model

The seasonal and steady-state unsaturated zone models with the same average annual recharge rate $\left(4.5 \times 10^{-4} \mathrm{~m} / \mathrm{d}\right)$, leaching rate $\left(g_{2}=0.00183 / \mathrm{d}\right)$ and no retardation are used to simulate the time dependent recharge rate and concentration for a hypothetical groundwater flow system. The groundwater model is based on the hydrologic conditions for a typical groundwater flow basin in the CNPP 30 kilometer zone. The hypothetical flow system is given the average hydraulic conductivity and depths to water table reported by Konoplev (1992) and others. The parameter values used in the simulations are listed in tables 4 and 5 . The zonation and model discretization presented in figure 34 are used for the 
groundwater system. A three layer model is used to describe the aquifer with layers 1 and 2 having identical hydraulic properties to the unsaturated zone. Layer 3 is used to simulate the effects of the Kiev marl on the flow system. The effects of the seasonal simulation on the water table elevation and soil column length are used to determine the significance and the importance of an iterative solution to the changing water table elevation on the predicted contaminant distribution.

The steady-state model is used to establish the initial conditions (starting heads) for the seasonal groundwater flow model. No-flow boundaries are used along the west, southeast and east sides of the model area. A specified head boundary is used to simulate a fully penetrating stream condition along the northwest boundary. The seasonal and the steady-state models use the recharge rate predicted by the unsaturated model for the upper, flux boundary.

A comparison of the two flow models' head distributions at the end of one year reveals almost identical flow fields. The only differences between the seasonal and steady-state simulations at the end of one year are slight differences in the heads at the west and east boundaries. The seasonal changes predicted in the water table elevation are shown in figure 38. Thicker unsaturated zones dampen the seasonal fluctuations in the water table elevation. The zones with the thinnest unsaturated zone have the largest fluctuations in the water table $(1 \mathrm{~m}$ sand and $1 \mathrm{~m}$ sandy loam). Since the fluctuations are significant $(>5 \mathrm{~cm})$ an iterative solution to the subsurface flow system is required. 

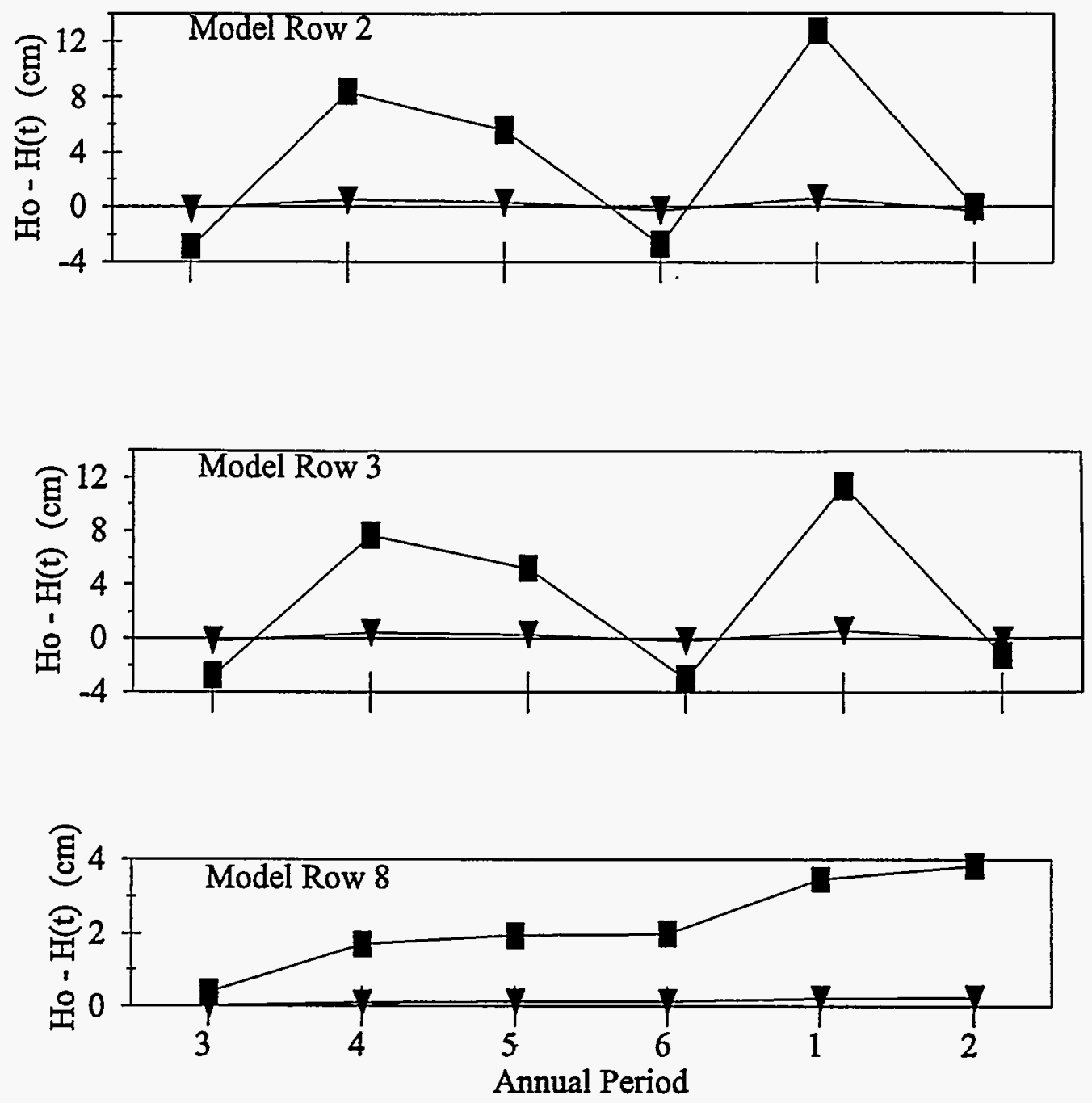

$\neg$ Variable Sy - - Sy $=0.30$

Figure 38 Simulated seasonal water table fluctuations as a function of model assumptions (constant or variable specific yield), soil texture and unsaturated thickness 
water table elevation. The variations in the water table are insignificant if time variant specific yield is used, and the length of the unsaturated column should remain constant throughout the simulation. The error in the simulated water table elevation caused by neglecting the time variant storage coefficient is relatively small because the changes in the water table elevations at the end of each annual cycle compared to the seasonal simulation using a constant specific yield are less than the thickness of the bottom cells of the unsaturated zone model $(5$ to $10 \mathrm{~cm}$ ) (Figure 39).

The concentration of recharge predicted by the unsaturated zone model is used as the upper specified-concentration boundary. In the steady state simulations, the recharge concentration is controlled by the soil type (sand or sandy loam) and the thickness of the unsaturated zone (Figure 35). Using a seasonal simulation reduces the lag time in the sandy-loam columns, spreads out the contaminant pulse in all the columns and produces recharge concentration functions for the one meter long sand and sandy loam columns that are nearly identical (Figure 36). The contaminant pulse is wider in the seasonal simulation than the steady state simulation because the leaching and suspension coefficients are set to 0 during periods when there is no runoff or infiltration. This reduces the amount of contaminant removed from the model area by recharge and retains more mass at the surface.

The groundwater transport model is used to compare the differences in the 


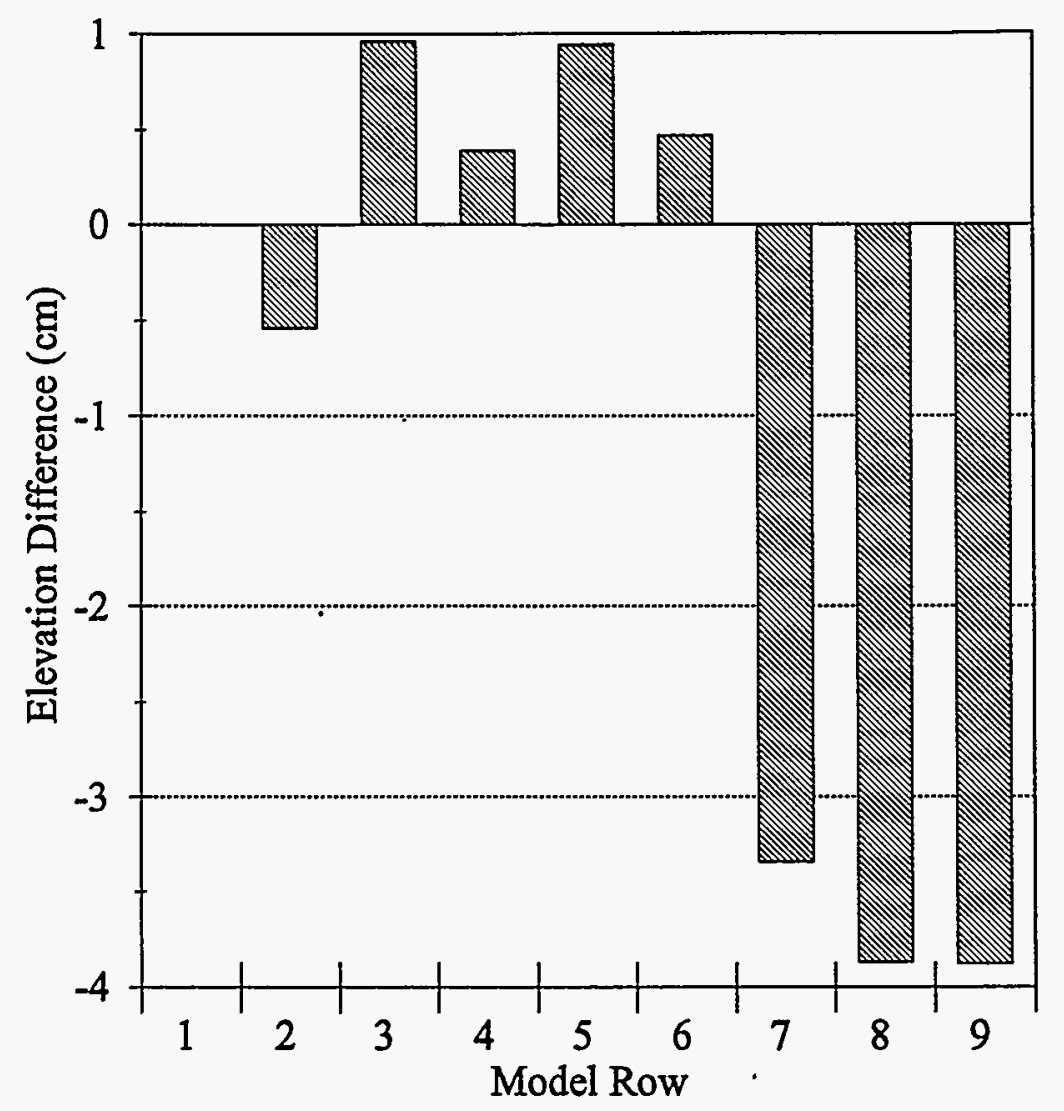

Figure 39 Average differences in the simulated water table elevation (by model row) using constant verses time variant specific yield ( $t=360$ days) in the seasonal simulation of the CNPP site 
groundwater contaminant concentration distribution predicted by the steady state and seasonal simulations. The groundwater no-flow boundaries are zero-flux contaminant boundaries and the specified head boundary serves as a specified-flux transport boundary condition. The initial conditions for the transport model are zero concentration everywhere. The seasonal transport model was run for one year to compare the results of using 30 day time steps to longer, seasonal time steps. There were no significant differences in the two simulations and seasonal time steps are used in all subsequent simulations.

The contaminant concentrations predicted by the seasonal and steady-state models are compared at 1 and 5 years after deposition (Figures 40 and 41 ). At the end of the one year simulation, both models predict that the contaminant will arrive in the groundwater below the zones of maximum contamination and minimum saturated thickness. During the first year, the seasonal model predicts much lower concentration values (approximately $1 / 6$ th lower) than the steady-state model (Figure 40). Concentration magnitudes affect the size of the impacted area. At five years, the seasonal model predicts higher concentrations (approximately 2 times greater) than the steady-state model (Figure 41). These differences are primarily due to the differences in the surface storage and simulated flow through the unsaturated zone.

The steady-state unsaturated model has a higher recharge concentration than the seasonal model for the one meter sand column during the first year (Figures 35 
Stoody Stote

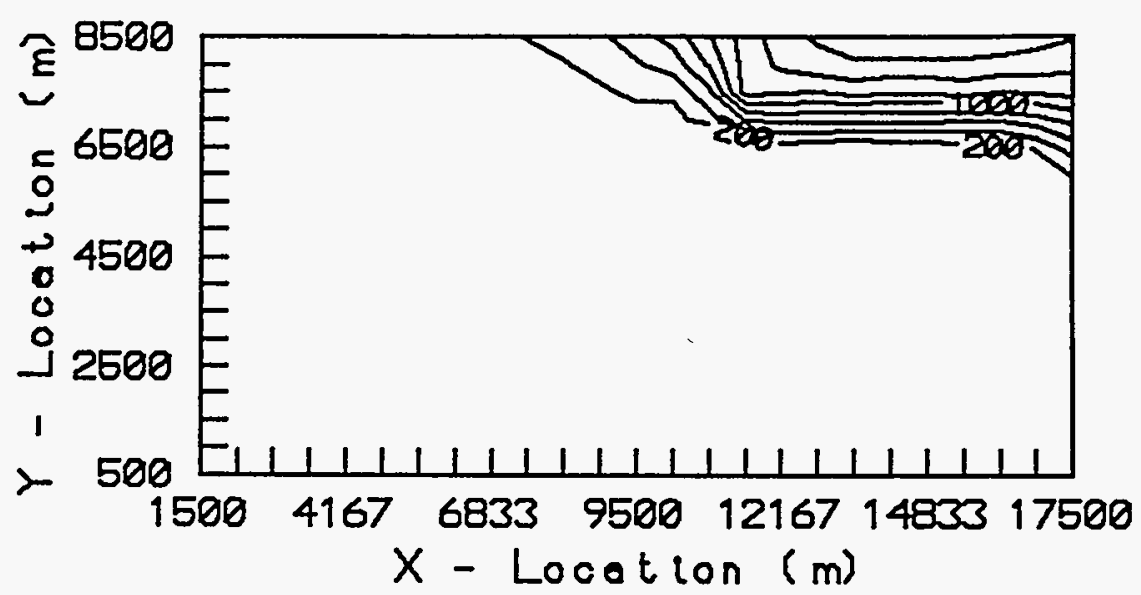

Soosonal Flow

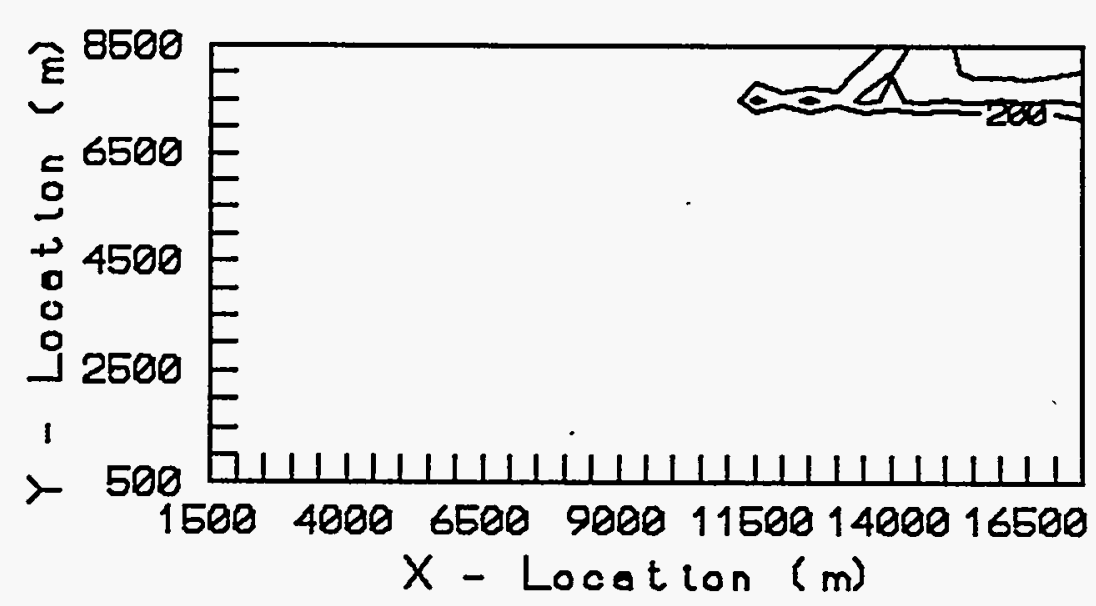

Figure 40 CNPP site simulated groundwater cesium concentrations $\left(\mathrm{Bq} / \mathrm{m}^{3}\right) 1$ year after deposition for steady-state and seasonal flow systems 
Stoody Stote

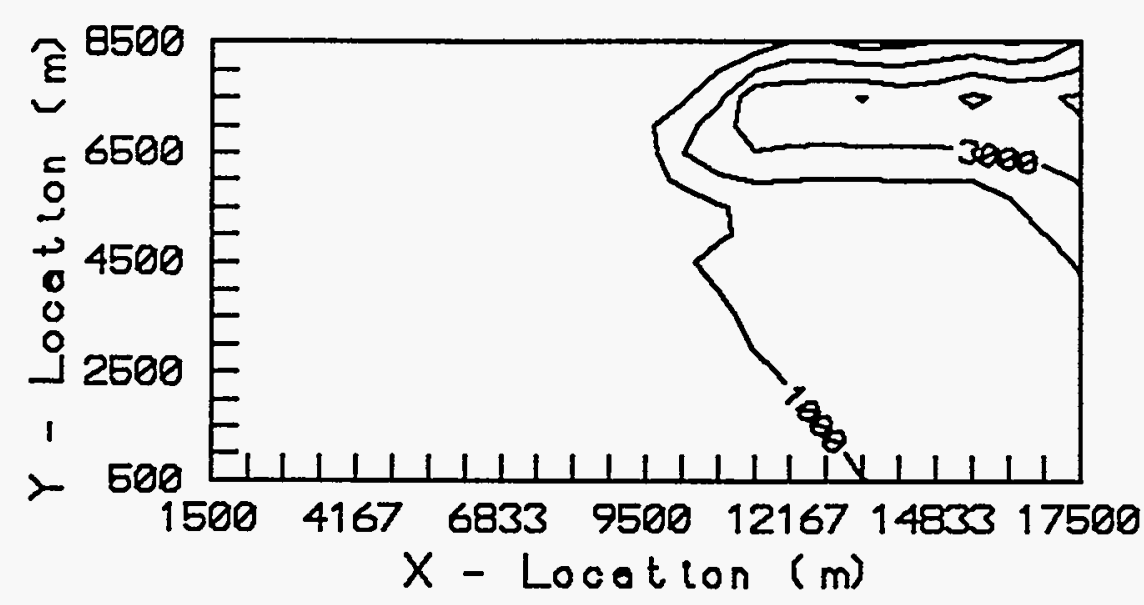

Soasonal Flow

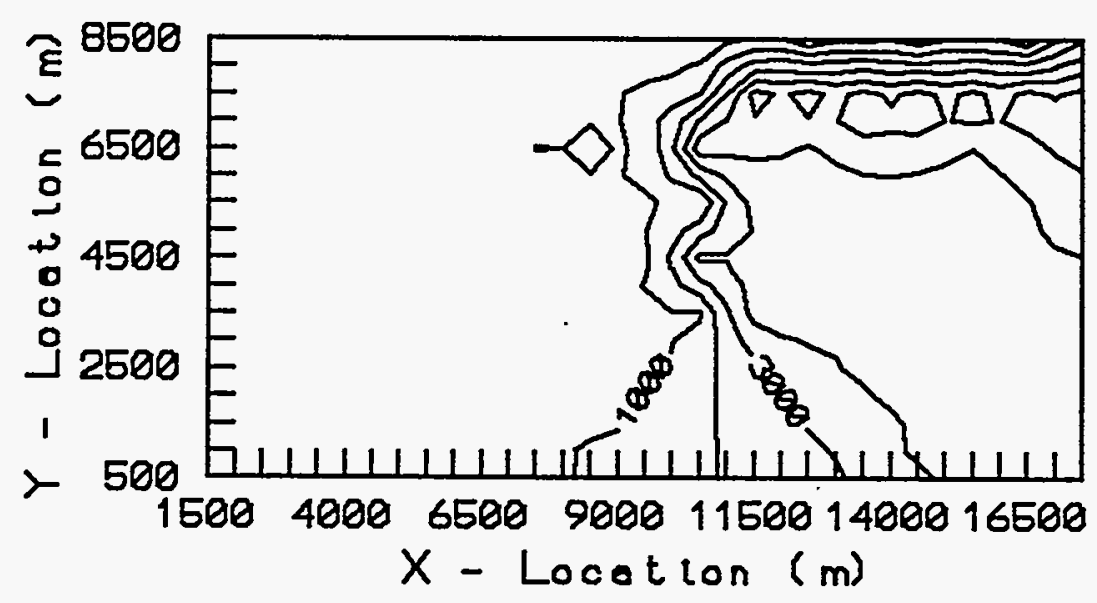

Figure $41 \mathrm{CNPP}$ site simulated groundwater cesium concentrations $\left(\mathrm{Bq} / \mathrm{m}^{3}\right) 5$ years after deposition for steady-state and seasonal flow systems 
and 36). The slightly higher recharge concentration predicted by the seasonal simulation of the one meter sandy loam column during the first year does not result in a significant increase in the groundwater concentration relative to the steady state simulation.

During the second year, the 1 meter thick sand and the sandy loams have the same peak concentration in the seasonal simulation, while only the sand column peaks in the steady state simulation. After the second year of the seasonal simulation, as the recharge concentrations in one zone begin to decline they begin to increase in another. From year 2 to year 9 of the seasonal simulation there is at least one zone within the zone of maximum contamination with a recharge concentration greater than $0.2 \mathrm{~Bq} / \mathrm{ml}(200 \mathrm{~Bq} / \mathrm{L})$. In the steady flow simulations the lag time between peak concentrations is greater and there are years when none of the zones have a recharge concentration greater than $0.2 \mathrm{~Bq} / \mathrm{ml}$ (e.g., years 4,5 , $8,9$ and 10$)$. As a result, the seasonal simulation predicts higher groundwater concentrations over a larger area for a longer period of time than the steady-state simulations.

Since the recharge concentration changes gradually and the peak recharge occurs during the April period of the annual cycle, the recharge concentration for each annual period is assumed to equal the recharge concentration in April. The error caused by this simplifying assumption is small for this site. Figure 42 shows the differences in the recharge concentration functions using the April recharge 


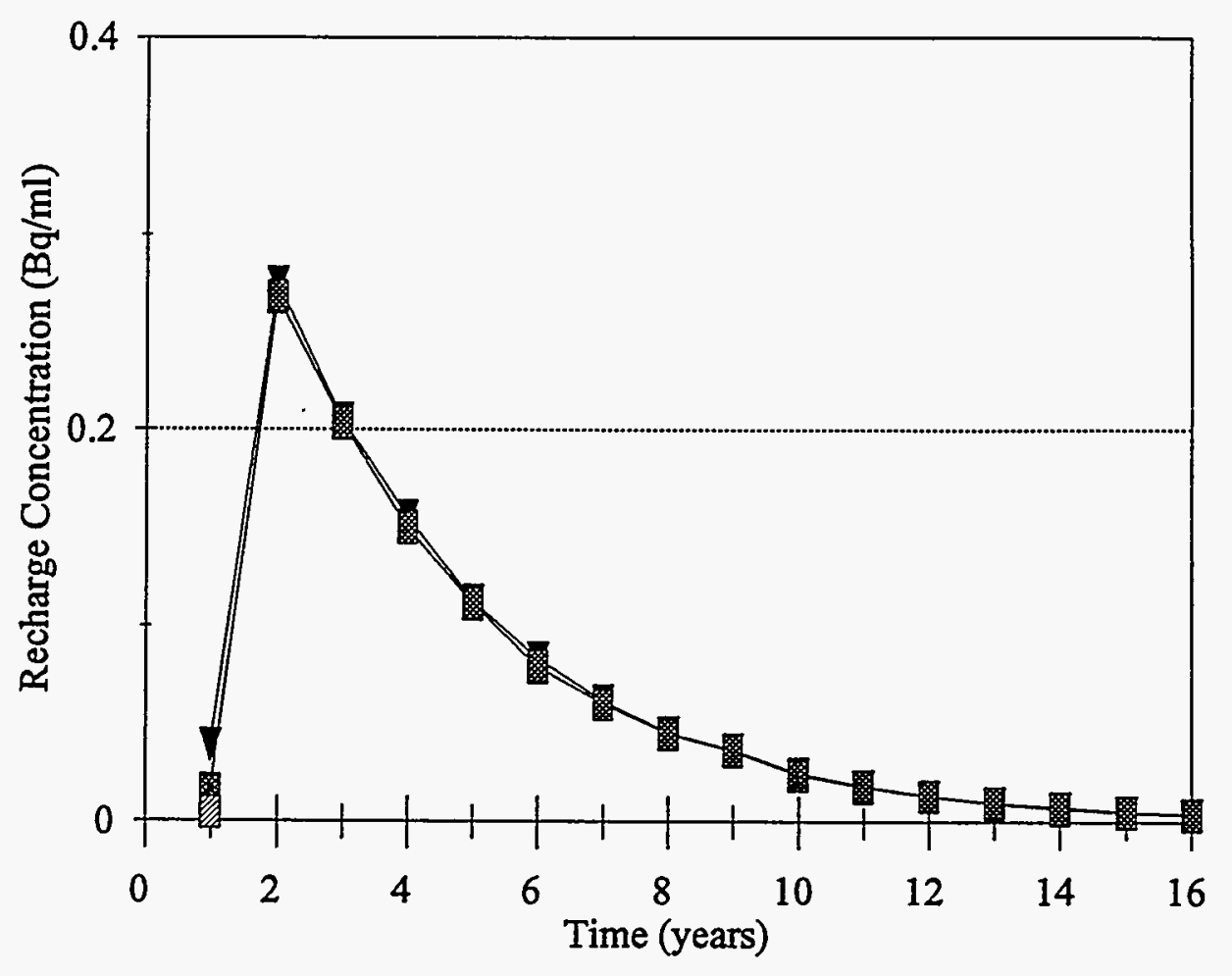

$\begin{array}{ll}-7 \text { sand, April } & \text { sandy loam } \\ -A \text { sand,rech.wt. } & \text { - sandy loam, rech.wt. }\end{array}$

Figure 42 Difference in CNPP site simulated recharge concentration functions using April recharge concentration and recharge weighted concentration for $1 \mathrm{~m}$ sand and sandy loam columns 
concentration and the recharge weighted concentration. The cumulative mass balance error for the CATS model steady-state and seasonal simulations of the CNPP site is around ten percent (Figures 43 and 44). The mass balance error is higher in the CNPP simulation than the Sturgeon Falls simulation because of the nature of the emission (ephemeral verses chronic). In the chronic case, the continual addition of mass to the system reduces the significance of round-off error and mass balance error in the groundwater transport model. The large model cells . for the CNPP site magnify the round-off errors. Even when the number of significant figures for the input files is increased, reducing the round-off error, a significant cumulative mass balance error remains. This is due to the manner in which the MT3D code calculates the mass balance. Cumulative mass balance errors of 5 to 10 percent (of the mass in the groundwater simulation) in simulations using MT3D are common (Zheng, 1992).

Summary

The CATS model simulations of the CNPP release and subsequent transport of radionuclides into the groundwater system illustrate the methods and linkages required to model an ephemeral emission and the sensitivity of the predicted recharge and groundwater concentrations to the model assumptions and parameter values.

The atmospheric transport and deposition model is capable of reproducing 


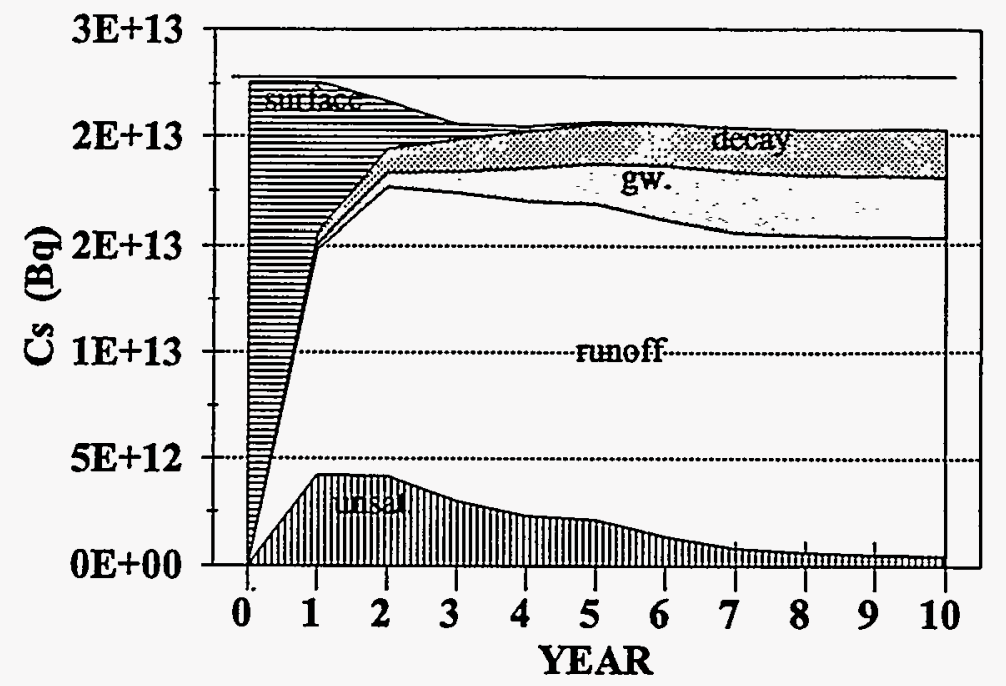

\begin{tabular}{|ll|}
\hline year & $\begin{array}{l}\text { cumulative \% mass } \\
\text { balance error }\end{array}$ \\
1 & 0.1 \\
2 & 4.1 \\
3 & 8.9 \\
4 & 9.5 \\
5 & 8.6 \\
6 & 8.7 \\
7 & 9.8 \\
8 & 10.3 \\
9 & 10.3 \\
10 & 10.2 \\
\hline
\end{tabular}

Figure 43 Cumulative mass distribution and mass balance errors in the CNPP site steady state simulation 


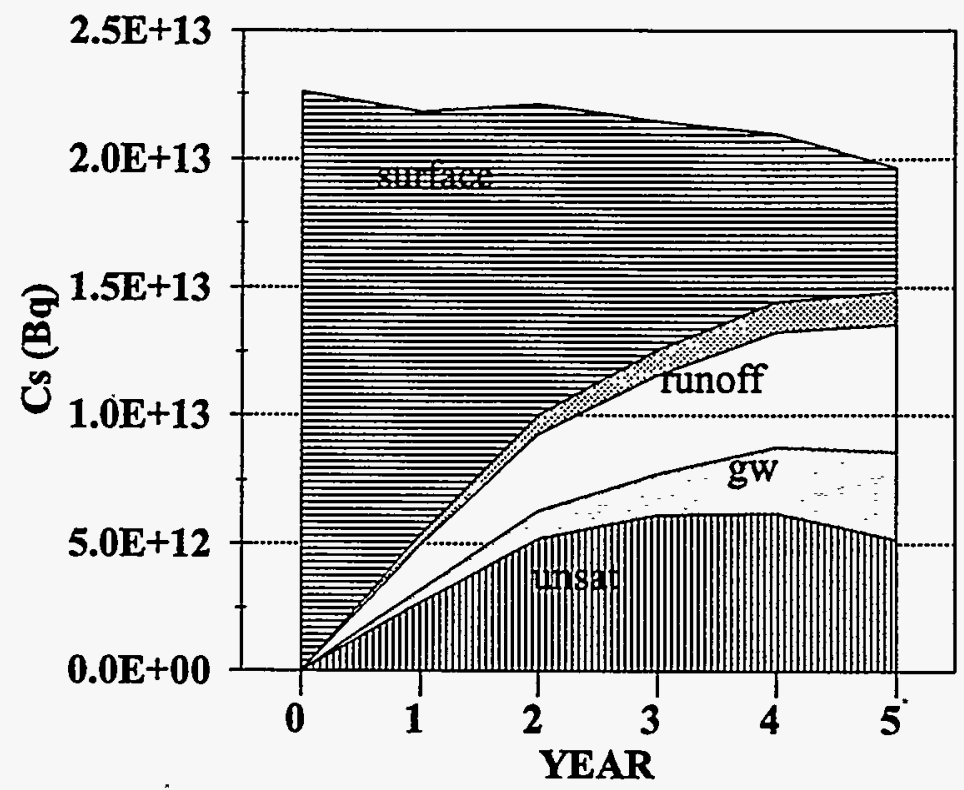

year cumulative \%

mass balance error

\begin{tabular}{|ll|}
\hline 1 & 3.1 \\
2 & 1.2 \\
3 & 2.8 \\
4 & 3.6 \\
5 & 7.9 \\
\hline
\end{tabular}

Figure 44 Cumulative mass distribution and mass balance errors in the CNPP site seasonal simulation 
the general pattern of measured ground-level activities. However, the lack of wind data prevents any conclusions about the appropriateness of the model to this emission. Overall, the CATS model fits the level and type of data available for an ephemeral release.

The use of a lumped parameter model of the ground surface to simulate contaminant storage provides a convenient method of accounting for the mass remaining in the system at the end of each time step and fits the level of data available for this site. However, resolution of the distribution of mass in this zone is lost. Using a time variant suspension coefficient provides a simple method of simulating the burial and movement of the particulate contaminant out of the runoff zone. Similarly, time variant dissolution coefficients can be used to account for the early, rapid dissolution of the more soluble constituents or an increase in dissolution over time as weathering increases the surface area of large fuel particles.

CATS provides a tool to evaluate the significance of seasonal changes in the hydrologic conditions on the distribution and concentration of the contaminant in the groundwater system. The linked unsaturated zone and groundwater flow models produce results that mimic field conditions where the shallow water table zones are the most dynamic because of variable hydraulic conditions and storage in the unsaturated zone (Keen and Pfannkuch, 1992). However, the fluctuations in the water table are minimized if time variant specific yields are used in the groundwater flow simulation. 
The cumulative mass balance for the steady-state and transient simulations shows how the dissolution and suspension coefficients influence where the mass is stored (subsurface, surface or runoff). Less mass is stored at the surface in the steady-state simulation because the dissolution coefficient is a constant over the entire simulation period and mass is continually removed from the surface. The amount of mass stored in runoff is higher for the steady-state simulation than the seasonal simulation because the suspension coefficient is kept at the same value as the steady-state simulation during periods when runoff occurs, but is set to 0 during periods without runoff.

From a groundwater perspective, the single most important variable in the CNPP model, other than the atmospheric source term, is the distribution coefficient. The distribution coefficient is significant partly because of the uncertainty in the parameter value, and mostly due to the control the distribution coefficient has on the transport of the contaminant through the unsaturated zone. In the 30 kilometer zone, surface water has been the primary water supply. The results of the simulations using adsorption indicate that if adsorption is significant, the contaminant is stored near the ground surface, indicating that the long-term threat to the surface water supply could come from erosional processes.

The hydraulic characteristics of the unsaturated zone have significant effects on the predicted magnitude and distribution of the contaminant in the groundwater system. The sensitivity analysis also shows the importance of the time discretization 
of the model and demonstrates that seasonalities in the flow system can cause significant differences in the predicted contaminant concentration and distribution. If there is a source, and infiltration occurs, the one process that can prevent the contaminant from reaching the groundwater at significant concentrations is adsorption. In the absence of adsorption, the unsaturated zone and timing of infiltration, seasonal or steady, control the arrival time, persistence and to some degree the concentration of the contaminant in the groundwater system.

The solute (recharge concentration) and water (recharge) source functions for the saturated system are very different. The recharge function for transient simulations oscillates while the recharge concentration function peaks once and changes more gradually than the recharge function. During periods of gradual change in the infiltration concentration the recharge weighted concentration can be used to simplify the transport simulation (minimizing the input requirements). Seasonal time steps are used to simulate advection, but the source term is an annual step function. 


\subsection{CONCLUSIONS}

The CATS model is a useful tool for evaluating the magnitude and distribution in groundwater of contaminants from chronic or ephemeral atmospheric emissions. The model provides a numerical tool to evaluate the effects of heterogeneities in the subsurface system, variations in the atmospheric flow field or emission rate, and seasonal changes in the system on the distribution of the contaminant in a three-dimensional groundwater system. The CATS model is designed to utilize the level of information normally available or attainable in a field setting. The model linkages are adaptable to many situations and hydrologic settings, allowing the use of time variant partitioning coefficients for precipitation, infiltration and runoff, time variant dissolution and suspension rates, linear and nonlinear equilibrium adsorption, first order decay and transient simulations of the subsurface flow system. The CATS model allows the evaluation of heterogeneities in the porous medium. It is most appropriate for layered heterogeneities due to the assumption of vertical flow in the unsaturated zone. However other spatial variations can be simulated in the groundwater system using changes in the hydraulic characteristics of individual model cells.

The models can be de-coupled at the boundaries, allowing the modeler to simulate multiple soil columns for a single groundwater cell. Then the results of the unsaturated zone models can be averaged over time or space using recharge weighted concentrations to provide the input for the groundwater model. 
Data from two types of atmospheric emissions, ephemeral and chronic, are used to demonstrate how the CATS modeling technique is applied and to test the sensitivity of the model to parameter uncertainty. The seasonal simulations of the CNPP site demonstrate how CATS can be used to simulate transient conditions and changes in the boundary conditions at the water table. For simple flow systems, the manual iterations to a final solution can be performed quickly. However, a more responsive system or one with greater transience will require numerous iterations and the manual iteration system employed in this version of CATS would not be practical.

The sensitivity analysis of the atmospheric and unsaturated zone link in chapters 3 and 4 shows how the storage and distribution of mass at the ground surface controls the distribution of mass in the subsurface. The seasonal simulations of the CNPP site also demonstrates the importance of the time dependant dissolution and suspension rate coefficients. These coefficients control the amount and distribution of mass stored on the ground surface and the timing of the maximum infiltration concentration. The sensitivity the models of the CNPP and the Sudbury emissions indicate that the important parameter values will depend on the site and the model's purpose. The scale of the problem or question to be answered will also determine the influence the model assumptions and parameter values have on the model results.

The number of parameters used in the model and the uncertainty in those 
parameter values indicate that a unique representation of a given system is unlikely. All modeling is an iterative process and the CATS model provides a framework for evaluating what parameters are the most significant, the impact of uncertainty in parameter value on the model results and the type of data that will be the most useful.

Improvements to the model to reduce the number of limitations and simplifying assumptions could include adding a runoff model component, modeling plume depletion due to wet and dry deposition, allowing for resuspension and transport in the atmosphere of contaminant stored at the ground surface, and revising the groundwater flow model to allow time variant storage coefficients during transient simulations. The models used in CATS can be updated as improved flow and transport models are developed (e.g., MOC solution for unsaturated transport (Huang et al., 1994)). Because of the versatility of the linkages developed for CATS, it is a modeling technique that is easily modified to fit the level of information available by substituting more appropriate flow or transport models (e.g., atmospheric trajectory model to estimate the atmospheric concentration for an ephemeral release). Other flow and transport codes can be substituted into the CATS model to fit the site specific hydraulic conditions (e.g., preferential flow and transport models for the unsaturated zone and saturated fracture flow models), but this may require adaptation and changes in the model links. A series of twodimensional unsaturated flow and transport models could be used to evaluate the 
effect of funnel flow on the recharge distribution and concentration. A user's manual and computer code to automate the model linkages are being written and will be published separately. Automating the model linkages will reduce the amount of mass balance error caused by round-off and decrease the input file preparation time. 


\subsection{REFERENCES}

Akan, A.O., 1987. "Pollutant Washoff by Overland Flow," Journal of Environmental Engineering 113(4), p.811-823.

Anderson, M.P., 1987. "Groundwater Degradation," in Resources and World Development, edited by D.J. McLaren and B.J. Skinner, John Wiley and Sons, p.727-740.

Arnold, J.G., P.M. Allen and G. Bernhardt, 1993. "A Comprehensive SurfaceGroundwater Flow Model," Journal of Hydrology, 142, p.47-69.

Barrow, A.E., 1902. "The Sudbury Mining District," Canadian Geological Survey Summary Report Vol. 65A, p. 254-269.

Bear, J., 1972. Dynamics of Fluids in Porous Media, Dover Publications, Inc., New York, p.483-485.

Beardsley, T., 1986. "Letters to Nature: U.S. Analysis Incomplete," Nature, v.321, p.187. 
Beasley, T.M., D. Elmore, P.W. Kubik and P. Sharma, 1992. "Chlorine-36 Releases from the Savannah River Site Nuclear Fuel Reprocessing Facilities," Ground Water 30(4) p.539-548.

Beattie, B.L. and D.M. Whelpdale, 1989. "Meteorological Characteristics of Large Acidic Deposition Events at Kejimkujik, Nova Scotia," Water Air Soil Pollution, vol. 46, p.45-59.

Bobovnikova, TS.I., YE.P. Virchenko, A.V. Konoplev, A.A. Siverina and I.G. Shkuratova, 1991. "Chemical Forms of Occurrence of Long-Lived Radionuclides and Their Alteration in Soils Near the Chernobyl Nuclear Power Station," Soviet Soil Science, 23(5), p.52-57.

Bradbury, K.R., 1991. "Tritium as an Indicator of Ground-Water Age in Central Wisconsin," Ground Water, 29(3), p.398-404.

Briggs, G., 1969. Plume Rise, U.S. Atomic Energy Commission Report \#TID-25075, pp.52.

Briggs, G., 1973. A Scheme for Estimating the Vertical Dispersion of a Plume from a Source Near Ground Level, NOAA-CRL-ARATDC \#79, pp.59. 
Brown, T. J., 1989. "Modeling the effects of aerosols on groundwater systems," unpub. M.A. thesis, Univ. Texas at Austin, Austin, pp.182.

Brown, T.J., and J.M. Sharp, Jr., 1992. "A Model for the Effects of Point-Source Emission of Aerosols on Groundwater Systems," Applied Hydrogeology, 92/93, p.3346.

Bulgakov, A.A., A.V. Konoplev, V.YE. Popov, TS.I. Bobovnikova, A.A. Siverina and I.G. Shkuratova, 1991. "Mechanisms of the Vertical Migration of Long-Lived Radionuclides in Soils Within 30 Kilometers of the Chernobyl Nuclear Power Station," Soviet Soil Science, 23(5), p.46-51.

Bulgakov, A.A., A.V. Konoplev, V.YE. Popov, TS.I. Bobovnikova and A.V. Shchereak, 1991. "Removal of Long-lived Radionuclides From the Soil by Surface Runoff Near the Chernobyl Nuclear Power Station," Soviet Soil Science 23(1), p.124-131.

Bunzl, K, H. Bachhuber and W. Schimmack, 1984. "Distribution Coefficients of ${ }^{137} \mathrm{Cs},{ }^{85} \mathrm{Sr},{ }^{141} \mathrm{Ce},{ }^{103} \mathrm{Ru},{ }^{131} \mathrm{I}$, and ${ }^{95 \mathrm{~m}} \mathrm{Tc}$ in the Various Horizons of Cultivated Soils in Germany," in: Recent Investigations in the Zone of Aeration, P. Udluft, B. Merkel and K.H. Pröst, eds., Druck und Verarbeitung: Copy Shop, Darmstadt, 
Deutschland, p.567-577.

Buravlev, YE.P., M.N. Lebedinskiy, S.S. Drich and V.K. Chumak, 1992. "Migration of Cesium-137 and Cerillium-144 in Soils of the Evacuated Zone Around the Chernobyl Nuclear Power Plant," Soviet Soil Science, 23(9), p.121-125.

Cabral, M.C., L. Garrote, R.L. Bras and D. Entekhabi, 1992. "A Kinematic Model of Infiltration and Runoff Generation in Layered and Sloped Soils," Advances in Water Resources 15(1992), p.311-324.

Carsel, R.F. and R.S. Parish, 1988. "Developing Joint Probability Distributions of Soil Water Retention Characteristics," Water Resources Research, 24(5). p.755-769. Chan, W.H., R.J. Vet, C.U. Ro, A.J.S. Tang, and M.A. Lusis, 1984. "Long Term Precipitation Quality and Wet Deposition Fields in the Sudbury Basin," Atmospheric Environment, v.18, p.1175-1188.

Cichowicz, N.L., 1979. Development and Application of a Linked unsaturatedSaturated Flow Model, Unpublished Master's Thesis, University of Wisconsin, Madison, p.98.

Clark, M.J. and F.B. Smith, 1988. "Letters to Nature: Wet and Dry Deposition of 
Chernobyl Releases," Nature, v.332, p.245.

Comans, R.N.J., T.J. Middelburg, J. Zonderhuis, J.R.W. Woittiez, G.J. DeLange, H.A. Das and C.H. Van Der Wejden, 1989. "Letters to Nature: Mobilization of Radiocaesium in Pore Water of Lake Sediments," Nature, v.339, p.367-369.

Crutcher, A.J. and J.F. Sykes, 1977. "Modelling Sanitary Landfill Leachates Using a Chemical Mass Balance Technique," EOS, 58(43), p.386.

Culkowski, W. and M. Patterson, 1976. A Comprehensive Atmospheric Transport and Diffusion Model, ORNL-EATC-17, pp.45.

Culliford, C.J., editor, 1982. "Updated 50th Anniversary edition of the Falcon" Falcon, pp.23.

Derwent, R.G., O. Hov, W.A.G. Asman, J.A. van Jaarsveld and F.A.A.M. de Leeuw, 1989. "An Intercomparison of Long-Term Atmospheric Transport Models: The Budgets of Acidifying Species for The Netherlands," Atmospheric Environment, 23 (9), p.1893-1909.

Dethier, D.P., 1979. "Atmospheric Contributions to Stream Water Chemistry in the 
North Cascade Range, Washington," Water Resources Research 15, p.787-794.

Dillon, P.J., 1984. "The Use of Mass Balances and Mass Balance Models for Quantification of the Effects of Anthropogenic Activities on Lakes Near Sudbury, Ontario," in: The Environmental Impact of Smelters, J. Nriagu, ed., Wiley Series in Advances in Environmental Science and Technology v. 15, J. Wiley and Sons, NY, Chapter 8, p.283-347.

Dillon, P.J., R.A. Reid and R. Girard, 1986. "Changes in the Chemistry of Lakes Near Sudbury, Ontario Following Reductions of Sulphur Dioxide Emissions," Water. Air and Soil Pollution 31, p.59-65.

Draaijers, G.P.J. and J.W. Erisman, 1993. "Atmospheric Sulphur Deposition to Forest Stands and Throughfall Estimates Compared to Estimates From Inference," Atmospheric Environment 27A(1), p.43-55.

Egboka, B.C.E., J.A. Cherry, J.A. Farvolden and E.O. Frind, 1983. "Migration of Contaminants in Groundwater at a Landfill: A Case Study, 3. Tritium as an Indicator of Dispersion and Recharge," Journal of Hydrology, vol. 63, p.51-80.

Ellis, H., P. Liu and C. Runyon, 1980. "Comparison of Predicted Concentrations for 
58 Alternative Models of Plume Transport in Complex Terrain," J. Air Pollution Control Assoc. 30(6), p.670-675.

Elzy, E., T. Lindstrom, L. Boersma, R. Sweet and P. Wicks, 1974. Analysis of the Movement of Hazardous Waste Chemicals in and from a Landfill Site via a Simple Vertical-Horizontal Routing Model, Special Report 414, Oregon State University, Corvallis, pp.109.

Environment Canada, 1982. Canadian Climate Normals Vol. 5, Wind 1951-1980, Atmospheric Environment Service, Canadian Climate Program, p.74-80.

Environment Canada, 1982. Canadian Climate Normals Vol. 3, Precipitation 19511980, Atmospheric Environment Service, Canadian Climate Program, p.29-295.

Erisman, J.W., F.A.A.M. de Leeuw and R.M. van Aalst, 1989. "Deposition of the Most Important Acidifying Components in The Netherlands in 1980-1986," Atmospheric Environment 23, p.1051-1062.

Falconbridge Nickel Company, 1959. "History of the Falconbridge Nickel Company," Canadian Mining Journal, 80(6), p.188-198. 
Freeze, R.A., 1971. "Three-Dimensional, Transient, Saturated-Unsaturated Flow in a Groundwater Basin," Water Resources Research, 7(2), 347-366.

Fisher, B.E.A., 1978. "Calculation of Long Term Sulphur Deposition in Europe," Atmospheric Environment 23(1-3), p.489-502.

Fowler, D., 1978. " Dry Deposition of $\mathrm{SO}_{2}$ on Agricultural Crops," Atmospheric Environment 12(1-3), p. 369-374.

Frind, E.O. and M.J. Verge, 1978. "Three-Dimensional Modeling of Groundwater Flow Systems," Water Resources Research, 14(5), p.844-856.

Fruchter, L.S., C.E. Cowan, D.E. Robertson, D.C. Girvin, A. Jenne, A. Toster, K. Abel, 1985. Radionuclide Migration in Groundwater Pacific Northwest Laboratory, NUREG/CR 4030,PNL 5299.

Fuhs, G.W., R. Olsen and A. Bucciffero, 1983. "Alkalinity and Trace Metal Content of Drinking Water in Areas of New York State Susceptible to Acid Deposition," in: Acid Deposition, D. Adams and W. Page, editors, Plenum Press, New York, NY.

Galloway, J.N. and G.E. Likens, 1979. "Atmospheric Enhancement of Metal Deposition in Adirondack Lake Sediments," Limonol. Oceanography 24, p.427-433. 
Garland, J.A., 1978. "Dry and Wet Removal of Sulphur From the Atmosphere," Atmospheric Environment 12(1-3), p.349-362.

Gass, T.E., 1991. "Ground Water in the News," Ground Water 29(3), p.470.

Gifford, F.A., 1960a. " Atmospheric Dispersion Calculations Using the Generalized Gaussian Plume," Nuclear Safety 2(2), p.56-59.

Gifford, F.A., 1960b. "Use of Routine Meteorological Observations for Estimating Atmospheric Dispersion," Nuclear Safety 2(4), 47-51.

Gilding, B.H., 1983. "The Soil-Moisture Zone in a Physically-Based Hydrologic Model," Advances in Water Resources 6, p.36-43.

Haith, D.A., 1966. "A Mathematical Model for Estimating Pesticide Losses in Runoff," Journal of Environmental Quality, 9, p.428-433.

Hanna, S.R., 1982. A Review of Atmospheric Dispersion Models for Regulatory Applications, World Meteorological Organization, Technical Note 177, Geneva, Switzerland, pp.37. 
Hanna, S.R., G.A. Briggs and R.P. Hosker, Jr., 1982. Handbook on Atmospheric Diffusion, United States Department of Energy, DOE/TIC-11223, pp. 98.

Heim, G.E. and P. Giuliana, 1988. "Chernobyl Provides Lessons Regarding Groundwater Contamination," in: Recent Advances in Ground-Water Hydrology, J.E. Moore, A.A. Zaporozec, S.C. Csallany and T.C. Varney, eds., American Institute of Hydrology, Minneapolis, p. 195-202.

Hendrey, G.R., 1983. Acid Deposition: a National Problem," in: Acid Deposition, D. Adams and W. Page, ed.s, Plenum Press, New York, NY, p.1-15.

Hicks, B.B., 1986. "Measuring Dry Deposition," Water Air Soil Pollution 30, p.7590.

Holzworth, G., 1972. Mixing Heights. Wind Speeds and Potential for Urban Air Pollution Throughout the Contiguous U.S., U.S. EPA Office of Air Programs Report AP-101, Research Triangle Park, NC, pp. 118.

Horst, T., 1977. "Surface Depletion Model for Deposition from a Gaussian Plume," Atmospheric Environment 11, p. 41-46. 
Hosker, R.P.,Jr., 1974. "Estimates of Dry Deposition and Plume Depletion over Forests and Grassland," in Physical Behavior of Radioactive Contaminants in the Atmosphere, IAEA, Vienna, p. 292-307.

Howes, J.E., Jr., D.F. Kohler, F.L. DeRoos, R.M. Riggin, R.L. Barbour and R.L. Bennett, 1987. "Characterization of Stack Emissions from Municipal Refuse-toEnergy Systems," EPA Project Summary, U.S. Environmental Protection Agency, Atmospheric Sciences Research Laboratory, Research Triangle Park, NC, EPA/600/S3-86/055, pp.4.

Hutton, M. and A. Wadge, 1987. "The Emissions of Cadmium and Lead from a Large Refuse Incinerator and Their Local Environmental Impact," in: International Conference on Heavy Metals in the Atmosphere, vol. II part 1, T.C. Hutchinson and A.L. Page, ed.s, Toronto, Canada, p.294-296.

Ilyin, L.A. and O.A. Pavlovskij, 1987. "Radiological Consequences of the Chernobyl Accident in the Soviet Union and Measures Taken to Mitigate Their Impact," IAEA Bulletin 29(4), p.17-24.

International Atomic Energy Assoc., 1986. Summary Report on the Post-Accident Review Meeting on the Chernobyl Accident, IAEA Safety Series \#75-INSAG-1, 
pp.106.

International Atomic Energy Assoc., 1991. Distribution of Surface Ground

Contamination by Caesium-137 Released in the Chernobyl Accident and Deposited in the Byelorussian SSR, the Russian SFSR and the Ukrainian SSR (December 1989), Map, IAEA, Vienna.

International Atomic Energy Assoc., 1991. Distribution of Surface Ground Contamination by Plutonium-239 and Plutonium-240 Released in the Chernobyl Accident and Deposited in the Byelorussian SSR, the Russian SFSR and the Ukrainian SSR (December 1989), Map, IAEA, Vienna.

International Atomic Energy Assoc., 1991. Distribution of Surface Ground Contamination by Strontium-90 Released in the Chernobyl Accident and Deposited in the Byelorussian SSR, the Russian SFSR and the Ukrainian SSR (December 1989), Map, IAEA, Vienna.

International Nickel Company, 1946. "History of the International Nickel Company of Canada, Limited," Canadian Mining Journal, 67(5), p.318-551.

Jeffries, D.S., 1984. "Atmospheric Deposition of Pollutants in the Sudbury Area," 
in: The Environmental Impact of Smelters, J. Nriagu, ed., Wiley Series in Advances in Environmental Science and Technology v. 15, J. Wiley and Sons, NY, Chapter 4, p.117-154.

Johnson, D.W. and Lindberg, S.E., 1992. Atmospheric Deposition and Forest Nutrient Cycling, Springer-Verlag, New York, Ecological Studies v.91, pp.707.

Jones, R.L., A.G. Hornsby, P.S.C. Rao and M.P. Anderson, 1987. "Movement and Degradation of Aldicarb Residues in the Saturated Zone Under Citrus Groves on the Florida Ridge," Journal of Contaminant Hydrology 1, p.265-285.

Jury, W.A., 1982. "Simulation of Solute Transport Using a Transfer Function" . Model," Water Resources Research 18(2), 363-368.

Kandil, H., C.T: Miller and R.W. Skaggs, 1992. "Modeling Long-Term Solute Transport in Drained Unsaturated Zones," Water Resources Research 28(10), p.2799-2809.

Kaufman, S. and W.F. Libby, 1954. "The Natural Distribution of Tritium," Physics Review, 93, p.1337-1344. 
Keen, K.L. and H.O. Pfannkuch, 1992. "Water-Table Fluctuations and Variable Storativity: Linking the Unsaturated and Saturated Zones," Eos 73(43), p.199.

Killey, R., D. Champ, H. Nakamura and Y. Sakamoto, 1990. " The Glass Block Site Radionuclide Migration Study - Database Review and Current Studies," in:

Proceedings of the International Conference and Workshop on Transport and Mass Exchange Processes in Sand and Gravel Chalk River Aquifers: Field and Modeling Studies, vol. 2, G. Moltyaner, ed., AECL-10308, Ottawa, Canada, p.850-866.

Kirk, W.S., 1991. Nickel, 1990 Annual Report, U.S. Department of the Interior, Bureau of Mines, pp.10.

Konikow, L.F. and J. Bredehoeft, 1978. Computer Model of Two Dimensional Solute Transport and Dispersion in Groundwater, U.S.G.S. WRI Book 7 Chapter C2.

Konoplev, A.V., 1992. Personal Communication with T. Brown, general climatic, hydrologic and precipitation data for the Chernobyl region, unpublished, written communication August, 1992.

Kool, J.B. and M.Th. van Genuchten, 1991. HYDRUS: One-Dimensional Variably 
Saturated Flow and Transport Model, Including Hysteresis and Root Water Uptake, Version 3.31, U.S. Salinity Laboratory, Riverside, CA, p.72.

Krishnamurthi, N., D.K. Sunada and R.A. Longenbaugh, 1977. "Mathematical Modeling of Natural Groundwater Recharge," Water Resources Research, 13(4). p.720-724.

Kruglov, S.V., R.M. Aleksakhin, N.A. Yasil'yeva, A.D. Kurinov and A.N. Ratnikov, 1991. "Evolution of the Radionuclide Composition of Soils Near the Chernobyl Nuclear Power Station," Soviet Soil Science, 23(5), p.58-66. (Translated from: Pochvovedeniye, 1990, \#10, p.26-34)

Kuck, P.H., 1992. Nickel, 1991 Annual Report, U.S. Department of the Interior, Bureau of Mines, pp.23.

Lappala, E.G., R.W. Healy and E.P. Weeks, 1987. Documentation of Computer Program VS2D To Solve the Equations of Fluid Flow in Variably Saturated Porous Media, USGS Water-Resources Investigation Report 83-4099, p.184.

Li, Y.-H. and S. Gregory, 1974. "Diffusion of Ions in Sea Water and Deep Sea Sediments," Geochimica Cosmochimica Acta, 138, p.703-714. 
Lindfors, V., S.M. Joffre and J. Damski, 1993. "Meteorological Variability of the Wet and Dry Deposition of Sulphur and Nitrogen Compounds Over the Baltic Sea," Water, Air and Soil Pollution 66, p.1-28.

Lohman, S.W., 1972. Ground-Water Hydraulics, U.S. Geological Survey Professional Paper, 708, pp.70.

Lukashev, V.K., 1993. "Some Geochemical and Environmental Aspects of the Chernobyl Nuclear Accident," Applied Geochemistry, v.8, p.418-436.

Lusis, M.A., A.J.S. Tang, W.H. Chan, D. Yap, J. Kurtz, P.K. Misra and G. Ellenton, 1986. "Sudbury Smelter Impact on Atmospheric Deposition of Acidic Substances in Ontario," Water, Air and Soil Pollution 30, p.897-908.

Malhotra, S.C., 1973. Bibliography on Copper Smelting, Insight Printing and Graphics, Salt Lake City, UT, pp.271.

Matt, D.R. and T.P. Meyers, 1993. "On the Use of the Inferential Technique to Estimate Dry Deposition of Sulphur Dioxide," Atmospheric Environment 27A(4), p.493-501. 
Maurice, S.C. and P.J. Mizzi, 1984. "An Analysis of Market Structure: The Nickel Industry," Ontario Bureau of Mines Background Paper, p.60-200.

McDonald, M.G. and A.W. Harbaugh, 1988. A Modular Three-Dimensional FiniteDifference Groundwater Flow Model, USGS Techniques of Water-Resources Investigations, Book 6, Cp. A1.

McMillen, R.T., 1990. Estimating the Spatial Variability of Trace Gas Deposition Velocities, NOAA Technical Memorandum ERL ARL-181, p.37.

Mercado, A., 1989. "Assessment of Groundwater Contamination Resulting form a Major Accident in Land Nuclear Power Plants (LNPP), I: Concepts and Methodology," Journal of Contaminant Hydrology, 5, p.33-41.

Morenco, A. and J. Fontan, 1976. "Influence of Dry Deposition on the Residence Time of Particulate Pollutants in the Troposphere," in: Proceedings AtmosphereSurface Exchange of Particulate and Gaseous Pollutants, 1974 Symposium, Richland WA, Energy Research and Development Symposium Series, p.54-61.

Mualem, Y., 1976. "A New Model For Predicting the Hydraulic Conductivity of Unsaturated Porous Media," Water Resources Research, v.12, p.513-522. 
Narasimhan, T.N. and P.A. Witherspoon, 1977. "Numerical Model for SaturatedUnsaturated Flow in Deformable Porous Media," Water Resources Research, 13(3), p.657-664.

Nielson, D.M., G.L. Yeates and C.M Ferry, 1983. "The Effects of Acid Precipitation on Groundwater Quality," in: Acid Deposition, D. Adams and W. Page, ed.s, Plenum Press, p.125-142.

Nielson, G.L. and J.M. Widjaya, 1989. "Modeling of Ground-Water Recharge in Southern Bali, Indonesia," Ground Water, 27(4), p.473-480.

Oakes, D.B., 1977. "Use of Idealized Models in Predicting the Pollution of Water Supplies Due to Leachate From Landfill Sites," in: Groundwater Quality Measurement, Prediction and Protection Papers and Proceedings, Water Resources Center Conference, Berkshire England, p.611-624.

Ontario Canada Task Force, 1982. Report of the Ontario/Canada Task Force for the Development and Evaluation of Air Pollution Abatement Options for Inco Ltd. and Falconbridge Mines Ltd., in the Regional Municipality of Sudbury, Ontario, Intergovernmental Task Force Report, Toronto, Ontario, pp.255.

Ontario Ministry of the Environment, 1986. unpublished atmospheric emission data 
Pasquill, F. and F.B. Smith, 1983. Atmospheric Diffusion, Ellis Horwood Series in Environmental Science, Chichester, pp.437.

Payne, B.R., 1972. "Isotope Hydrology," Advances in Hydroscience, 8, p.95-138.

Pikul, M.F., R.L. Street and I. Remson, 1974. "A Numerical Model Based on Coupled One-Dimensional Richards and Boussinesq Equations," Water Resources Research, 10(2), p.295-302.

Pope, A.A., 1990. Toxic Air Emission Factors, U.S. EPA report 4050/2-90-046.

Prister, B.S., N.P. Omel'yanenko and L.V. Perepelyatnikova, 1991. "Migration of Radionuclides in Soil and Their Transfer to Plants Within the Zone of Chernobyl Nuclear Power Plant Accident," Soviet Soil Science 23(2), p.76-86.

Purkey, D.R. and W.W. Wallender, 1993. "Linking Saturated and Unsaturated Modelling Domains for Regional Scale Hydrologic Investigations: The Importance of Simplifying Assumptions in Model Structure," EOS 74(43), p.303.

Pye, V.I., R. Patrick and J. Quarles, 1983. Groundwater Contamination in the United States, University of Pennsylvanịa Press, pp.513. 
Raridon, R.J. and A.W. Andren, 1975. "Computer Simulation of Trace Metal Transport," Symposium Proceedings: International Conference on Heavy Metals in the Environment, Volume II Part 1, Toronto, Canada Oct.27-31, T.C. Hutchinson and A.L. Page ed.s, p.321-330.

Raunemaa, T. et al., 1987. " 2-10 $\mu \mathrm{m}$ Sized Hot Particles in Chernobyl Fallout to Finland," J. Aerosol Science, 18(6), p. 693-696.

Rawls, W.J., and D.L. Brakensiek, 1982. "Estimating Soil Water Retention from Soil Properties," Journal of the Irrigation and Drainage Division, v. 108(IR2), US Department of Agriculture, p.166-171.

Raynal, D.J., F.S. Raleigh and A.Y. Mollitor, 1983. "Atmospheric Deposition and Ionic Movement in Adirondack Forests," in: Acid Deposition, D. Adams and W. Page, ed.s, Plenum Press.

Rich, V., 1986. "News: Chernobyl, Now for the Long Haul," Nature, v.371., p.641.

Robertson, W.D. and J.A. Cherry, 1989. "Tritium as an Indicator of Recharge and Dispersion in a Groundwater System in Central Ontario," Water Resources Research 25(6), p.1097-1109. 
Robertson, W.D., J.A. Cherry and S.L. Schiff, 1989. "Atmospheric Sulfur Deposition 1950-1985 Inferred from Sulfate in Groundwater," Water Resources Research 25(6), p.1111-1123.

Royal Ontario Nickel Commission, 1917. Nickel Report, Wm. Biggs, Toronto, pp.584.

Scheider, W.A., 1984. "Lake Water Budgets in Areas Affected by Smelting Practices Near Sudbury, Ontario," in: The Environmental Impact of Smelters, J. Nriagu, ed., Wiley Series in Advances in Environmental Science and Technology v. 15, J. Wiley and Sons, NY, Chapter 57, p.155-194.

Schleyer, R. and Milde, G., 1990. "Well-head protection areas for preserving natural drinking water quality - experiences and new developments in the Federal Republic of Germany:" in International Association of Hydrogeologists, Selected Papers from the 28th International Geological Congress (Simpson, E. S. and Sharp, J. M., Jr., editors), Heise, Hannover, p.379-392.

Sehmel, G.A., 1980. "Particle and Gas Dry Deposition: A Review," Atmospheric Environment 14, p.983-1011. 
Sheih, C.M., M.L. Wesely and C.J. Walcek, 1986. "A Dry Deposition Module for Regional Acid Deposition," U.S. EPA Project Summary EPA/600/S3-86/037, pp.4.

Sirois, A. and P. Summer, 1989. "An Estimation of Atmospheric Deposition Input of Sulphur and Nitrogen Oxides to the Kejimkujik Watershed 1979-1987," Water Air Soil Pollution, vol. 46, p.29-43.

Sjoreen, A.L., D.C.Kocher, G.G. Killough and C.W. Miller, 1984. MFSOIL and DFSOIL - Computer Codes to Estimate Effective Ground Surface Concentration for Dose Computations, Oak Ridge National Laboratory, ORNL-5974, p.9-11.

Slade, D.H., 1965. "Dispersion Estimates from Pollutant Releases of a Few Seconds to Eight Hours Duration," unpublished U.S. Weather Bureau report, August 1965.

Smith, F.B., 1973. "A Scheme for Estimating the Vertical Dispersion of a Plume for a Source Near Ground Level," in Proceedings of the Third Meeting of the Panel on Air Pollution Modeling Oct. 2-3, 1972, U.S. EPA Proceedings \#14.

Smith, F.B. and R.D. Hunt, 1978. "Meteorological Aspects of the Transport of Pollution Over Long Distances," Atmospheric Environment 12(1-3), p.461-478. 
Solomon, D.K., S.L. Schiff, R.J. Poreda and W.B. Clarke, 1993. "A Validation of the ${ }^{3} \mathrm{H} /{ }^{3} \mathrm{He}$ Method for Determining Groundwater Recharge," Water Resources Research, 29(9), p.2951-2962.

Sorbo, N.W., G. Tchobanoglous and J.D. Lucero, 1986. "Fate of Selected Metals and Emissions from a Sludge/Wastepaper Gasifier," EPA Project Summary, U.S. Environmental Protection Agency, Water Engineering Laboratory, Cincinnati OH EPA/600/S2-85/135, pp.5.

Steenhuis, T.S. and M.R. Walter, 1980. "Closed Form Solution for Pesticide Loss in Runoff Water," Transactions ASAE, 23, p.615-620.

Stoertz, M.W., M.P. Anderson and K.R. Bradbury, 1991. Field Investigations and Numerical Studies of Groundwater Recharge Through Unsaturated Sand: A Methodology Applied to Central Wisconsin, Wisconsin Geological and Natural History Survey Information Circular 71, pp.52.

Surkova, L.V. and R.I. Pogodin, 1992. "Status and Forms of Occurrence of Cesium137 in Soils as a Function of Distance from the Chernobyl Nuclear Power Plant," Soviet Soil Science 23(10), p.100-103. (Translated from: Agrokhimiya, 1991, \#4, 8486) 
Tikhomirov, F.A., A.I. Shcheglov, O.B. Tsvetnova and A.L. Klyashtorin, 1991.

"Geochemical Migration of Radionuclides in Forest Ecosystems Within the Radioactive Contamination Zone of the Chernobyl Nuclear Power Plant," Soviet Soil Science 23(2), p.66-75. (Translated from: Pochvovedenive, 1990, \#10, p.41-50)

Trenholm, A., T. Lapp, G. Scheil, J. Cootes, S. Klamm and C. Cassady, 1987. "Total Mass Emissions from a Hazardous Waste Incinerator," EPA Project Summary, U.S. Environmental Protection Agency, Hazardous Waste Engineering Laboratory, Cincinnati OH EPA/600/S2-87/064, pp.7.

Troutman, D.E. and N.E. Peters, 1982. "Deposition and Transport of Heavy Metals in Three Lake Basins Affected by Acid Precipitation in the Adirondack Mountains, New York," in: Energy and Environmental Chemistry v.2 Acid Rain, L. Keith, ed., Ann Arbor Science Publ., p.33-61.

Trouwborst, T., 1981. "Groundwater Pollution by Volatile Halogenated Hydrocarbons; Sources of Pollution and Methods to Estimate Their Relevance," in: Quality of Groundwater, Studies in Environmental Science: Volume 17, Elsevier Scientific Publishing Co., The Netherlands, W. van Duijvenbooden, P. Glasbergen and H. van Lelyveld, eds., p.193-198. 
Turner, D. B., 1969, Workbook of Atmospheric Dispersion Estimates, U.S. Dept. of Health AP-26, Washington, D.C., pp.59.

Turner, R.R. and S.E. Lindberg, 1978. "Behavior and Transport of Mercury in River-Reservoir System Downstream of Inactive Chloralkali Plant," Environmental Science and Technology, 12(8), p.918-923.

U.S. Environmental Protection Agency, 1977. Determining Input Variables for Calculation of Impact of New Source Performance Standards, U.S.EPA 450/3-76018E, p.48-60.

Van der Hoven, I., 1968. "Deposition of Particles and Gases," Meteorology and Atomic Energy, U.S. Atomic Energy Commission TID 84190, p. 202-288.

Van der Zee, S.E.A.T.M. and J.J.T.I. Boesten, 1991. "Effects of Soil Heterogeneity on Pesticide Leaching to Groundwater," Water Resources Research, 27(12), p.30513063.

van Genuchten, M.Th., F.J. Leij and S.R. Yates, 1991. The RETC Code for Quantifying Hydraulic Functions of Unsaturated Soils, U.S. Environmental Protection Agency, EPA/600/2-91/065. 
van Genuchten, M.Th., 1980. "A Closed-Form Equation for Predicting the Hydraulic Conductivity of Unsaturated Soils," Soil Science Society of America Journal, v.44, p.892-898.

van Ommen, H.C., 1986. " Calculating the Impact of a Momentary Input of a Decaying Solute - and Its Decay Components- on the Quality of Outflowing Groundwater," Journal of Hydrology, 89 (1986) p.59-64.

Van Voris, P., C.E. Cowan, D.A. Cataldo, R.E. Wildung and H.H. Shugart, 1990. "Chernobyl Case Study: Modeling the Dynamics of Long term-cycling a Storage of cesium-137 in Forested Ecosystems," in: Transfer of Radionuclides in Natural and Semi-Natural Environments, G. Desmet, P. Nassimbeni and M. Belli, ed.s, Elsevier Applied Science, London, p.61-73.

Voldner, E.C. and W.H. Schroeder, 1989. "Modeling of Atmospheric Transport and Deposition of Toxaphene into the Great Lakes Ecosystem," Atmospheric Environment 23(9), p.1949-1961.

von Gunten, H.R., U.E. Waber and U. Krähenbühl, 1988. "The Reactor Accident at Chernobyl: A Possibility to Test Colloid-Controlled Transport of Radionuclides in a Shallow Aquifer," Journal of Contaminant Hydrology, 2 (1988) p.237-247. 
Wallace, J.M. and P.V. Hobbs, 1977. Atmospheric Science, Academic Press, San Diego, p.444.

Wallach, R. and R. Shabtai, 1993. "Surface Runoff Contamination by Chemicals Initially Incorporated Below the Soil Surface," Water Resources Research, 29(3), p.697-704.

Wang, H.F. and M.P. Anderson, 1982. Introduction to Groundwater Modeling, W.H. Freeman and Company, New York, NY, pp. 237.

Winter, T.C., 1983. "The Interaction of Lakes With Variably Saturated Porous Media," Water Resources Research, 19(5), p.1203-1218.

Winter, T.C., 1984. "Modeling the Interrelationship of Groundwater and Surface Water," Modeling Total Acid Precipitation Impacts, J.I. Teasley ed., Butterworth Publishers, Boston, p.89-119.

Yadigaroglu, G. and H. Munera, 1987. "Transport of Pollutants: Summary of Physical Dispersion Models," Nuclear Technology 77, p.759-764.

Yan, N.D. and G.E. Miller, 1984. "Effects of Deposition of Acids and Metals on 
Chemistry and Biology of Lakes Near Sudbury, Ontario," in: The Environmental

Impact of Smelters, J. Nriagu, ed., Wiley Series in Advances in Environmental

Science and Technology v. 15, J. Wiley and Sons, NY, Chapter 7, p.243-282.

Zheng, C., 1992. MT3D: A Modular Three-Dimensional Transport Model, Version 1.5, Papadopulos \& Assoc., Bethesda MD. 


\subsection{APPENDIX}

\subsection{Conversion Factors}

Tritium Units to Activity per volume of water

$1 \mathrm{TU}=0.188 \mathrm{~Bq}{ }^{3} \mathrm{H} / \mathrm{L} \mathrm{H}_{2} \mathrm{O}=188 \mathrm{~Bq} / \mathrm{m}^{3}$

Curies to Becquerels

$1 \mathrm{Ci}=3.695 \times 10^{10} \mathrm{~Bq}$

Tons to Kilograms

1 short ton $=907.2 \mathrm{~kg}$

1 long ton $=1016 \mathrm{~kg}$

1 metric tonne $=1000 \mathrm{~kg}$

Mole Weights to Grams

$1 \mathrm{~mol} \mathrm{~S}=32.06 \mathrm{~g}$

$1 \mathrm{~mol} \mathrm{SO}_{2}=64.0496 \mathrm{~g}$

$1 \mathrm{~mol} \mathrm{SO}_{4}=96.036 \mathrm{~g}$ 
7.2 Symbols

NOTATION

a

b

b1

b2

c

$\mathrm{C}(\mathrm{x}, \mathrm{y}, \mathrm{z})$

$\mathrm{C}_{\mathrm{a}}\left(\mathrm{x}, \mathrm{y}, \mathrm{z} ; \mathrm{h}^{\prime}\right)$

$\mathrm{C}_{\mathrm{a}}(\mathrm{x}, \omega)$

$\mathrm{C}_{\mathrm{i}}$

$\mathrm{C}_{\mathrm{P}}$

C

$\mathrm{C}_{\mathrm{s}}$

$\mathrm{C}_{\mathrm{w}}$

D

$\mathrm{D}_{\mathrm{d}}$

E

$\mathrm{F}\left(\omega, \mathrm{S}, \mathrm{N}^{\prime}\right)$

$f_{1}(z)$

$\mathrm{f}_{2}(\mathrm{z})$
DESCRIPTION

fraction of ore roasted

fraction of ore smelted

fraction of ore emitted in smelting

conversion factor

fraction of ore refined

conc. of solute in subsurface

conc. of aerosol in atmosphere

conc. of aerosol in atmosphere

conc. in infiltration @ surface

conc. in precipitation

conc. in recharge @ water table

conc. of solute source/sink in gw

specific water capacity function

coef. of hydrodynamic dispersion

effective molecular diffusion coef.

evapotranspiration

frequency function (wind)

initial head dist. function (unsat)

initial conc. dist. function (unsat)
UNITS

[]

[]

[]

$[\mathrm{g} / \mathrm{mol}]$

[]

$\left[\mathrm{M} / \mathrm{L}^{3}\right]^{*}$

$\left[\mathrm{M} / \mathrm{L}^{3}\right]^{*}$

$\left[\mathrm{M} / \mathrm{L}^{3}\right]^{*}$

$\left[\mathrm{M} / \mathrm{L}^{3}\right]^{*}$

$\left[\mathrm{M} / \mathrm{L}^{3}\right]^{*}$

$\left[\mathrm{M} / \mathrm{L}^{3}\right]^{*}$

$\left[\mathrm{M} / \mathrm{L}^{3}\right]^{*}$

[1/L]

$\left[\mathrm{L}^{2} / \mathrm{T}\right]$

$\left[\mathrm{L}^{2} / \mathrm{T}\right]$

[L] 


\begin{tabular}{|c|c|c|}
\hline$f_{3}(x, y, z)$ & initial head dist. function (gw) & \\
\hline$f_{4}(x, y, z)$ & initial conc. dist. function (gw) & \\
\hline$g_{1}$ & solvent coefficient & {[]} \\
\hline$g_{2}$ & dissolution coefficient & {$[1 / \mathrm{T}]$} \\
\hline$g_{3}$ & suspension coefficient & {$[1 / \mathrm{T}]$} \\
\hline $\mathrm{g}_{4}$ & runoff dissolution coefficient & {$[1 / \mathrm{T}]$} \\
\hline $\mathrm{g}_{\mathrm{e}}$ & evapotranspiration partitioning coef. & {[]} \\
\hline$g_{r}$ & runoff partitioning coefficient & {[]} \\
\hline $\mathrm{h}$ & hydraulic head & {$[\mathrm{L}]$} \\
\hline $\mathrm{h}_{\mathrm{p}}$ & pressure head & {$[\mathbf{L}]$} \\
\hline$h^{\prime}$ & effective source release height & {$[\mathrm{L}]$} \\
\hline I & infiltration & {$[\mathrm{L}]$} \\
\hline $\mathrm{K}$ & hydraulic conductivity & {$[\mathrm{L} / \mathrm{T}]$} \\
\hline $\mathrm{K}_{\mathrm{s}}$ & saturated hydraulic conductivity & {$[\mathrm{L} / \mathrm{T}]$} \\
\hline $\mathrm{k}_{1}$ & Freundlich isotherm parameter & {$\left[\mathrm{L}^{3} / \mathrm{M}\right]$} \\
\hline $\mathrm{k}_{\text {refine }}$ & atmospheric source term parameter & [ ] \\
\hline$k_{\text {roast }}$ & atmospheric source term parameter & {[]} \\
\hline $\mathrm{k}_{\text {smelt }}$ & atmospheric source term parameter & [ ] \\
\hline M & mass (or activity) stored at surface & {$\left[\mathrm{M} / \mathrm{L}^{2}\right]^{*}$} \\
\hline $\mathrm{M}_{\mathrm{D}}$ & dry deposition concentration & {$\left[\mathrm{M} / \mathrm{L}^{2}\right]^{*}$} \\
\hline$N^{\prime}$ & wind speed class & [ ] \\
\hline
\end{tabular}




\begin{tabular}{|c|c|c|}
\hline $\mathrm{n}$ & effective porosity & [ ] \\
\hline $\mathbf{P}$ & precipitation & {$[\mathrm{L}]$} \\
\hline $\mathrm{q}$ & groundwater flux & {$[\mathrm{L} / \mathrm{T}]$} \\
\hline $\mathrm{q}_{\mathrm{I}}$ & infiltration flux @ surface & {$[\mathrm{L} / \mathrm{T}]$} \\
\hline$q_{R}$ & recharge flux @ water table & {$[\mathrm{L} / \mathrm{T}]$} \\
\hline $\mathrm{q}_{\mathrm{s}}$ & solute source/sink (gw) & {$[1 / \mathrm{T}]$} \\
\hline $\mathrm{Q}_{\text {site }}$ & atmospheric emission rate & {$[\mathrm{M} / \mathrm{T}]^{*}$} \\
\hline $\mathrm{Q}_{0}$ & atmospheric emission rate & {$[\mathrm{M} / \mathrm{T}]^{*}$} \\
\hline $\mathbf{R}$ & runoff & {$[\mathrm{L}]$} \\
\hline$S^{\prime}$ & wind stability class & {[]} \\
\hline $\mathrm{S}_{\mathrm{s}}$ & specific storage & {$[1 / \mathrm{L}]$} \\
\hline$S_{y}$ & specific yield & [ ] \\
\hline $\mathbf{S}$ & storage coefficient & {[]} \\
\hline$t_{1 / 2}$ & radioactive half-life & {$[\mathrm{T}]$} \\
\hline $\mathrm{u}$ & mean wind speed & {$[\mathrm{L} / \mathrm{T}]$} \\
\hline$v_{d}$ & deposition velocity (atm) & {$[\mathrm{L} / \mathrm{T}]$} \\
\hline W & specific water source/sink (gw) & {$[1 / \mathrm{T}]$} \\
\hline $\mathrm{z}_{0}$ & reference altitude for $v_{d}(a t m)$ & {$[\mathrm{L}]$} \\
\hline $\mathrm{z}_{\text {bottom }}$ & elevation of aquifer bottom & {$[\mathrm{L}]$} \\
\hline $\mathrm{z}_{\mathrm{wt}}$ & elevation of water table & {$[\mathrm{L}]$} \\
\hline$\alpha_{L}$ & longitudinal dispersivity & {$[\mathrm{L}]$} \\
\hline
\end{tabular}




$\begin{array}{lll}\alpha & \text { fitting parameter (unsat) } & {[1 / \mathrm{L}]} \\ \beta & \text { fitting parameter (unsat) } & {[]} \\ \eta & \text { Freundlich isotherm parameter } & {[]} \\ \theta & \text { relative saturation } & {[]} \\ \theta & \text { volumetric soil water content } & {[]} \\ \theta_{\mathrm{r}} & \text { residual } \theta & {[]} \\ \theta_{\mathrm{s}} & \text { saturated } \theta & {[]} \\ \lambda_{1} & \text { solute decay parameter } & {[1 / \mathrm{T}]} \\ \lambda_{2} & \text { adsorbed phase decay parameter } & {[1 / \mathrm{T}]} \\ \rho_{\mathrm{b}} & \text { soil bulk density } & {\left[\mathrm{M} / \mathrm{L}^{3}\right]} \\ \sigma_{\mathrm{y}} & \text { cross wind dispersion coef. } & {[\mathrm{L}]} \\ \sigma_{\mathrm{z}} & \text { vertical dispersion coef. (atm) } & {[\mathrm{L}]} \\ \omega & \text { wind direction class } & {[]}\end{array}$


7.3 Governing Equations for Mass Stored at the Ground Surface

The governing equations for mass stored at the ground surface and the time rate of change of mass at the surface as a function of contaminant decay and transport off the surface in runoff and infiltration depend on how the dissolution and suspension of the contaminant are modeled.

Decay Only ( $g_{2}$ and $\left.g_{3}=0\right)$ :

$$
\begin{aligned}
A & =A_{0} e^{-\lambda t} \\
\frac{d A}{d t} & =A_{0} \frac{d}{d t} e^{-\lambda t} \\
& =-\lambda A_{0} e^{-\lambda t}
\end{aligned}
$$

For dissolution and suspension at constant rates

$$
\begin{gathered}
A=A_{0} e^{-\lambda t}-A_{0} e^{-\lambda t}\left(g_{2}+g_{3}\right) t \\
=A_{0} e^{-\lambda t}\left[1-\left(g_{2}+g_{3}\right) t\right] \\
\frac{d A}{d t}=A_{0}\left[\frac{d}{d t} e^{-\lambda t}\left[1-\left(g_{2}+g_{3}\right) t\right]\right. \\
\frac{d A}{d t}=A_{0}\left[\frac{d}{d t} e^{-\lambda t}-\frac{d}{d t} g_{2} t e^{-\lambda t}-\frac{d}{d t} g_{3} t e^{-\lambda t}\right] \\
=A_{0}\left[-\lambda e^{-\lambda t}-\left(g_{2}+g_{3}\right)\left(\frac{d}{d t} t e^{-\lambda t}\right)\right] \\
\text { chain rule } \\
\frac{d A}{d t}=A_{0}\left[-\lambda e^{-\lambda t}-\left(g_{2}+g_{3}\right)\left(-\lambda e^{-\lambda t} t+e^{-\lambda t}\right)\right] \\
=-A_{0} e^{-\lambda t}\left[\lambda+\left(g_{2}+g_{3}\right)(1-\lambda t)\right]
\end{gathered}
$$


For $g_{2}$ and $g_{3}$ linear functions $\left[\left(g_{2}=a t+b\right)\right.$ and $\left.\left(g_{3}=c t+d\right)\right]$

$$
\begin{gathered}
\text { let } \mathrm{a}+\mathrm{c}=c_{1} \text { and } \mathrm{b}+\mathrm{d}=c_{2} \\
A=A_{0} e^{-\lambda t}\left[1-c_{1} t^{2}-c_{2} t\right] \\
\frac{d A}{d t}=A_{0} \frac{d}{d t}\left[e^{-\lambda t}\left(1-c_{1} t^{2}-c_{2} t\right)\right] \\
\text { by parts } \\
\frac{d A}{d t}=A_{0}\left[-\lambda e^{-\lambda t}\left(1-c_{1} t^{2}-c_{2} t\right)+e^{-\lambda t}\left(-2 c_{1} t-c_{2}\right)\right] \\
=A_{0} e^{-\lambda t}\left[-\lambda+c_{1}\left(\lambda t^{2}-2 t\right)+c_{2}(\lambda t-1)\right] \\
\text { substitution } \\
\frac{d A}{d t}=A_{0} e^{-\lambda t}[-\lambda+t(a+c)(\lambda t-2)+(b+d)(\lambda t-1)]
\end{gathered}
$$


For $g_{2}$ and $g_{3}$ exponential functions

$$
\begin{aligned}
& {\left[g_{2}=c_{1} t^{-1 / c 2 t} \text { and } g_{3}=e^{-(c 3 t+c 4)}\right]} \\
& A=A_{0} e^{-\lambda t}\left[1-\left(e^{-\left(c_{3} t+c_{4}\right)}+c_{1} t^{\frac{-1}{c_{2} t}}\right) t\right] \\
& \quad \text { for } \\
& \begin{array}{c}
0<c_{3}<c_{4} ; 0<c_{1}<1 ; 0<c_{2} \\
d t
\end{array}=A_{0} \frac{d}{d t}\left[e^{-\lambda t}-t e^{-\left(\lambda t+c_{3} t+c_{4}\right)}-c_{1} e^{-\lambda t} t^{1-\frac{1}{c_{2} t}}\right] \\
& =-A_{0} e^{-\lambda t}\left\{\lambda+e^{-\left(c_{3} t+c_{4}\right)}-t\left(c_{3}+\lambda\right) e^{-\left(c_{3} t+c_{4}\right)}+c_{1}\left[-\lambda t^{\frac{-1}{c_{2} t}}+\frac{t^{1-\frac{1}{c_{2} t}}}{c_{2} t^{2}}\right]\right\}
\end{aligned}
$$


7.4 Data for the Sturgeon Falls Site Simulations

Nickel Production History and Atmospheric Parameter Data

The nickel production history and calculated total ore processed are shown in the figure on the next page. When two sources report different amounts of nickel produced for the same year, the average of the reported values is used to estimate the total ore processed in that year. This model assumes that the time lag between processing and sale is insignificant (i.e., that the amount of nickel sold (production records) is equal to amount produced in that year). The ore mined before 1903 was high grade ore containing an average of 2.4 percent nickel (Barrow, 1902).

Beginning in 1903, lower grade ore with approximately 1.3 percent nickel was mined (Royal Ontario Nickel Commission, 1917; INCO, 1946; Culliford, 1982).

Once the total ore production is estimated, the emission rate is estimated based on the process used. For open roasting, the sulfur emitted equals approximately 15 percent of the total ore processed (Royal Ont. Nickel Com., 1917). With the open roasting and smelting method a total of 20 percent of the total ore is released to the atmosphere as sulfur (Royal Ont. Nickel Com.,1917). Closed smelting (no open roasting) without sulfur removal results in an emission of 17 percent of the total ore as sulfur dioxide (Ontario Canadian Task Force, 1982). Refining releases another 1 percent as sulfur dioxide (Royal Ontario Nickel Commission., 1917). Sulfur removal and sulfuric acid production began at the Falconbridge smelter in 1968 and were increased in 1979: The Copper Cliff smelter 
Nickel Production and Estimated Ore Processed

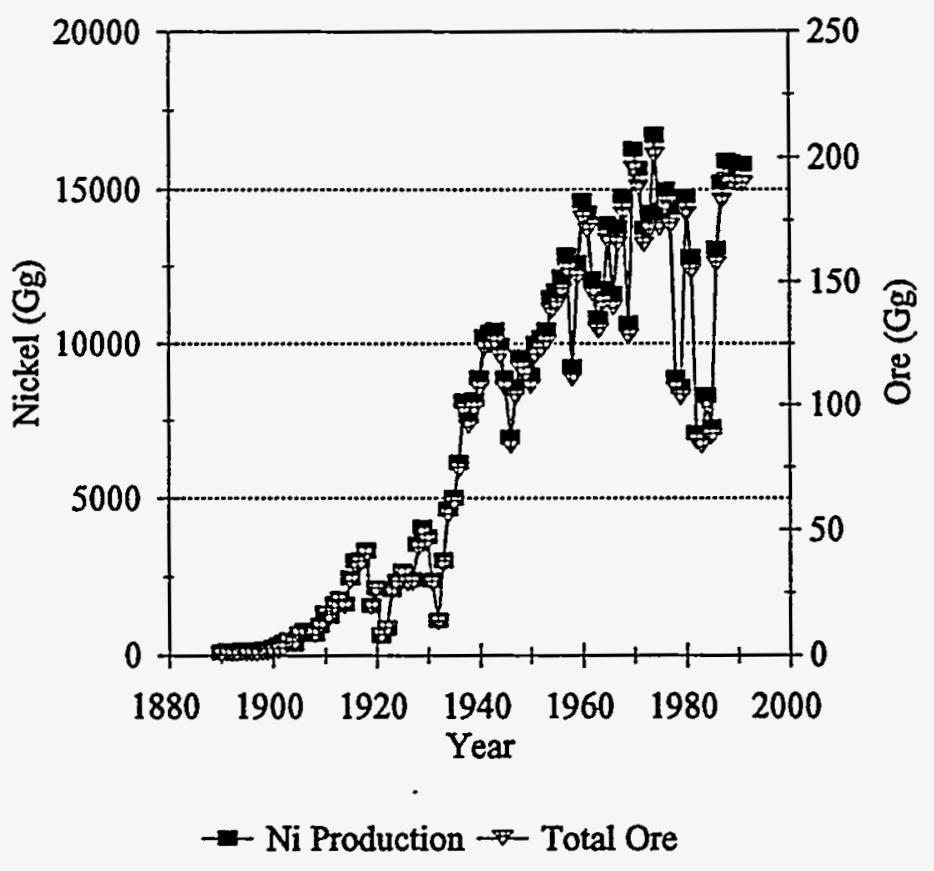


began sulfur removal in 1972 . The emissions were reduced to 7 to 11 percent of the total ore processed (Ontario Ministry of the Environment, 1986).

The percent of the total ore processed at each smelter is estimated based on nickel production data for the individual companies (INCO, 1946; Malhotra, 1973; Culliford, 1982; Maurice and Mizzi, 1984). The source term model is a function of the fraction of the total annual ore processed and the processes used at each smelter site (equation 7.1).

$$
Q_{\text {size }}=\operatorname{Ore}_{T}\left[k_{\text {roast }}(0.15)+k_{\text {smelt }}(0.05)+k_{\text {refine }}(0.01)\right]
$$

The constants used for the source term model are summarized in table 7.1. The dimensions of $\mathrm{Q}_{0}$ are moles of sulfur per unit time. Since the nickel production data are known for a minimum of one year intervals, this limits the atmospheric model to annual average emission rates.

The smelter stack history at Copper Cliff began in 1902 with a single stack 60 meters high. In 1930, 3 new stacks began operation, one each for the roaster (152 $\mathrm{m})$, refinery $(107 \mathrm{~m})$ and smelter $(155 \mathrm{~m})$. Since 1972, all emissions at Copper Cliff have been released through the 381 meter high "super" stack (Malhotra, 1973). The Coniston smelter used a 53 meter high stack from 1913 until 1965 when taller, 114 meter stacks were installed. From 1930 to 1971 Falconbridge used two stacks, one 53 meters for the sinter emissions and the other 93 meters high for the smelter. In 1978 the sintering line at Falconbridge was closed and an 83 meter stack replaced 
the 93 meter smelter stack.

The mixing layer thickness varies diurnally and seasonally. The mean seasonal mixing depths for the Sudbury area are estimated from Holzworth (1972).

Sturgeon Falls Site Water Table Elevations (calibration values)

\begin{tabular}{|c|c|c|c|c|c|c|}
\hline \multirow{2}{*}{ ROW } & \multirow{2}{*}{\multicolumn{6}{|c|}{$\begin{array}{l}\text { WATER TABLE ELEVATION CALIBRATION VALUES (m) } \\
\text { ALONG TRANSECT (COLUMN 12) }\end{array}$}} \\
\hline & & ALC & & & & \\
\hline & 1 & 2 & 3 & 4 & 5 & 6 \\
\hline 6 & 215.2 & 214.8 & 214.6 & 214.4 & 214.2 & 214.0 \\
\hline 7 & 217.2 & 217.2 & 217.1 & 217.0 & 215.5 & 214.1 \\
\hline 8 & 218.3 & 218.3 & 218.2 & 218.1 & 216.4 & 214.3 \\
\hline 9 & 219.1 & 219.0 & 218.7 & 218.3 & 216.9 & 214.4 \\
\hline 10 & 219.1 & 219.0 & 218.8 & 218.4 & 217.3 & 214.5 \\
\hline 11 & 219.0 & 219.0 & 218.8 & 218.4 & 217.0 & 214.4 \\
\hline 12 & 218.3 & 218.2 & 218.1 & 218.1 & 217.4 & 214.3 \\
\hline 13 & 218.0 & 218.0 & 218.0 & 217.7 & 216.9 & 214.3 \\
\hline 14 & 217.1 & 217.0 & 217.0 & 217.0 & 216.0 & 214.2 \\
\hline 15 & 218.5 & 215.8 & 215.8 & 215.7 & 215.0 & 214.1 \\
\hline \multicolumn{7}{|c|}{ VERTICAL GRADIENTS (m) } \\
\hline ROW & L1-L2 & L2-L3 & L3-LA & L4-L5 & L5-L6 & \\
\hline 6 & 0.4 & 0.2 & 0.2 & 0.2 & 0.2 & \\
\hline 7 & 0 & 0.1 & 0.1 & 1.5 & 1.4 & \\
\hline 8 & 0 & 0.1 & 0.1 & 1.7 & 2.1 & \\
\hline 9 & 0.1 & 0.3 & 0.4 & 1.4 & 2.5 & \\
\hline 10 & 0.1 & 0.2 & 0.4 & 1.1 & 2.8 & \\
\hline 11 & 0 & 0.2 & 0.4 & 1.4 & 2.6 & \\
\hline 12 & 0.1 & 0.1 & 0 & 0.6 & 3.1 & \\
\hline 13 & 0 & 0 & 0.3 & 0.8 & 2.6 & \\
\hline 14 & 0.1 & 0 & 0 & 1.0 & 1.8 & \\
\hline 15 & 0 & 0 & 0.1 & 0.7 & 0.9 & \\
\hline
\end{tabular}




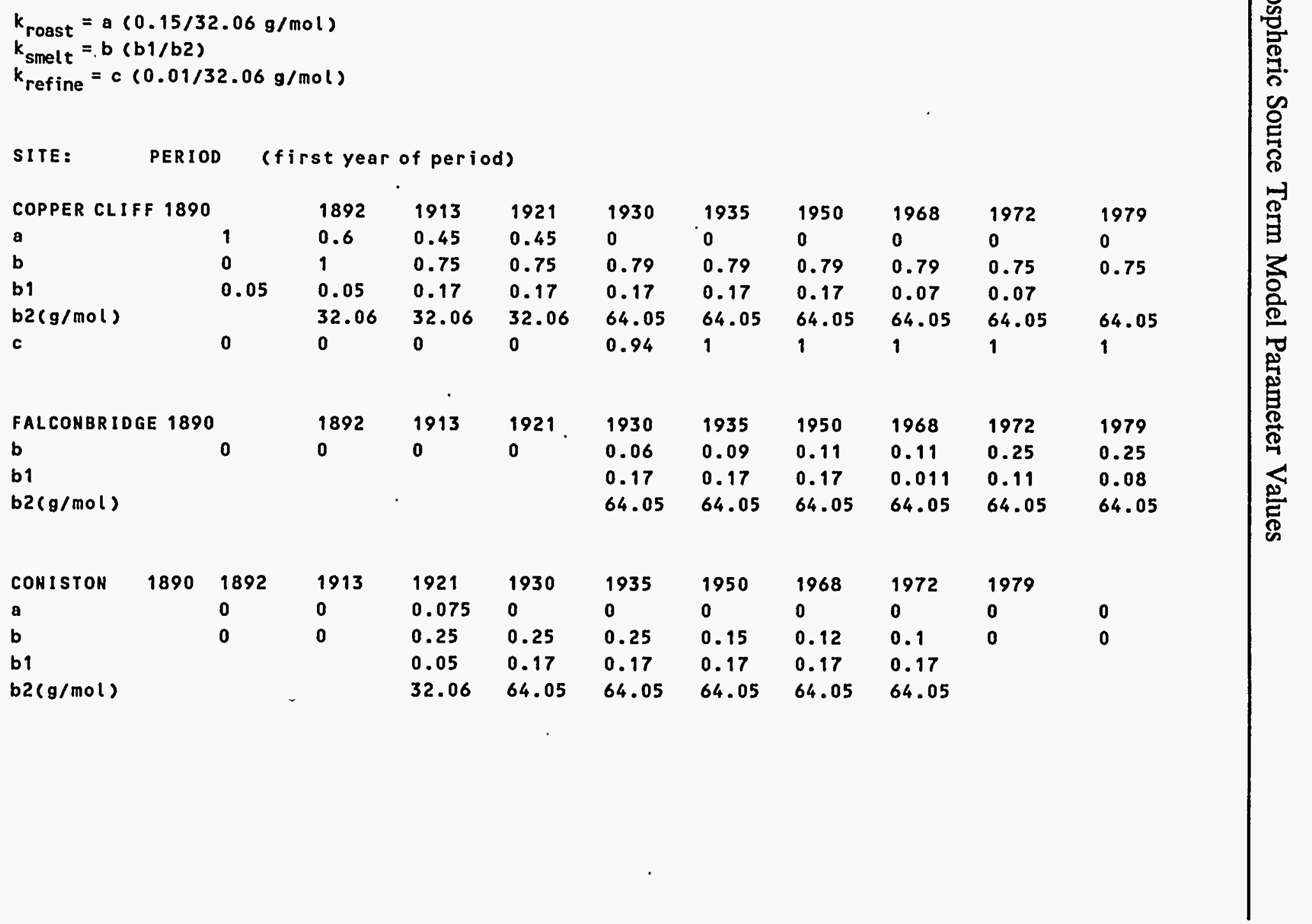


$\mathrm{SO}_{2}$ Deposition Velocities

\begin{tabular}{|c|c|c|}
\hline $\begin{array}{c}V_{d} \\
(M / S)\end{array}$ & NOTES & SOURCE \\
\hline 0.008 & $\begin{array}{l}\mathrm{SO}_{2} \text {, used for models of the } \\
\text { Sudbury Area by Jeffries, } 1984\end{array}$ & Garland, 1978 \\
\hline $\begin{array}{l}\mathrm{a} 0.002 \\
\mathrm{~b} 0.005\end{array}$ & $\begin{array}{l}\mathrm{SO}_{2} \text {, measured bulk and wet } \\
\text { deposition, }{ }^{a} \text { winter rate } \\
\text { b summer rate, Oak Ridge, TN }\end{array}$ & Matt and Meyers, 1993 \\
\hline $\begin{array}{l}0.0049 \\
a_{0.0023} \\
0.0060\end{array}$ & $\begin{array}{l}\mathrm{SO}_{2} \text {, ave. daily, }{ }^{\mathrm{a}} \text { rate over corn, } \\
\mathrm{b}_{\text {rate over grass, } \mathrm{PA} \text { sites }}\end{array}$ & McMillen, 1990 \\
\hline $\begin{array}{l}{ }^{a} 0.0023 \\
(0.0008 \text { to } 0.0030) \\
\text { b } 0.0037 \\
(0.0020 \text { to } 0.0050)\end{array}$ & $\begin{array}{l}\text { a } \mathrm{SO}_{2} \text {, ave. annual,(range: low } \\
\mathrm{Jan}-\mathrm{Mar} \text {., high Apr.-Aug.) } \\
\mathrm{SO}_{4}{ }^{2-} \text {, ave. annual (low Jan.- } \\
\mathrm{Mar.,high} \mathrm{Jun.-Aug)} \mathrm{Nova} \mathrm{Scotia}\end{array}$ & Sirois and Summers, 1989 \\
\hline $\begin{array}{l}\mathrm{a} 0.009 \\
\mathrm{~b} 0.0015\end{array}$ & ${ }^{\mathrm{a}} \mathrm{SO}_{2},{ }^{\mathrm{b}} \mathrm{SO}_{4}{ }^{2-}$, The Netherlands & Erisman, et al., 1989 \\
\hline $\begin{array}{l}0.01 \\
(0.0 \text { to } 0.0275) \\
\end{array}$ & $\begin{array}{l}\mathrm{SO}_{2} \text {, ave. daily Borden site in } \\
\text { winter, trees leafless } \\
\text { (range of ave. hourly meas.) }\end{array}$ & Padro, et al., 1992 \\
\hline $\begin{array}{l}\text { a } 0.0017 \\
{ }^{\mathrm{b}} 0.001\end{array}$ & $\begin{array}{l}\text { ave. annual }{ }^{\mathrm{a}} \mathrm{SO}_{2}, \\
{ }^{b} \mathrm{SO}_{4}{ }^{2-} \text { Turkey Lakes, Ontario }\end{array}$ & Johnson and Lindberg, 1992 \\
\hline 0.0016 to 0.0033 & $\begin{array}{l}\mathrm{SO}_{4}{ }^{2-}, \mathrm{RADM} \text { model est. for the } \\
\text { Sudbury/North Bay area }\end{array}$ & Sheih, et al., 1986 \\
\hline 0.0068 to 0.0073 & $\begin{array}{l}\mathrm{SO}_{2} \text {, ave. annual resistance } \\
\text { analog model est. over the Baltic } \\
\text { Sea }\end{array}$ & Lindfors, et al.,1993 \\
\hline 0.007 & $\begin{array}{l}\mathrm{SO}_{4}{ }^{2-} \text {, ave. annual over trees in } \\
\text { The Netherlands }\end{array}$ & Draaijers and Erisman, 1993 \\
\hline $\begin{array}{l}\mathrm{a} 0.0004 \text { to } 0.075 \\
\mathrm{~b} 0.002 \text { to } 0.029\end{array}$ & $\begin{array}{l}{ }^{a} \mathrm{SO}_{2} \text { and }{ }^{b} \mathrm{SO}_{4}{ }^{2-} \text { ranges from } \\
\text { the literature }\end{array}$ & Sehmel, 1980 \\
\hline $\begin{array}{l}\mathrm{a} 0.0001 \text { to } 0.05 \\
{ }^{b} 0.01 \text { to } 0.20\end{array}$ & $\begin{array}{l}\text { general ranges } \\
\text { a over grass and } b \text { over } \\
\text { woodlands }\end{array}$ & Hosker, 1974 \\
\hline 0.005 & $\begin{array}{l}\mathrm{SO}_{2} \text { ave. from this table } \\
\text { (excluding Sehmel and Hosker } \\
\text { ranges) }\end{array}$ & \\
\hline
\end{tabular}




\begin{tabular}{|l|l|l||}
\hline 0.002 to 0.008 & $\begin{array}{l}\text { "reasonable" range estimated } \\
\text { from the values in this table (ave. } \\
\pm 1 \mathrm{SD} \text { ) }\end{array}$ & \\
\hline
\end{tabular}


Sturgeon Falls Site Groundwater Sulfate Data (Robertson and Cherry, 1989) and Calibration Values

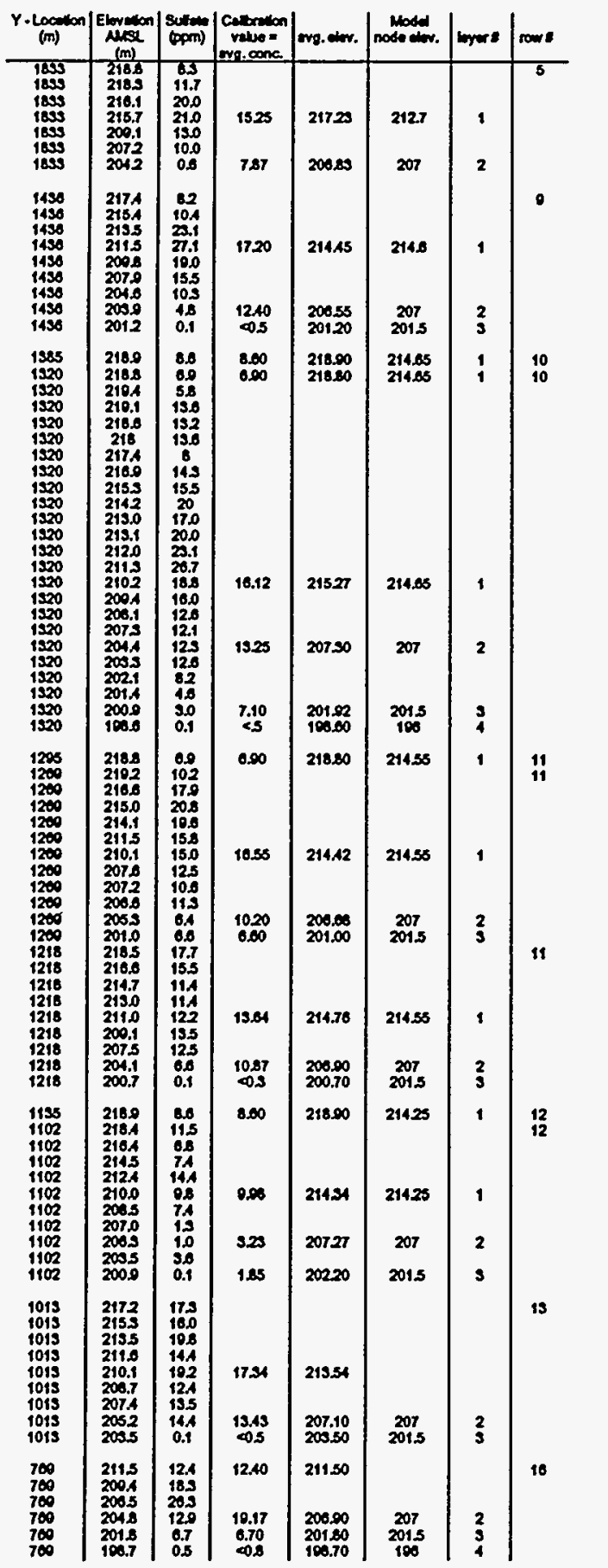




\subsection{CNPP Data}

Atmospheric Source Term

An explosion at the CNPP on April 26, 1986 as a result of an operating error, caused a fire and possibly a partial melt-down of the reactor core. The fire and subsequent high temperatures in the reactor caused the release of radionuclides to continue at very high rates for the next nine days (IAEA, 1986). The total radiation released at the CNPP between April 26 and May 5, 1986 is estimated at $1.9 \times 10^{18}$ Bq (IAEA, 1986; Ilyin and Pavlovskij, 1987).

The primary radionuclides were ${ }^{131} \mathrm{I},{ }^{134} \mathrm{Cs},{ }^{137} \mathrm{Cs}$ and ${ }^{90} \mathrm{Sr}$. The radionuclides ${ }^{137} \mathrm{Cs}$ and ${ }^{90} \mathrm{Sr}$ are of the greatest concern in the long term; ${ }^{137} \mathrm{Cs}$ due to its abundance (1 to $22 \times 10^{16} \mathrm{~Bq}$ released) and half-life (30.2 years) (IAEA, 1986), and ${ }^{90} \mathrm{Sr}$ because of its abundance in the 30 kilometer zone $\left(8 \times 10^{15} \mathrm{~Bq}\right.$ released), half-life (28.9 years) and high solubility (Ilyin and Pavlovskij, 1987; Bulgakov et al., 1991). The nature of the ${ }^{137} \mathrm{Cs}$ and the ${ }^{90} \mathrm{Sr}$ atmospheric transport were different. Strontium was transported as larger fuel particles while cesium was transported as an aerosol (i.e., microscopic particles) (Bobovnikova et al., 1991). The initial explosion resulted in an effective release height of 1000 to 6000 meters (Beardsley, 1986; Park, 1989). After the initial release, the effective release height was within several hundred meters of the ground surface (Beardsley, 1986). 
Climatic and Precipitation Data

\begin{tabular}{|l|l|}
\hline \multicolumn{2}{|c|}{ CLIMATOLOGICAL DATA FOR THE CHERNOBYL REGION } \\
\hline Characteristic & Value \\
\hline Avg. Annual Temperature & $6.6^{\circ} \mathrm{C}$ \\
Maximum Temperature & $39^{\circ} \mathrm{C}$ \\
Minimum Temperature & $-35^{\circ} \mathrm{C}$ \\
Avg. Annual Precipitation & $0.487 \mathrm{~m}$ \\
Snow Period & Dec. - Mar. \\
Avg. Maximum Snow Depth & $0.170 \mathrm{~m}$ \\
Avg. Frost Depth & $0.74 \mathrm{~m}$ \\
Prevailing Winds & $16 \% \mathrm{NW} ; 15 \% \mathrm{~W}$ \\
Avg. Annual Wind Speed & $4.2 \mathrm{~m} / \mathrm{s}$ \\
Maximum Wind Speed & $24 \mathrm{~m} / \mathrm{s}$ \\
Avg. \# of days/yr. u $>15 \mathrm{~m} / \mathrm{s}$ & 13 \\
Max. \# of days/yr u $>15 \mathrm{~m} / \mathrm{s}$ & 38 \\
& \\
\hline
\end{tabular}

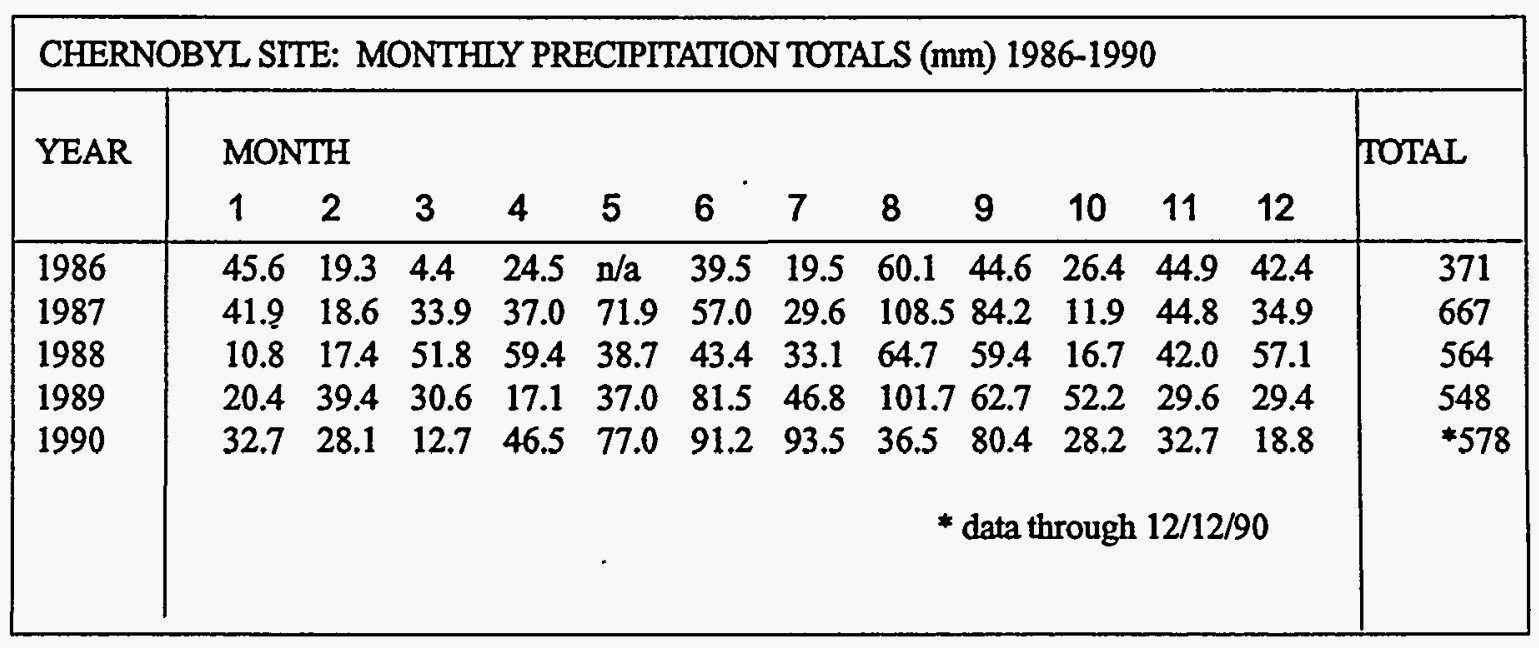


Coordinate Conversion Factors

$(X, Y)=$ LOCATION USING SITE COORDINATE SYSTEM

ATMOSPHERIC MODEL

SOUTHEAST PLUME

$\begin{array}{llll}\mathrm{X}_{1}(\mathrm{~m}) & \mathrm{Y}_{1}(\mathrm{~m}) & \mathrm{r}(\mathrm{m}) & \varpi_{1} \\ \mathrm{Y}+15000 & \mathrm{X}-2300 & \left(\mathrm{X}^{2}+\mathrm{Y}^{2}\right)^{0.5} & \tan ^{-61}\left(\mathrm{Y}_{1} / \mathrm{X}_{1}\right)\end{array}$

\section{SOUTH PLUME}

$\begin{array}{lll}\varpi_{2} \text { (radians) } & X_{2} & Y_{2} \\ \omega_{1}+0.45 & \mathrm{r} \cos \left(\varpi_{2}\right) & \mathrm{r} \sin \left(\varpi_{2}\right)\end{array}$

GROUNDWATER MODEL

$\mathrm{X}_{\mathrm{gw}} \quad \mathrm{Y}_{\mathrm{gw}}$

$\mathrm{X} \quad 8500-\mathrm{Y}$ 